\author{
Universidade de São Paulo - USP \\ Escola de Engenharia de São Carlos - EESC \\ Departamento de Engenharia Elétrica e de Computação - SEL \\ Programa de Pós-Graduação em Engenharia Elétrica
}

Eduardo Augusto Pereira Gomes

\title{
DETECÇÃO DE ILHAMENTO DE GERADORES SÍNCRONOS DISTRIBUÍDOS POR CORRElaÇões da MineraÇÃo COMPleXa DE DADOS
}



Eduardo Augusto Pereira Gomes

\section{DETECÇÃO DE ILHAMENTO DE GERADORES SÍNCRONOS DISTRIBUÍDOS POR CORRELAÇões da MINERAÇÃO COMPleXa DE DADOS}

Dissertação apresentada à Escola de Engenharia de São Carlos da Universidade de São Paulo, como parte dos requisitos para obtenção do Título de Mestre em Ciências pelo Programa de Engenharia Elétrica.

Área de Concentração: Sistemas Elétricos de Potência

Orientador: Prof. Tit. Denis Vinicius Coury

São Carlos

2016

Trata-se da versão corrigida da dissertação. A versão original se encontra disponível na EESC/USP que aloja o programa de pós-graduação de Engenharia Elétrica 
AUTORIZO A REPRODUÇÃO TOTAL OU PARCIAL DESTE TRABALHO, POR QUALQUER MEIO CONVENCIONAL OU ELETRÔNICO, PARA FINS DE ESTUDO E PESQUISA, DESDE QUE CITADA A FONTE.

Gomes, Eduardo Augusto Pereira

Detecção de Ilhamento de Geradores Síncronos Distribuídos por Correlações da Mineração Complexa de Dados / Eduardo Augusto Pereira Gomes; orientador Denis Vinicius Coury. São Carlos, 2016.

Dissertação (Mestrado) - Programa de Pós-Graduação em Engenharia Elétrica e Área de Concentração em Sistemas Elétricos de Potência -- Escola de Engenharia de São Carlos da Universidade de São Paulo, 2016.

1. Geração distribuída. 2. Proteção anti-ilhamento. 3. Mineração de dados. 4. DAMICORE. I. Título. 


\section{FOLHA DE JULGAMENTO}

Candidato: Bacharel EDUARDO AUGUSTO PEREIRA GOMES

Título da dissertação: "Detecção de ilhamento de geradores síncronos distribuídos por correlações da mineração complexa de dados"

Data da defesa: 31/08/2016

Comissão Julgadora:

Resultado:

Prof. Titular Denis Vinicius Coury

APROXADO (Orientador)

(Escola de Engenharia de São Carlos/EESC)

Prof. Dr. Walmir de Freitas Filho

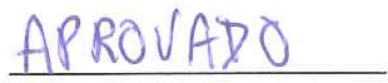

(Universidade Estadual de Campinas/UNICAMP)

Prof. Dr. Fábio Bertequini Leão Aprovado (Universidade Estadual Paulista "Júlio de Mesquita Filho"/UNESP - Ilha Solteira)

Coordenador do Programa de Pós-Graduação em Engenharia Elétrica: Prof. Associado Luís Fernando Costa Alberto

Presidente da Comissão de Pós-Graduação:

Prof. Associado Luís Fernando Costa Alberto 



\section{Dedicatória}

Com carinho especial dedico este trabalho aos meus pais João e Maria, aos meus avós (in memorian) e a todos que me incentivam a nunca desistir de sonhar. 



\section{Agradecimentos}

Confesso que esta carta é uma das tarefas mais difíceis de meu mestrado. Conheci pessoas que ao longo destes dois anos me receberam com muito carinho e mesmo que eu não cite o nome de todos nesta carta gostaria de lhes dizer que me ajudaram a ter forças para que eu pudesse concluir esta dissertação. Por isso, agradeço a Deus por ter colocado vocês para me servirem de inspiração e terem feito meus dias melhores.

Especialmente eu agradeço aos meus pais João Batista e Maria, afinal foi só por vocês que eu pude dar continuidade aos estudos. Obrigado por todo o suporte financeiro, pelo amor incondicional que tem por mim e por acreditarem em meus sonhos. Não tenham dúvidas de que os amo muito!

Neste ano de 2016 foi preciso me despedir de meu avô e a sua partida marca o fim da geração de meus avós maternos e paternos. A saudade ainda dói, embora seja com muita alegria que me lembro de vocês. Admiro a vida que tiveram, as linhas de pobreza que enfrentaram e principalmente por terem me ensinado que as dificuldades desta vida resolvemos com amor e dedicação. Afinal, mesmo com todas as diferenças tenho uma família grande e que se mantém unida sempre. Muito obrigado meus queridos: avó Flor e avô Josias, avó Catarina e avô Jordão. Fiquem com Deus!

Aos meus irmãos Marcelo Henrique e João Guilherme, obrigado por todo o carinho que tem por mim, saiba que os admiro muito. Vocês são o meu espelho. Sei que vivem um momento difícil, mas tenho a esperança de que logo as coisas melhoram. Meu irmão Marcelo, muito obrigado por me presentear com o Raphael e confiar a mim o papel de padrinho.

Muito obrigado aos meus queridos primos e primas, tios e tias, padrinho e madrinha, cunhadas e meu sobrinho Miguel. O apoio de vocês foi essencial minha família.

Aos professores que me auxiliaram durante a pesquisa. Ao meu orientador prof. Denis obrigado por ter me aceitado no programa de pós-graduação, pelos incentivos e por ter confiado a mim o projeto que resultou nesta dissertação. A você prof. José Carlos, confesso que me faltam palavras. Obrigado primeiramente pela amizade, por ter me ajudado durante toda a pesquisa, por ter acreditado em meu trabalho e dessa forma lutar por meu crescimento e reconhecimento profissional. Ao prof. Alexandre Delbem por todas a sugestões e ideias. Não 
poderia deixar de citar o prof. Mário. Com você tive meu primeiro artigo publicado e pude ir ao meu primeiro congresso. Ainda devo meus sinceros agradecimentos aos professores da PUC-Minas, foram vocês a minha inspiração para continuar minha carreira como pesquisador. Guardo vocês com muito carinho: Rodrigo, Márcia, Marcelo, Delboni, Francislei e Trevisan.

Meus caros amigos do Laboratório de Sistemas de Energia Elétrica (LSEE), obrigado por toda a amizade e carinho que tiveram por mim. Vocês são especiais em minha vida, agradeço principalmente por terem a paciência de sempre me ensinar um pouco do trabalho de cada um de vocês. A troca ideias me ajudou muito no desenvolvimento de minha pesquisa. Em especial agradeço ao Fabricio, Thais, Vinicius, Aline, Daniel Motter, Rodrigo, Rui, Rodolfo, Douglas, Athila e Gerson.

A você Cristiane por ter sido minha companhia nos momentos difíceis. Desejo muita força e muito sucesso em sua vida.

Por fim, meus agradecimentos ao LSEE, da Escola de Engenharia de São Carlos (EESC-USP) pela infraestrutura proporcionada, assim como aos funcionários do Departamento de Engenharia Elétrica e de Computação.

Muito Obrigado! 


\section{Resumo}

GOMES, E. A. P. Detecção de Ilhamento de Geradores Síncronos Distribuídos por Correlações da Mineração Complexa de Dados. 2016. Dissertação (Mestrado) - Escola de Engenharia de São Carlos, Universidade de São Paulo, São Carlos, 2016.

Um dos principais problemas que podem ocorrer em sistemas de distribuição ou de subtransmissão de energia elétrica com geração distribuída (GD) é o ilhamento. O ilhamento ocorre quando um ou mais geradores distribuídos alimentam uma porção do sistema que se encontra eletricamente isolada do restante do sistema elétrico. Logo, geradores distribuídos têm de ser equipados com esquema de proteção anti-ilhamento, pois a operação ilhada pode colocar em risco a segurança das pessoas e equipamentos e pode deteriorar a qualidade da energia elétrica suprida aos consumidores locais. Este trabalho está inserido no contexto de proteção de sistemas elétricos de distribuição com GD e propõe uma nova técnica passiva-inteligente de proteção anti-ilhamento para geradores síncronos distribuídos. $\mathrm{O}$ método proposto utiliza a mineração de dados do Data Mining of Code Repositories (DAMICORE), o qual possui grandes potencialidades para descobrir correlações em dados complexos. Para realizar essa tarefa, três algoritmos são executados em sequência. São eles: o Normalized Compression Distance (NCD) para calcular a matriz de distância do conjunto de dados; o Neighbor-Joining (NJ) para construir as árvores filogenéticas; e por fim o Fast Newman (FN) para buscar grupos na árvore filogenética nos quais os dados apresentam alto grau de independência. O método de detecção de ilhamento nesta dissertação utiliza 10 características importantes dos sinais de tensão e corrente trifásicas no ponto de acoplamento comum (PAC). Essas 10 características são utilizadas como entrada ao DAMICORE para formular um algoritmo baseado em mineração de dados capaz de detectar ilhamento e de diferenciá-los de outros tipos de distúrbios. Os resultados mostram que o método identifica o ilhamento corretamente, detectando-o rapidamente, especialmente nos casos em que a detecção do ilhamento por relés baseados em medidas de frequência falha ou é lenta.

Palavras-chave: DAMICORE; Geração distribuída; Mineração de dados; Proteção anti-ilhamento. 


\section{Abstract}

GOMES, E. A. P. Islanding Detection of Distributed Synchronous Generators by Complex Data-Mining Correlations. 2016. Dissertation (Master Degree) - São Carlos School of Engineering, University of São Paulo, São Carlos, 2016.

One of the main issues that can occur into distribution power systems with distributed generation is islanding. Islanding occurs when one or more distributed generators feed a portion of the distribution system that becomes electrically isolated from the rest of the power system. Thus, distributed generators have to be equipped with anti-islanding protection schemes, because the islanded operation may put at risk the safety of people and the equipment. It can also deteriorate the power quality supplied to local consumers. This work is in the context of the protection schemes for distribution power systems with distributed generation and it proposes a new intelligent passive anti-islanding protection scheme for distributed synchronous generators. The scheme is based on the Data Mining of Code Repositories (DAMICORE), which finds the similarity within complex data sets. This task is performed by computing the following algorithms, in sequence: the Normalized Compression Distance (NCD) to calculate a distance matrix among the data sets; the Neighbor-Joining (NJ) to build the phylogenetic trees; and the Fast Newman (FN) to find clusters with high degree of independence by using the phylogenetic trees. The proposed method comprises the extraction of 10 important features of the three-phase voltages and currents measured at the point of common coupling of the distributed generator. These 10 features are then used as input to the DAMICORE in order to formulate a data mining-based algorithm capable of detecting islanding and of distinguishing it from other disturbances. The results show that the method identifies the islanding correctly, detecting it quickly, especially where the detection of islanding by frequency-based relays are slow.

Index Terms - Anti-islanding protection; DAMICORE; Data-Mining; Distributed Generation. 


\section{Lista de Figuras}

Figura 1.1 - Potência fiscalizada das usinas a base de biomassa de cana de açúcar por estado e região. Extraído da base de dados da ANEEL [6] ..................................................................

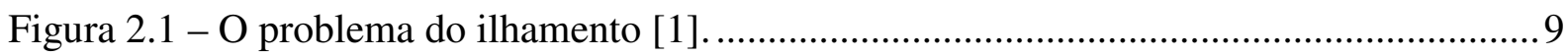

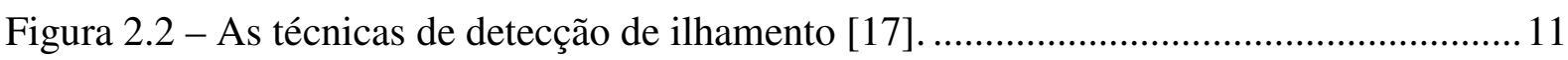

Figura 3.1 - Exemplo de execução do DAMICORE. ........................................................... 30

Figura 3.2- exemplo de dois arquivos com forte correlação................................................... 31

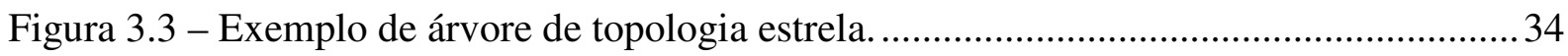

Figura 3.4 - Exemplo da junção entre dois nós de uma árvore com topologia estrela. ............35

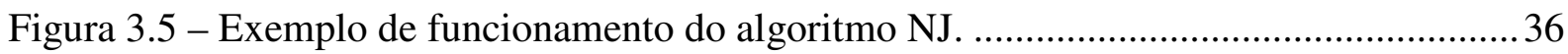

Figura 3.6 - Exemplo de estrutura com três comunidade em uma rede.................................. 37

Figura 4.1 - Interconexão dos modelos lineares e não-lineares. ............................................4 43

Figura 4.2 - Circuito equivalente do modelo do transformador........................................... 45

Figura 4.3 - Modelo do Regulador de Velocidade...............................................................46

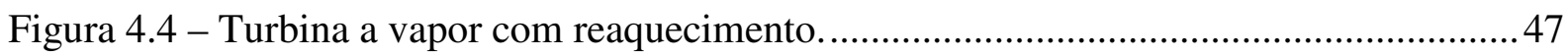

Figura 4.5 - Sistema de controle de excitação de um gerador síncrono. ................................. 48

Figura 4.6 - Diagrama simplificado do sistema de excitação IEEE tipo DC1A.....................49

Figura 4.7 - Diagrama unifilar do sistema de distribuição................................................... 51

Figura 5.1 - O esquema de proteção anti-ilhamento proposto...............................................54

Figura 5.2 - Etapas do processo KDD e o esquema de proteção anti-ilhamento.....................54

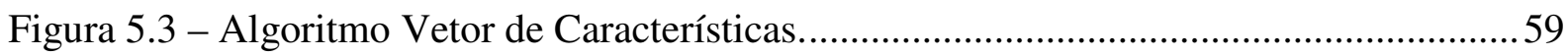

Figura 5.4 - Algoritmo de transformação dos dados. ............................................................... 60

Figura 5.5 - Função data-mining para a proteção anti-ilhamento..........................................61

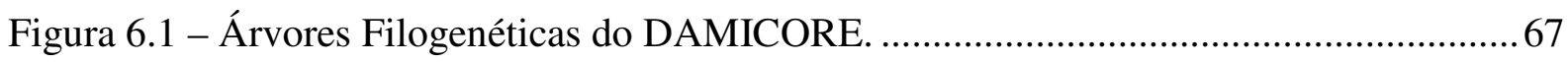

Figura 6.2 - Percentual de clusters de ilhamento em relação ao total de clusters.................... 71

Figura 6.3 - Teste de desempenho geral dos algoritmos de proteção anti-ilhamento.............. 76

Figura 6.4 - Teste de variação do desbalanço de potência ativa para o cenário de carga I. .... 80

Figura 6.5 - Teste de variação do desbalanço de potência ativa para o cenário de carga II. ... 80

Figura 6.6 - Teste de variação do desbalanço de potência ativa para o cenário de carga III... 82

Figura 6.7 - Assinatura da frequência e da tensão durante ilhamento com $\Delta \mathrm{P}$ de $0 \mathrm{MW}$........85 
Figura 6.8 - Assinatura da frequência e da tensão durante ilhamento com $\Delta \mathrm{P}$ de $1 \mathrm{MW}$....... 86

Figura 6.9 - Assinatura da frequência e da tensão durante ilhamento com $\Delta \mathrm{P}$ de 4 MW. ...... 87

Figura 6.10 - Assinatura da frequência e da tensão durante ilhamento com $\Delta \mathrm{P}$ de $5 \mathrm{MW}$.... 89 


\section{Lista de Tabelas}

Tabela 2.1 - Quadro de parâmetros encontrados nas técnicas de detecção de ilhamento........25

Tabela 5.1 - Configuração das simulações. ..............................................................................56

Tabela 5.2 - Cenários de Carga para eventos de ilhamento ..................................................57

Tabela 5.3 - Saídas geradas pelo algoritmo vetor de características......................................59

Tabela 6.1 - Características dos Clusters do DAMICORE..................................................... 70

Tabela 6.2 - Quantidade de clusters por classe................................................................. 70

Tabela 6.3 - Quadro de ajustes dos relés de frequência....................................................... 72

Tabela 6.4 - Quadro de ajustes das funções data-mining. ...................................................... 73

Tabela 6.5 - Cenários de carga para eventos de ilhamento e chaveamento de carga ..............74

Tabela 6.6 - Configuração dos casos de chaveamento de carga............................................... 75

Tabela 6.7 - Tempo de detecção médio dos algoritmos de proteção anti-ilhamento............... 76

Tabela 6.8 - Desempenho geral do relé de frequência 2 ..................................................... 77

Tabela 6.9 - Casos de atuação indevida do relé de frequência 2 …...................................... 78

Tabela 6.10 - Cenários de carga para testes dos esquemas de proteção anti-ilhamento...........78

Tabela 6.11 - Configuração dos testes de análise da frequência e tensão durante ilhamento. 83

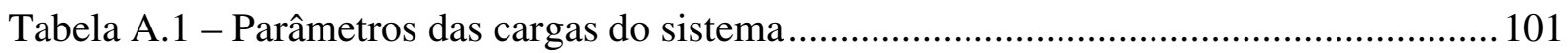

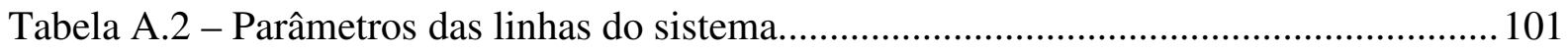

Tabela A.3 - Parâmetros dos transformadores do sistema..................................................... 102

Tabela A.4 - Parâmetros do gerador síncrono do sistema .................................................. 102

Tabela A.5 - Parâmetros do regulador de tensão e sistema de excitação ............................... 102

Tabela A.6 - Parâmetros da turbina a vapor e regulador de velocidade ............................... 103 



\section{Lista de Abreviaturas e Siglas}

AFD

Active Frequency Drift

ALFC

Automatic Load-Frequency Controller

ANEEL

Agência Nacional de Energia Elétrica

ANSI

American National Standards Institute

APS

Automatic Phase-Shift

ARPS

Adaptative Reactive Power Shift

BIG

Banco de Informações de Geração

DAMICORE

Data Mining of Code Repositories

DFA

Deslocamento de Fase

DSP

Digital Signal Processor

DT

Decision Tree

FFST

Frequency Filtering S-Transform

FN

Fast Newman

FPGA

Field Programmable Gate Array

GD

Geração Distribuída

KDD

Knowledge Discovery in Databases

MME

Ministério de Minas e Energia

NCD

Normalized Compression Distance

NJ

Neighbor-Joining

PAC

Ponto de Acoplamento Comum

$\mathrm{PCH}$

Pequenas Centrais Hidrelétricas

PLCC

Power Line Carrier Communication

PRODIST

Procedimentos de Distribuição de Energia Elétrica no Sistema Elétrico Nacional

PROINFA Programa de Incentivo às Fontes Alternativas de Energia Elétrica

PSS

Power System Stabilizer

RF

Random Forest

RNA

Redes Neurais Artificiais 
Realimentação positiva

RPV

Reactive Power Variation

SCADA

Supervisory Control and Data Acquisition

SEP

Sistema Elétrico de Potência

SFS

Sandia Frequency Shift

SMS

Slip Mode Frequency Drift

SOM

Self-Organizing Maps

SSF

Sub ou Sobrefrequência

SST

Sub ou Sobretensão

SVM

Support Vector Machine

SVS

Sandia Voltage Shift

TDF

Transformada Discreta de Fourier

TDW

Transformada Discreta de Wavelet

TVF

Taxa de Variação de Frequência

TVP

Taxa de Variação de Potência Ativa

TVP

Taxa de Variação de Potência Reativa

TVT

Taxa de Variação de Tensão

UPGMA

Unweighted Pair Grouping Method of Agglomeration

VU

Desequilíbrio de Tensão 


\section{Lista de Símbolos}

$\Delta \mathrm{f}$

$\frac{\mathrm{df}}{\mathrm{dt}}$

$\Delta \phi$

$\frac{\mathrm{d} \phi}{\mathrm{dt}}$

V

$\Delta \mathrm{V}$

$\frac{d V}{d t}$

$\mathrm{V}_{\text {NEG }}$

$\frac{d V_{\mathrm{NEG}}}{\mathrm{dt}}$

$\mathrm{P}$

$\frac{\mathrm{dP}}{\mathrm{dt}}$

Q

$\frac{\mathrm{dQ}}{\mathrm{dt}}$

$\frac{\mathrm{df}}{\mathrm{dP}}$

$\frac{d V}{d Q}$

dQ

$\cos (\phi)$

$\frac{\mathrm{d} \cos (\phi)}{\mathrm{dt}}$

$\mathrm{V}_{\mathrm{THD}}$

$\frac{d V_{\text {THD }}}{d t}$

$\mathrm{C}_{\mathrm{THD}}$
Sub ou sobrefrequência

Taxa de variação da frequência

Desvio de fase

Taxa de variação do ângulo de fase

Tensão

Sub ou sobretensão

Taxa de variação da tensão

Tensão de sequência negativa

Taxa de variação da tensão de sequência negativa

Potência ativa

Taxa de variação da potência ativa

Potência reativa

Taxa de variação da potência reativa

Taxa de variação da frequência em relação à potência ativa

Taxa de variação da tensão em relação à potência reativa

Fator de potência

Taxa de variação do fator de potência

Distorção harmônica total da tensão

Taxa de variação da distorção harmônica total da tensão

Distorção harmônica total da corrente 
$\frac{\mathrm{dC}_{\mathrm{THD}}}{\mathrm{dt}}$

$\mathrm{I}_{\mathrm{NEG}}$

$\frac{\mathrm{dI}_{\mathrm{NEG}}}{\mathrm{dt}}$

$\mathrm{P}_{\mathrm{NEG}}$

$\frac{\mathrm{dP}_{\mathrm{NEG}}}{\mathrm{dt}}$

$\mathrm{U} \cos (\phi)$

$\underline{\mathrm{dU} \cos (\phi)}$

$Q_{m}$

$\Delta \mathrm{P}$

$\Delta \mathrm{Q}$
Taxa de variação da distorção harmônica total de corrente

Corrente de sequência negativa

Taxa de variação da corrente de sequência negativa

Potência de sequência negativa

Taxa de variação da potência de sequência negativa

Módulo da tensão de fase vezes o fator de potência

Taxa de variação do módulo da tensão de fase vezes o fator de potência

Função de qualidade ou modularidade

Desbalanço de Potência Ativa

Desbalanço de Potência Reativa 


\section{Sumário}

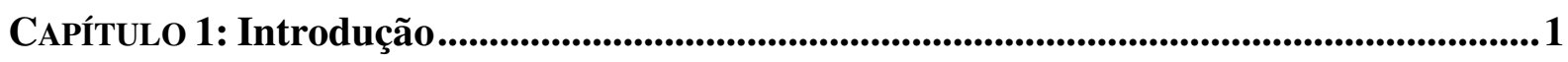

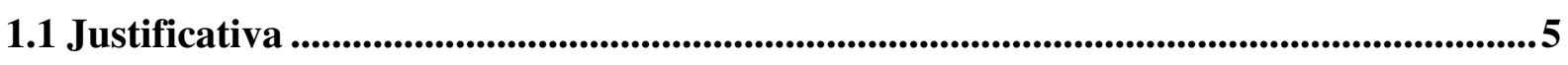

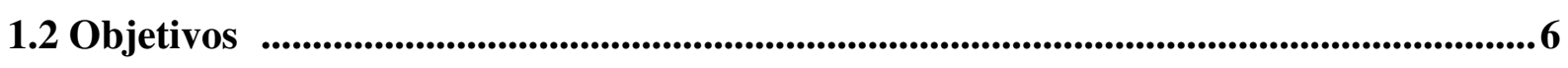

1.3 Organização da dissertação ............................................................................................................ 7

CAPítulo 2: Técnicas de Detecção de Ilhamento de Geração Distribuída ...........................9

2.1 Técnicas de detecção de ilhamento ....................................................................11

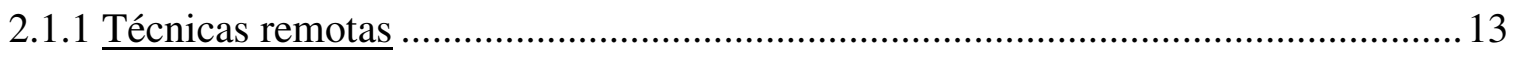

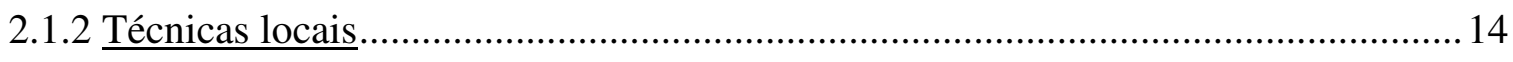

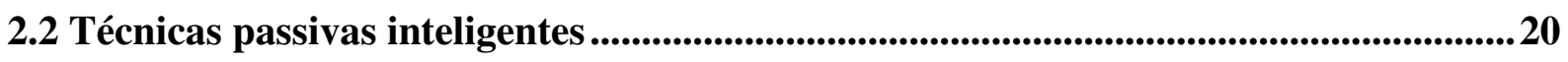

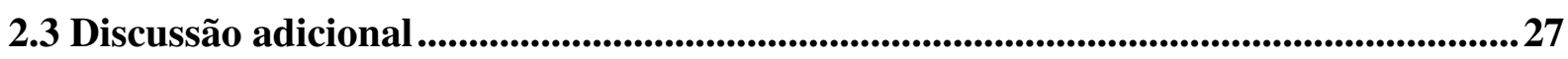

CAPítulo 3: A Técnica de Mineração de Dados DAMICORE ........................................29

3.1 Métricas de dissimilaridades para matriz de distâncias ..............................................31

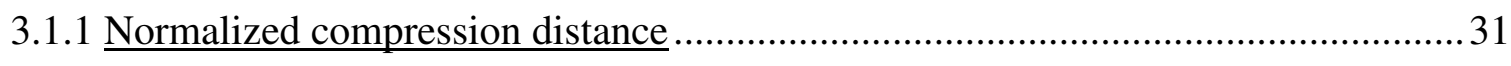

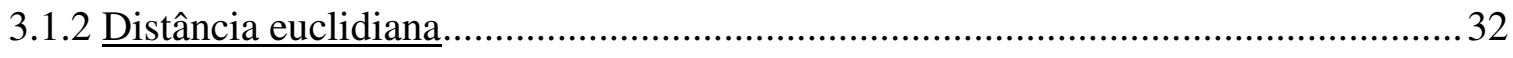

3.2 Técnicas de construção de árvores filogenéticas.....................................................................33

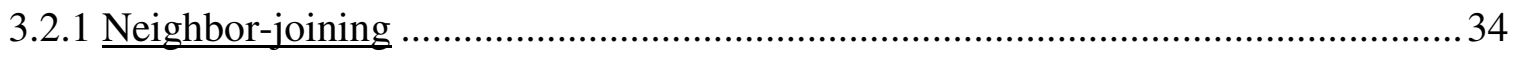

3.3 Técnicas de detecção de comunidades em redes complexas ........................................37

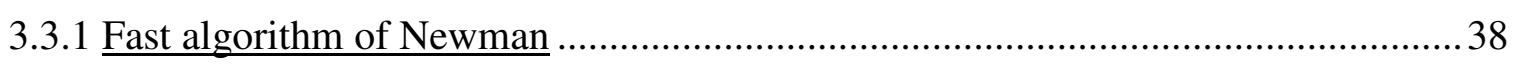

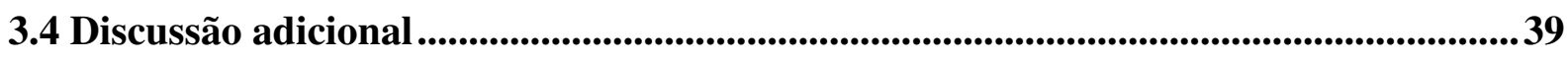

CAPítulo 4: Modelagem do Sistema Elétrico .................................................................41

4.1 O SimPowerSystems....................................................................................................................................42

4.2 Modelos dos componentes do sistema elétrico ............................................................................4 43

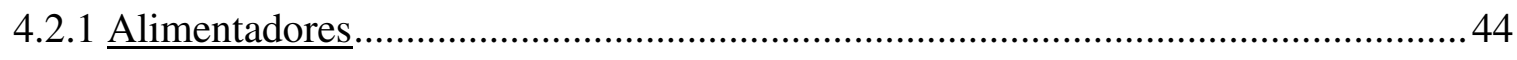

4.2.2 Cargas elétricas ......................................................................................... 44

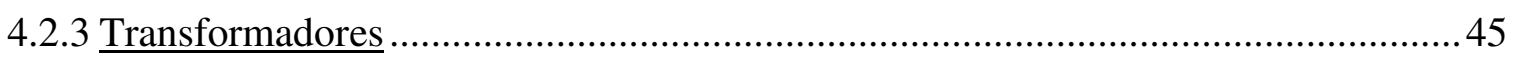

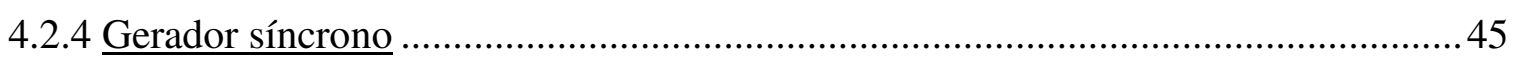

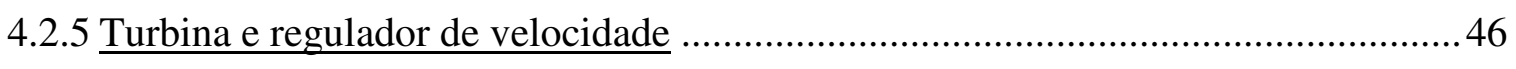

4.2.6 Excitatriz e regulador automático de tensão........................................................... 47 


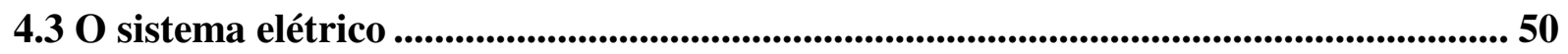

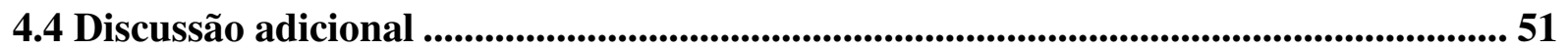

CAPítulo 5: O Esquema de Proteção Anti-Ilhamento ............................................................. 53

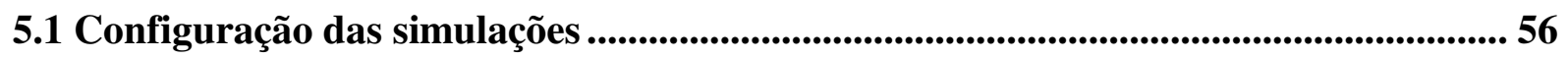

5.1 .1 Obtenção do banco de dados de simulação................................................................... 57

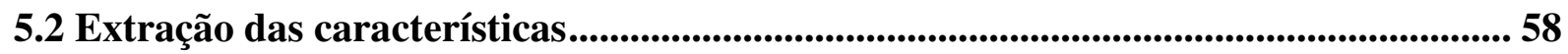

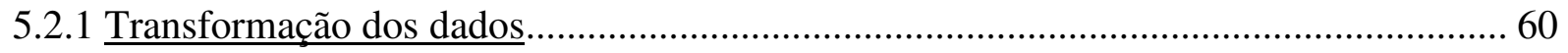

5.3 Função data-mining de proteção anti-ilhamento........................................................... 61

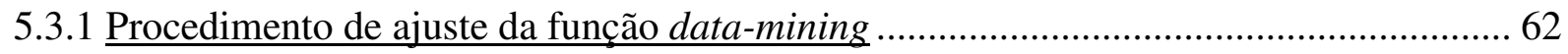

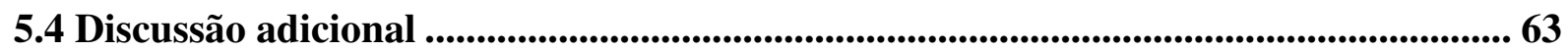

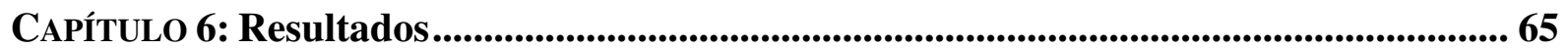

6.1 Análise de padrões do DAMICORE............................................................................66

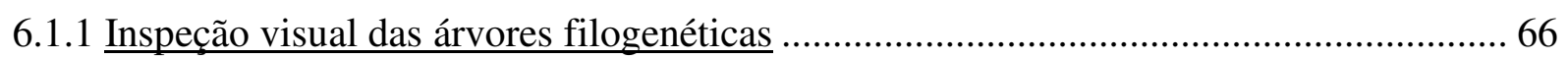

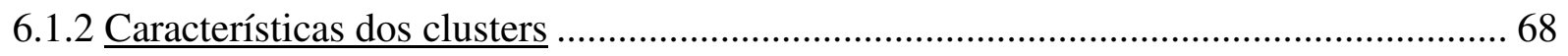

6.2 Avaliação e testes dos esquemas de proteção anti-ilhamento ........................................... 72

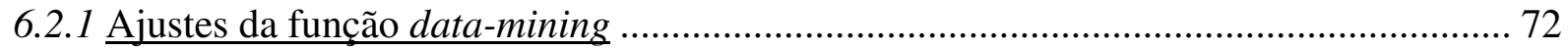

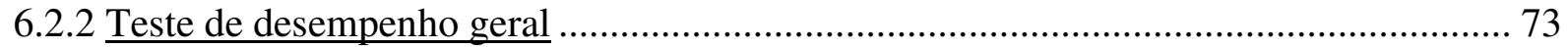

6.2.3 Teste de variação do desbalanço de potência ativa.......................................................... 78

6.3 Análise da frequência e tensão durante o ilhamento ...................................................... 83

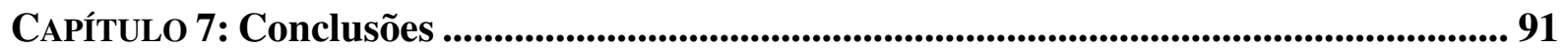

7.1 Sugestões para trabalhos futuros........................................................................................... 93

7.2 Publicação resultante do trabalho até o momento ..................................................... 94

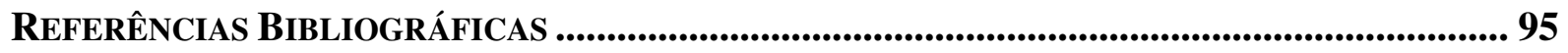

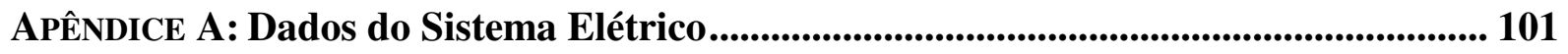




\section{CORÍNTIOS 12:31}

Entretanto, procurai, com zelo, os melhores dons.

\section{O AMOR E O DOM SUPREMO}

E eu passo a mostrar-vos um caminho sobremodo excelente. 



\section{CAPrituo 1}

\section{Introdução}

A origem dos sistemas elétricos de potência se deu no intuito de suprir demandas locais, sendo construídos e operados por produtores independentes de energia elétrica. Por serem caracterizados dessa forma, os primeiros sistemas elétricos de distribuição, datados de 1880, possuíam geração local. Todavia, com a expansão da demanda de energia elétrica, foi crucial criar um sistema interligado, planejado e operado por uma organização específica, tornando-o eficaz, razoavelmente seguro e econômico. Isso levou aos projetos de geração centralizada, suprindo as demandas via transmissão e distribuição de energia elétrica. Consequentemente, projetos de geradores de menor potência instalados em local próximo ao consumidor final deixaram de ser incentivados e voltam a ser discutidos no início dos anos 90 com a geração distribuída (GD) [1], [2].

Nos últimos anos, em decorrência do processo de reestruturação do setor de energia elétrica ocorrido em muitos países, foram reduzidas de maneira significativa, ou mesmo eliminadas completamente, barreiras legais e econômicas ao segmento de geração de energia elétrica, possibilitando que novas fontes de energia, sendo elas de natureza renovável ou não sejam interconectadas aos sistemas de distribuição e subtransmissão [3]. Porém, com a pressão mundial em desenvolver práticas sustentáveis e limpas, as fontes que tiveram maior crescimento foram: processo de biomassa, geração eólica, geração solar fotovoltaica, pequenas centrais hidrelétricas $(\mathrm{PCH})[4]$.

No Brasil o crescimento das fontes renováveis, sobretudo a dos parques eólicos, ocorreu em 2004 quando foi instituído o programa de incentivo às fontes alternativas de energia elétrica (PROINFA), que previa até 2010 a implantação de 144 usinas, totalizando 3.299 MW de capacidade instalada, sendo: 1.191 MW provenientes de 63 PCHs; $1.423 \mathrm{MW}$ de 54 parques eólicos; e $685 \mathrm{MW}$ de 27 usinas a base de biomassa [5]. De fato, o cenário atual mostra uma grande perspectiva de crescimento de geradores distribuídos. As informações contidas no banco de informações de geração (BIG) [6] em setembro de 2016 mostram que 
estão em construção 33 projetos de PCHs cuja capacidade instalada totaliza $428 \mathrm{MW}$ e mais 1.757 MW, o que corresponde a 124 projetos, estão outorgadas pela ANEEL. Além disso, a análise da Figura 1.1 mostra que o potencial advindo da biomassa com base no bagaço de cana de açúcar monta o total de 11.573 MW, dos quais 48\% (5.570 MW) dessa fonte em relação ao total de biomassa estão instalados no estado de São Paulo. Em relação aos parques eólicos 386 já estão em operação, totalizando 9.489 MW, e estão em construção mais 141 projetos, totalizando 3.219 MW.
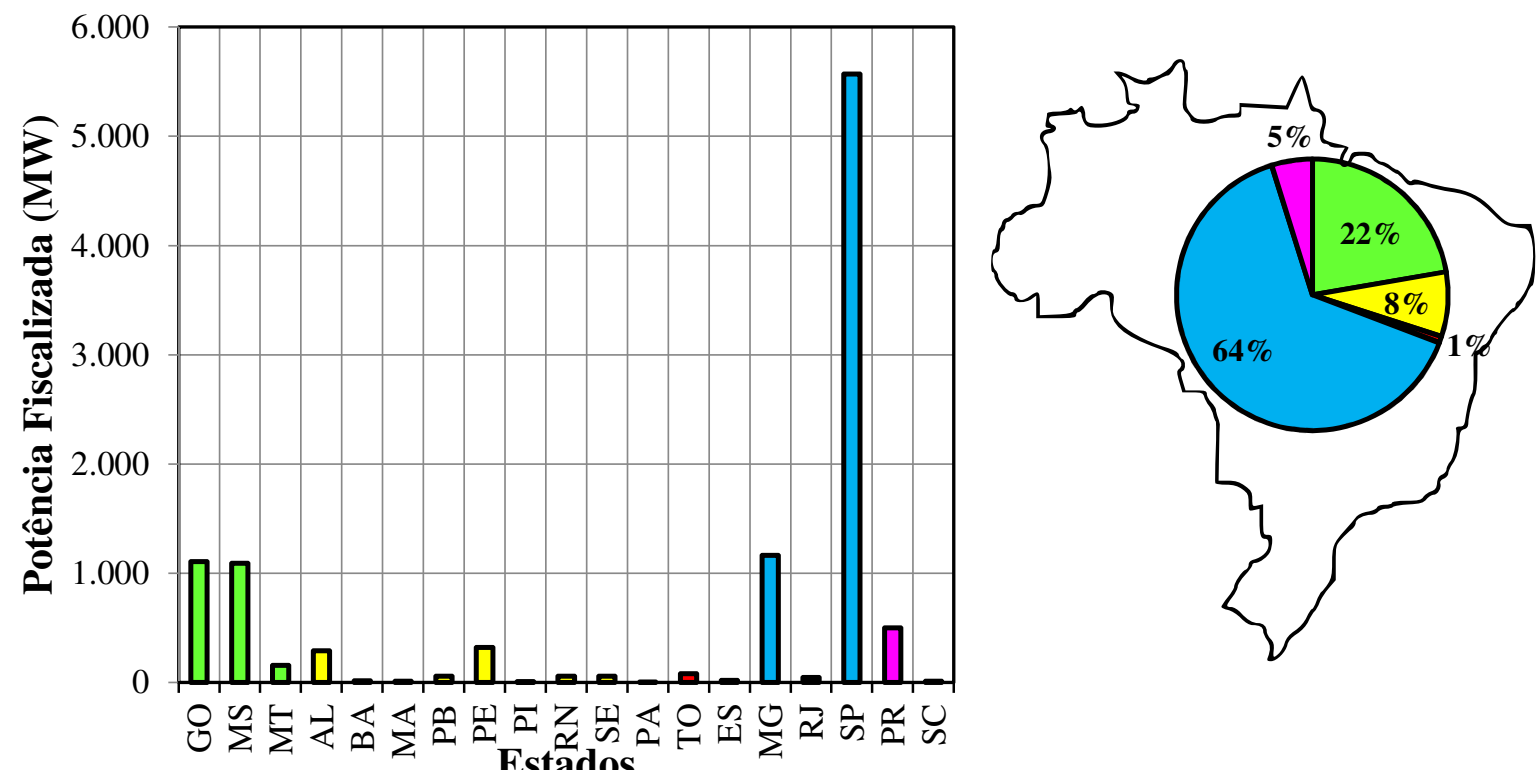

Estados

\section{$\square$ Sudeste $\square$ Centro-Oeste $\square$ Sul $\square$ Nordeste $\square$ Norte}

Figura 1.1 - Potência fiscalizada das usinas a base de biomassa de cana de açúcar por estado e região. Extraído da base de dados da ANEEL [6].

Do ponto de vista regulatório um dos avanços recentes para a GD ocorreu em 2012 com a aprovação pela ANEEL da resolução normativa $n^{\circ}$ 482/2012 que estabelece as condições gerais para o acesso de microgeração e minigeração distribuídas aos sistemas de distribuição de energia elétrica e o sistema de compensação de energia elétrica. Nessa resolução, denomina-se microgeração distribuída a central geradora com potência instalada até 100 kW e minigeração distribuída aquela com potência acima de $100 \mathrm{~kW}$ e menor ou igual a 1 MW, conectadas na rede de distribuição por meio de instalações de unidades consumidoras [7]. Em novembro de 2015, foram atualizados os limites definidos nessa resolução para mini e microgeração distribuída. Portanto, em março de 2016, definiu-se microgeração distribuída a central geradora com potência menor ou igual a $75 \mathrm{~kW}$ e minigeração distribuída aquela com potência superior a $75 \mathrm{~kW}$ e menor ou igual a $5 \mathrm{MW}$ 
(sendo 3 MW para a fonte hídrica) [8]. Desde a publicação da resolução nº 482/2012 em 2012 até outubro de 2015, já foram instaladas 1.285 centrais geradoras, sendo 1.233 (96\%) com a fonte solar fotovoltaica, 31 eólicas, 13 híbridas (solar/eólica), 6 movidas a biogás, 1 a biomassa e 1 hidráulica. Além dos incentivos regulatórios, o Ministério de Minas e Energia (MME) lançou no dia 15 de dezembro de 2015, por meio da portaria $\mathrm{n}^{\circ} 538$, o programa de desenvolvimento da geração distribuída de energia elétrica (ProGD) cuja promessa é movimentar até $2030 \mathrm{R} \$ 100$ bilhões em investimentos [9].

Com relação à tecnologia, os sistemas com GD não utilizam apenas geradores síncronos, como são em grande escala no caso do Brasil utilizados nas grandes usinas de geração de energia elétrica. Ambas as máquinas, síncronas ou de indução, são utilizadas no intuito de extrair as máximas potencialidades de cada insumo energético. Por exemplo, os parques eólicos em sua maioria utilizam geradores de indução em diferentes configurações. Já a máquina síncrona é mais comum em PCHs e nas usinas térmicas a biomassa [10], [11].

Nos trabalhos [1], [2], [10], [12]-[14] pontua-se com clareza a série de benefícios de conectar ao sistema elétrico geradores distribuídos. Seguindo com rigor recomendações técnicas de conexão, instalando-os próximo as cargas e com potência compatível à demanda do sistema de distribuição de energia elétrica, é possível reduzir as perdas elétricas associadas à transmissão e distribuição de energia elétrica. Além disso, é possível que os investimentos relacionados à construção de grandes centrais geradoras ou novas linhas de transmissão sejam adiados no curto prazo. Porém, a inserção de geração distribuída nos sistemas de distribuição faz com que os sistemas se tornem complexos, visto que, originalmente estes foram projetados para operar com fluxos de potência unidirecionais. Portanto, embora haja benefícios, uma série de desafios tem de ser superados para explorar os benefícios da GD. Nesse contexto, a instalação de geradores distribuídos deve ser precedida de estudos detalhados para identificar os impactos na operação das redes de distribuição.

Entre os itens contemplados nas recomendações do IEEE 1547 [15], é exigido que geradores distribuídos sejam equipados com proteção anti-ilhamento. O ilhamento é uma condição na qual o gerador distribuído alimenta uma porção do sistema de distribuição que se encontra eletricamente isolada do restante do sistema elétrico, tornando-se fonte de energia independente da concessionária. Após o desligamento do sistema da concessionária (ilhamento) a recomendação é desconectar do sistema os geradores distribuídos em tempo hábil entre 100 a 2.000 ms. Caso não haja a desconexão do gerador distribuído numa condição de ilhamento ou a mesma não seja detectada, implicará numa série de riscos, por exemplo, a segurança das equipes de manutenção e da população, a descoordenação do 
sistema de proteção de sobrecorrente, o aterramento inadequado, e o religamento automático fora de sincronismo [15]-[17].

O interesse atual quanto ao problema do ilhamento de geradores distribuídos é o de melhorar as técnicas atuais e propor soluções mais eficazes. Para isso é desejável reduzir ou eliminar o efeito de três características principais intrínsecos aos métodos (remotos, ativos, ou passivos) [17], [18]. O primeiro é o de diminuir custos, que podem ser alcançados se forem evitadas a construção de canais de comunicação necessários para soluções baseadas em técnicas remotas [17]-[20]. O segundo é o de evitar a injeção de perturbações controladas no sistema elétrico, que no caso, é a característica principal de técnicas ativas [18], [21], [22]. O terceiro efeito está relacionado com as falhas na atuação das proteções contra o ilhamento via técnicas passivas [2], [16], [19]-[21], [23]. Essa falha pode ocorrer quando o desbalanço de potência (ativa e reativa) entre a carga do subsistema ilhado e o gerador distribuído for pequeno, pois os sinais de frequência e de tensão do subsistema ilhado variam pouco e ou lentamente. Isso caracteriza uma condição de operação dentro de suas zonas de não detecção. Portanto, é desejável que essas zonas de não detecção sejam minimizadas. Além disso, é desejável eliminar casos de atuação indevida, pois há situações em que as proteções passivas podem se confundir. Ao utilizar a mineração de dados como técnica passiva para identificar o ilhamento é possível diferenciar situações de ilhamento de situações de não ilhamento e desse modo diminuir os casos em que os esquemas passivos tradicionais falham.

Nesse contexto, será apresentado ao longo dessa dissertação um novo esquema para proteção anti-ilhamento aplicável a geradores síncronos distribuídos. O método baseia-se em explorar padrões das grandezas amostradas por técnicas passivas, ou seja, que se baseiam em ler os sinais apenas do ponto de acoplamento comum (PAC) entre a GD e o sistema da distribuidora. Ao construir um banco contendo esses dados, com casos relevantes para caracterizar o ilhamento, algumas questões são apontadas. Qual o conhecimento sobre o problema que esses dados poderiam trazer? Correlaciona-los traria formas de melhorar a confiabilidade, segurança, precisão, e, respeitaria o tempo proposto pelas recomendações técnicas para identificar o ilhamento?

Para responder a essas questões que surgem quando os dados possuem natureza complexa e utilizar a informação obtida para projetar um novo esquema de proteção anti-ilhamento será utilizada a técnica de mineração de dados do Data Mining of Code Repositories (DAMICORE). O DAMICORE é uma combinação de algoritmos que buscam encontrar relações fortes entre dados, sejam eles de qualquer tipo, utilizando como critério a 
mineração de dados baseada na compressão de amostras, construindo ao final de sua execução uma árvore filogenética ${ }^{1}$ [24], [25].

\subsection{Justificativa}

Geralmente a detecção do ilhamento, em especial a de geradores síncronos, é feita por esquemas de proteção passiva. Os métodos passivos convencionais para a detecção de ilhamento (relés de frequência, taxa de variação de frequência, salto de vetor e tensão) estão sujeitos a zonas de não detecção. Essas zonas podem ser minimizadas se os ajustes das funções de proteção anti-ilhamento passivas, instaladas junto ao gerador distribuído, forem feitos sensíveis em relação à detecção do ilhamento. No entanto, se isso for feito, a proteção estará susceptível a casos de atuação indevida. Por isso, é preciso encontrar ajustes que torna o esquema de proteção anti-ilhamento sensível e ao mesmo tempo seguro. Esses ajustes não são triviais de serem obtidos utilizando os esquemas de proteção anti-ilhamento tradicionais, sejam eles baseados em medidas de frequência ou de tensão, pois a variação da tensão e frequência é dependente do cenário de carga e de geração do sistema ilhado, além disto, depende das características construtivas do gerador distribuído. Logo, é necessária uma ferramenta capaz de detectar o ilhamento rapidamente, sendo capaz de distinguir o que é ilhamento de outros eventos do sistema elétrico. Uma potencial técnica para tentar solucionar esse problema é a mineração de dados pelo DAMICORE.

Considerar e incluir a natureza transitória dos sinais entre os diversos fenômenos que possam vir a ocorrer em um sistema elétrico pode dar indicativos mais apurados para caracterizar o fenômeno ilhamento. Se um banco de dados for construído com a prerrogativa de extrair conhecimento dos sinais é necessário recorrer a métodos e técnicas de mineração de dados (data-mining), que no caso, são algoritmos específicos com a função de extrair padrões dos dados, sendo consideradas técnicas cerne no processo de extrair conhecimento útil de banco de dados, sejam eles de qualquer tipo [26]. Portanto, para aprimorar a estrutura de decisão das técnicas locais passivas utilizadas para caracterizar o ilhamento, é necessário entender um pouco mais sobre os dados que essas técnicas utilizam como entrada. Aventurar-se em descobrir os possíveis padrões que essas grandezas quando correlacionadas possam apresentar é o que justifica o uso de técnicas de mineração de dados para solucionar o

\footnotetext{
${ }^{1}$ Termo referido no ramo da biologia para representações gráficas, na forma de árvore, que mostra a relação entre várias espécies que possam ter um ancestral em comum, ou seja, são relações de hereditariedade que representam a correlação entre os dados [47].
} 
problema do ilhamento. Por estes motivos, adotaram-se as técnicas do DAMICORE. Esse algoritmo é poderoso como técnica de mineração de dados, por dois motivos: o primeiro, de buscar relações fortes entre dados naturalmente complexos independentemente do tipo de informação contida nos arquivos sob análise (imagem, texto, matrizes, etc). O segundo, de apresentar graficamente a correlação entre os dados na forma de árvore filogenética. Além disto, é uma técnica nova e que ainda não foram exploradas as possibilidades de aplicação envolvendo a área de sistemas elétricos de potência (SEP).

Para garantir um bom funcionamento da técnica ao aplicá-la no problema do ilhamento é necessário incluir no banco de dados uma série de fenômenos transitórios que contenham informação representativa e significativa do sistema elétrico em específico. Portanto, é primordial o uso de ferramentas computacionais que simulem fidedignamente os efeitos transitórios que possam vir a ocorrer no SEP em que o gerador distribuído será interconectado. Para atender esse requisito recorreu-se ao MATLAB e os componentes e ferramentas de análise da biblioteca SimPowerSystems do ambiente Simulink/MATLAB (R2010a). Adicionalmente, a grande vantagem é a integração em um único ambiente de programação todos os recursos necessários para o desenvolvimento desta dissertação, ou seja, o algoritmo do DAMICORE; a modelagem e simulação do SEP; o sistema de aquisição e organização de dados; o estimador de parâmetros baseado em medidas locais; e finalmente os testes da função de proteção anti-ilhamento proposta nesta dissertação.

\subsection{Objetivos}

O objetivo geral desse documento é propor uma solução de proteção anti-ilhamento para geradores síncronos distribuídos utilizando a técnica de mineração de dados do DAMICORE. Para atingir o objetivo geral foi necessário concluir uma série de objetivos específicos:

\section{- Compreender requisitos técnicos por meio de revisão bibliográfica:}

1 Compreender as implicações da operação ilhada e as estratégias utilizadas nas técnicas existentes tradicionais e inteligentes para detecção de ilhamento;

2 Buscar na literatura os parâmetros convencionais e não convencionais que podem ser utilizados como métricas de decisão nas técnicas de mineração de dados considerando o problema ilhamento; 
3 Compreender o princípio de funcionamento da técnica de mineração de dados DAMICORE;

- Modelar o sistema elétrico com gerador distribuído:

1 Configurar os elementos do sistema, controles do gerador síncrono, preparando-o para simulações de ilhamento, chaveamento de cargas e etc;

2 Criar scripts capazes de configurar com facilidade simulações de ilhamento e outros fenômenos transitórios;

- Configurar técnicas de aquisição de dados:

1 Estimar parâmetros relevantes para a detecção do ilhamento de geradores síncronos;

2 Selecionar região de interesse das simulações;

3 Preparar os dados para aplicar a técnica DAMICORE;

4 Realizar testes indicativos de funcionamento da técnica DAMICORE;

5 Extrair das simulações um banco contendo dados relevantes para caracterizar o ilhamento;

- Projetar a proteção anti-ilhamento utilizando a técnica de mineração de dados do DAMICORE, implementando algoritmos no MATLAB para testes off-line ou simulações de laço aberto;

- Realizar testes da proteção anti-ilhamento projetada utilizando a técnica de mineração de dados do DAMICORE;

\subsection{Organização da dissertação}

Este trabalho foi organizado conforme os capítulos a seguir:

- Capítulo 2: apresenta o porquê da detecção de ilhamento de geradores distribuídos e uma revisão bibliográfica das técnicas convencionais às técnicas inteligentes utilizadas para a detecção do ilhamento. No final deste capítulo é dada uma ênfase para o quadro de parâmetros que as técnicas atuais utilizam como métricas de decisão para detectar o ilhamento, pois podem ser úteis para projetar metodologias de mineração de dados para a detecção do ilhamento de geradores síncronos. 
- CApí́tulo 3: apresenta o princípio de funcionamento, algoritmos e os passos necessários para utilizar a técnica de mineração de dados (DAMICORE), proposta nesta dissertação para a proteção anti-ilhamento.

- Capítulo 4: apresenta o princípio de funcionamento das ferramentas SimPowerSystems do ambiente Matlab/Simulink R2010a, o qual foi o programa utilizado para o desenvolvimento desta dissertação. Trata dos modelos matemáticos dos componentes do sistema elétrico e ao final do capítulo apresenta o sistema elétrico, com seu respectivo diagrama unifilar, para o qual foi projetado o esquema de proteção anti-ilhamento baseado na mineração de dados do DAMICORE.

- CAPítulo 5: apresenta a metodologia utilizada para projetar o esquema de proteção anti-ilhamento, o qual foi intitulado função data-mining, proposto nesta dissertação. Trata das simulações realizadas para gerar o banco de dados, dos algoritmos que preparam os dados para o DAMICORE, da função data-mining e o procedimento necessário para ajusta-la.

- Capítulo 6: apresenta a análise dos resultados obtidos ao longo desta dissertação, os quais foram divididos em 3 análises. A primeira é a análise dos padrões de ilhamento obtidos no processo de mineração de dados via DAMICORE. A segunda trata de testes comparativos de desempenho dos esquemas de proteção anti-ilhamento proposto nesta dissertação com um relé de frequência. A terceira trata do comportamento do sinal de frequência e tensão eficaz para algumas simulações de ilhamento, considerando desbalanços de potência ativa específicos em que o ilhamento pode ocorrer para o sistema desta dissertação.

- CAPítulo 7: apresenta as conclusões e principais contribuições deste trabalho.

- APÊNDiCE A: apresenta dados do sistema elétrico utilizado nesta dissertação. 


\section{Técnicas de Detecção de Ilhamento de}

\section{Geração Distribuída}

As recomendações para conexão de geradores distribuídos nos sistemas elétricos de potência apresentadas em IEEE 1547 [15] definem ilhamento com as seguintes palavras:

\footnotetext{
"Quando parte da área de um SEP é energizada exclusivamente por redes locais através de seu PAC, e, essa porção passa a operar eletricamente isolada do restante do sistema elétrico é caracterizado o ilhamento" [15].
}

Para ilustrar o problema propõe-se a Figura 2.1: caso o disjuntor A abra, talvez por uma falta no sistema, a corrente de curto-circuito pode ser insuficiente para abrir o disjuntor B, forçando uma situação em que o gerador distribuído continua alimentando a carga. Se o gerador distribuído fornecer precisamente as potências ativas e reativas demandadas pela carga, não haverá desvios na frequência e tensão do sistema ilhado.

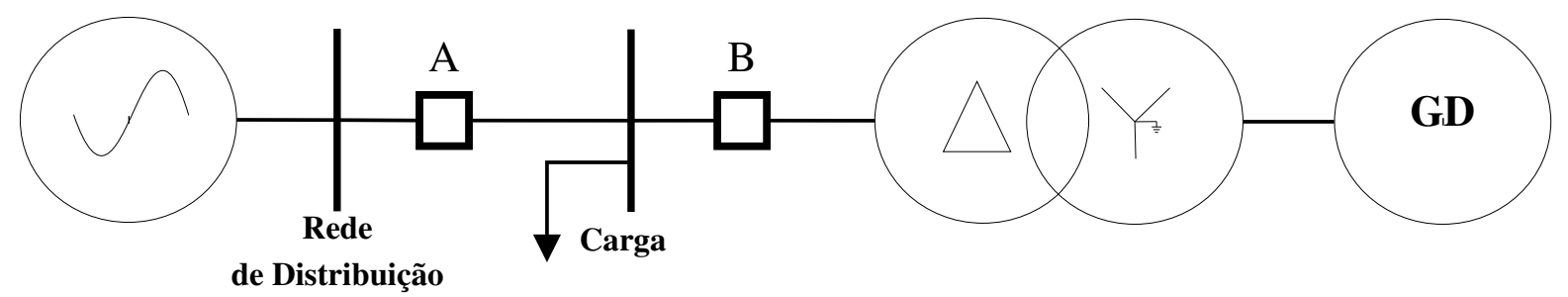

Figura 2.1 - O problema do ilhamento [1]. 
Caso ocorra situação próxima a essa singularidade, para a maioria dos esquemas de proteção anti-ilhamento, o tempo para sensibilizar a decisão de abertura dos relés convencionais será demasiadamente longo [16]. A operação ilhada de geradores distribuídos, se não detectada e eliminada em tempo hábil, apresenta riscos, conforme apresentados em [1], [3], [17], [21], [22]:

1 A segurança das equipes de manutenção e operação do sistema: uma porção do sistema poderá estar energizada sem o conhecimento da distribuidora, levando a riscos de choques elétricos.

2 Perda da coordenação das proteções de sobrecorrente: a corrente de curto-circuito do subsistema ilhado é drasticamente reduzida após a perda de conexão com a concessionária, levando os dispositivos de proteção a perderem completamente a coordenação entre si.

3 A segurança da população: caso ocorra uma situação de falta de alta impedância, a concessionária poderia detecta-la e interromper o fornecimento de energia na tentativa de eliminá-la. No entanto, caso algum gerador distribuído permaneça conectado, a falta seria mantida e comprometeria a segurança de pessoas que estão no local.

4 A qualidade da energia: os geradores distribuídos podem prejudicar o módulo e a frequência das tensões do sistema ilhado, pois essas grandezas passam a ser controladas pelos geradores distribuídos. Isso impede que a distribuidora tenha o controle de tensão e frequência, uma vez que os geradores distribuídos normalmente não pertencem a ela.

5 Aterramento inadequado: na operação ilhada, dependendo do tipo de conexão entre o gerador distribuído e o transformador de acoplamento, a porção do sistema ilhado poderá perder a referência de aterramento. A operação sem a referência de neutro aterrado é considerada inaceitável em muitos países, podendo apresentar valores pequenos e não detectáveis pela proteção de sobrecorrente.

6 Religamento automático fora de sincronismo: na tentativa de eliminar faltas e aumentar os índices de confiabilidade dos sistemas de subtransmissão e de distribuição, é comum reenergizar trechos ou linhas utilizando religadores automáticos. Se o subsistema ilhado for reconectado ao sistema elétrico dessincronizado, elevados valores de corrente e de torque poderão danificar os geradores. Os efeitos transitórios gerados poderão inclusive danificar outros equipamentos da concessionária ou dos consumidores.

7 Restauração do sistema: as operações de subsistemas ilhados podem dificultar a restauração manual ou automática do sistema. 
A série de implicações do ilhamento de geradores distribuídos tem direcionado as pesquisas em abordar diferentes técnicas ou meios de melhorar as mais tradicionais de forma que sejam reduzidos ou eliminados os casos em que o ilhamento não é detectado. Nesse sentido, as próximas seções deste CAPÍTUlO 2 apresentam as abordagens disponíveis para detectar o ilhamento de geradores distribuídos. Primeiramente serão discutidas as técnicas convencionais, sendo elas as técnicas remotas e locais, desenvolvendo a revisão para as técnicas locais e passivas mais recentes. Essas técnicas podem ser classificadas como técnicas passivas inteligentes, pois utilizam dentro de suas metodologias as técnicas de mineração de dados, as redes neurais artificiais, e os sistemas de inferência fuzzy.

\subsection{Técnicas de detecção de ilhamento}

De um modo geral, as principais filosofias de proteção para detecção de ilhamento utilizam medidas de tensões e correntes (ou outra grandeza elétrica) disponíveis no local de instalação do gerador distribuído, ou utilizam de esquemas de comunicação entre a concessionária, o gerador distribuído, os dispositivos de proteção e manobra. Desse modo, as técnicas atuais para detecção de ilhamento, mesmo que possuam algoritmos mais sofisticados ou inteligentes, podem ser subdivididas em técnicas locais e técnicas remotas. Das técnicas locais derivam as técnicas ativas, passivas e híbridas assim como mostra a Figura 2.2 [17], [23].

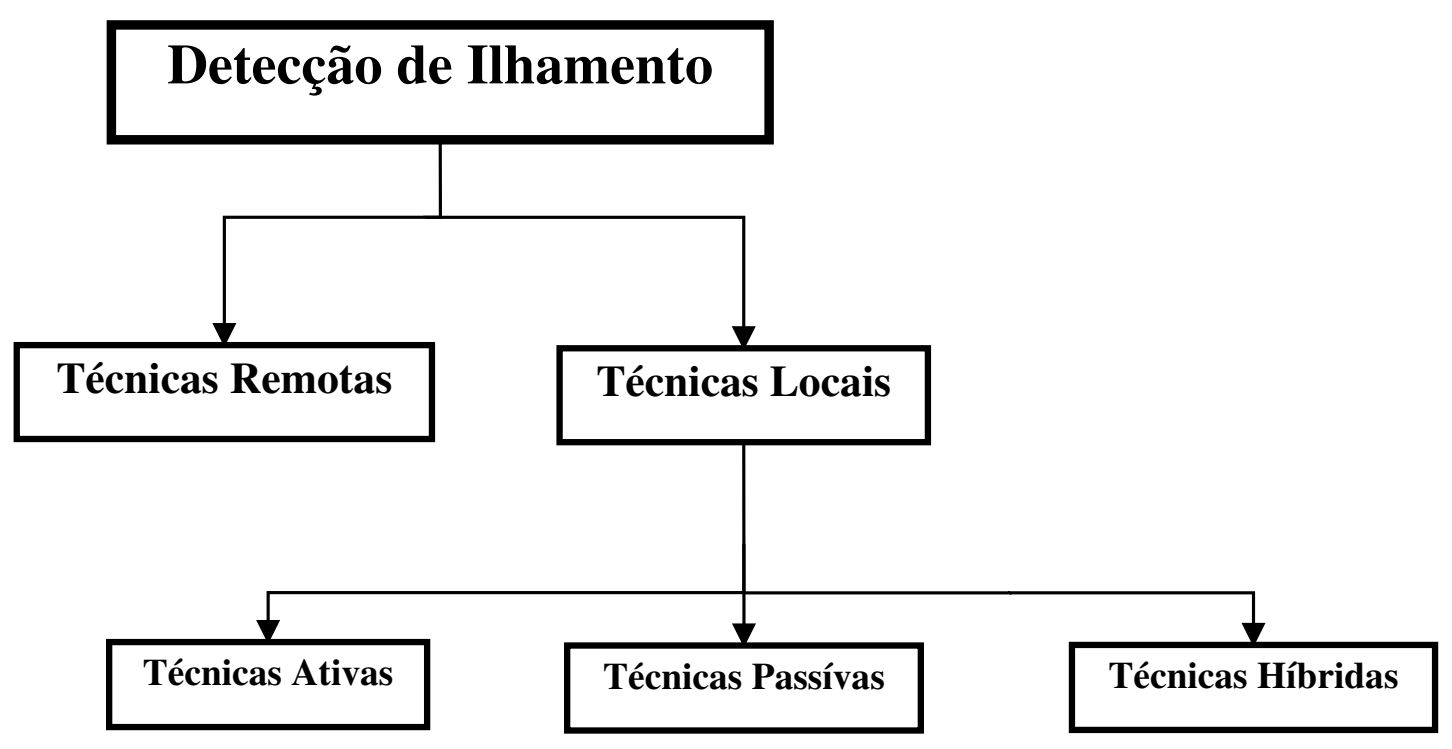

Figura 2.2 - As técnicas de detecção de ilhamento [17]. 
De acordo com [21] é importante considerar na escolha de uma das técnicas de proteção anti-ilhamento as características técnicas do gerador. Em sua maioria, geradores distribuídos podem ser agrupados em três tipos:

- Geradores síncronos: esse tipo de gerador é tipicamente conectado ao alimentador primário e pode chegar a gerar tipicamente 30 MW. Devido à característica de potência mais elevada, as opções de controlar geradores síncronos com a proposta de facilitar a detecção do ilhamento, como é o caso das técnicas ativas, são poucas se comparadas com os esquemas de geradores equipados com inversores. Por esses motivos, a tarefa de detecção do ilhamento em sistemas com geradores síncronos distribuídos é o cenário mais desafiador entre as tecnologias de geradores que podem ser utilizadas como GD.

- Geradores de indução: assim como nos geradores síncronos, esse tipo de gerador é tipicamente conectado ao alimentador primário. A capacidade de geração também pode chegar a valores elevados (10 a 20 MW). Porém, geradores de indução, devido a sua necessidade de consumir potência reativa da rede elétrica, não são capazes de sustentar a operação ilhada. A única rara exceção é caso exista potência reativa suficiente para que o gerador de indução fique auto-excitado. Como resultado, um simples relé de frequência pode ser usado para detectar o problema da auto-excitação, portanto a proteção anti-ilhamento não é considerada um problema para os geradores de indução.

- Geradores equipados com inversores: estes tipos de geradores distribuídos são tipicamente conectados ao alimentador secundário devido ao seu tamanho relativamente pequeno (da ordem de alguns $\mathrm{kW}$ ). Geradores equipados com inversores são capazes de sustentar uma ilha, embora inversores interativos possam ser projetados para detectar e controlar a operação ilhada. O inversor é uma interface entre o sistema elétrico e o gerador. $\mathrm{O}$ gerador pode ser painéis fotovoltaicos, células a combustível, microturbinas etc. Desde que o inversor interaja com a rede elétrica, todos os geradores distribuídos equipados com inversores têm características operativas que respeitam a interação com a rede que é primordialmente determinada pela topologia e controles do inversor. 


\subsubsection{Técnicas remotas}

Técnicas remotas são todas aquelas que utilizam algum tipo de esquema de comunicação entre a concessionária, o gerador distribuído, os dispositivos de proteção e manobra para identificar o ilhamento. Embora tenham maior confiabilidade do que as técnicas locais são necessários investimentos em sistemas de comunicação que tornam os sistemas caros e muitas vezes inviáveis do ponto de vista econômico. Adicionalmente à questão econômica, na indisponibilidade de sistemas de comunicação, ou caso esses sistemas de comunicação apresentem falhas ou respostas lentas, sistemas que utilizam técnicas locais, são necessários [14]. Os exemplos de técnicas remotas discutidos em [17]-[20] estão apresentados a seguir:

- Os sistemas Supervisory Control and Data Acquisition (SCADA): utilizam esquema de comunicação para monitorar o estado de todos os disjuntores desde a subestação até os geradores distribuídos. O estado dos disjuntores indicará a porção do sistema que se encontra isolado, caso haja GDs que continuam alimentando a porção ilhada, esquemas de teleproteção podem ser utilizados. É uma técnica eficiente, embora possua custos de implantação elevados e que tendem a crescer à medida que o tamanho e o número de disjuntores da rede elétrica aumentem.

- Os sistemas Power Line Carrier Communication (PLCC): utilizam a estrutura existente de linhas do sistema elétrico como canal de comunicação. A ideia é monitorar sinais que são continuamente transmitidos dos alimentadores de distribuição para os geradores distribuídos equipados com receptores. Se em algum ponto do sistema o sinal for interrompido, não sensibilizando os receptores instalados nos geradores distribuídos, o ilhamento será identificado. Nesse caso, não há as mesmas implicações, discutidas para os sistemas SCADA, quanto a mudanças na estrutura do sistema elétrico, pois dependem apenas do enlace de comunicação entre os geradores distribuídos e a concessionária. Embora seja uma técnica com elevada confiabilidade, caso haja a interrupção momentânea do sinal de tensão da rede, o sistema poderá desconectar os geradores distribuídos indevidamente. 
- Redes de comunicação dos dispositivos de proteção: podem ser utilizadas para minimizar a possibilidade de falsa operação dos relés equipados com função de proteção anti-ilhamento. Nesse caso, os dispositivos de proteção dos geradores distribuídos e/ou da subestação são interligados pelas redes de comunicação, trocando e comparando parâmetros entre si. Essa técnica não melhora a capacidade de detecção de ilhamento do relé diretamente, mas reduz a possibilidade de falsa operação devido a perturbações no sistema de transmissão.

\subsubsection{Técnicas locais}

Técnicas locais são todas aquelas que utilizam medidas de tensões, correntes ou outras grandezas elétricas disponíveis no local de instalação do gerador distribuído para identificar o ilhamento. Essas técnicas são divididas em três grupos que serão expostas a seguir. São elas, as técnicas passivas que utilizam apenas os sinais disponíveis no PAC; as técnicas ativas que utilizam os sinais do PAC e inserem perturbações controladas para facilitar a detecção do ilhamento; e as técnicas híbridas que são uma combinação de ambas as técnicas locais, passivas e ativas, para a detecção do ilhamento [18], [20], [21].

\section{Técnicas passivas}

Normalmente as técnicas passivas são as mais empregadas para a proteção anti-ilhamento. Isso se deve às seguintes razões: são de fácil instalação, visto que utilizam apenas medidas do local de instalação do GD; possuem custo menor, pois não necessitam da infraestrutura de sistemas de comunicação como é o caso das técnicas remotas; e não inserem nenhum tipo de distúrbio que possa degradar a qualidade da energia para assim como é o caso das técnicas ativas. No entanto, os esquemas passivos tendem a falhar se o desbalanço de potência entre a carga do subsistema ilhado e o GD for pequeno, caracterizando uma condição de operação dentro de suas zonas de não detecção. Por isso, ainda há o desejo de reduzir e/ou eliminar essas zonas de não detecção, justificando a grande quantidade de técnicas e investigações sobre o ilhamento que surgiram nos últimos anos. Os exemplos de técnicas passivas serão discutidos a seguir, apresentando métodos que utilizam parâmetros derivados da frequência, tensão e potência. 
Parâmetros derivados da frequência, entre as técnicas passivas, são os mais comuns para geradores síncronos. Entre os relés disponíveis comercialmente, que utilizam medidas baseadas na frequência, podem-se elencar três [2], [20], [21]:

- Relés de sub ou sobrefrequência (SSF): os relés de SSF ou 81O/U pela tabela ANSI [28] calculam a frequência da forma de onda da tensão nos terminais do PAC. Podem apresentar ajustes temporizados e também um ajuste de mínima tensão de operação. Assim, a frequência calculada é comparada com os ajustes de sub/sobrefrequência. Caso a frequência do sistema exceda um dos ajustes durante um tempo determinado e se a tensão terminal for superior ao ajuste, então o relé enviará o sinal de abertura do disjuntor do GD [3].

- Relés de taxa de variação de frequência (TVF): os relés de TVF ou função ANSI 81R [28] calculam a TVF da forma de onda da tensão nos terminais do GD. Esse método acelera a detecção do ilhamento, sobretudo quando a frequência varia lentamente. Normalmente, os ajustes para sistemas com frequência de $60 \mathrm{~Hz}$ situam-se entre os limiares $0,10 \mathrm{~Hz} / \mathrm{s}$ a 1,20 Hz/s. Outra característica importante é a função de bloqueio com base na tensão terminal mínima. Isso evita a atuação do relé TVF durante a partida da máquina ou curtos-circuitos.

- Relés de deslocamento de fase (DFA): também conhecidos como "salto de vetor" calculam o DFA da forma de onda de tensão em relação a um sinal senoidal de referência. Tal parâmetro é uma forma indireta de medida da frequência. Como resultado, seu desempenho será similar ao apresentado pelo relé de SSF.

Complementando as análises de [21] em termos comparativos, [29] propôs analisar o tempo de detecção versus o desbalanço de potência ativa e os desbalanços críticos de potência ativa das técnicas TVF e DFA. Relés que utilizam TVF precisam de menores desbalanços de potência ativa para detectar o ilhamento se comparados com o DFA, por outro lado, relés que utilizam TVF são mais susceptíveis a falsa operação.

Parâmetros derivados da tensão, além da frequência, também podem ser úteis para detectar ilhamentos. Entre os relés disponíveis comercialmente, que utilizam medidas baseadas na tensão, podem-se elencar dois [18], [19], [23]: 
- Relés de sub ou sobretensão (SST): os relés de SST ou funções ANSI 27/59 [28] calculam o valor eficaz da forma de onda da tensão nos terminais do GD. É considerada uma janela de medida de alguns ciclos elétricos sobre a forma de onda da tensão. Antes de ser processado o sinal é filtrado para eliminar imprecisões na medida. Geralmente os relés de SST são os mais empregados dos esquemas que utilizam medidas da tensão [18].

- Relés de taxa de variação de tensão (TVT): os relés TVT calculam a taxa de variação da tensão nos terminais do gerador distribuído. Assim como na comparação dos relés TVF serem mais sensíveis do que os relés de SSF, os relés TVT são mais sensíveis que os de SST.

De acordo com [16], os relés de tensão são capazes de detectar o ilhamento, pois a tensão no sistema ilhado pode ser desviada devido ao desbalanço de potência reativa. Caso o sistema de excitação seja configurado para controlar a tensão terminal, os relés de tensão não são adequados para detectar o ilhamento de geradores síncronos. Se o GD for configurado para controlar potência reativa, a tensão apresenta variações que podem ser facilmente detectadas pelos relés de tensão. No entanto, se o desbalanço de potência reativa for pequeno dificultará a detecção do ilhamento, pois pode ser que a tensão não seja sensibilizada o suficiente para caracteriza-lo.

Parâmetros derivados da potência são apresentados na referência [21]. Não são parâmetros convencionais para detecção de ilhamento, porém alguns exemplos são:

- Taxa de variação de potência ativa (TVP): o esquema TVP monitora a taxa de variação da potência ativa fornecida pelo gerador distribuído. Essa técnica é mais rápida se comparadas com o desempenho dos relés baseados em medidas da frequência, pois as variações na frequência são acopladas com as constantes de inércia do gerador distribuído, enquanto que a potência ativa varia diretamente com a relação entre a tensão e a corrente $(v \times i)$. Contudo, algumas perturbações na máquina podem alterar a potência ativa. Portanto, é uma tarefa difícil estabelecer ajustes para os métodos que consideram TVP.

- Taxa de variação de potência reativa (TVQ): o esquema TVQ monitora variações na potência reativa fornecida pelo GD. Esse parâmetro pode apresentar desempenho melhor se comparado com os relés baseados em 
medidas de tensão, pois é necessária muita potência reativa para que a tensão seja detectável em aplicações com baixa penetração de GD. Para viabilizar a técnica é recomendável que o gerador seja configurado para controlar a tensão terminal, no entanto, isso é frequentemente proibido pelas concessionárias. As mesmas implicações enfrentadas pelos relés de tensão são relatadas nessa técnica.

- Fator de potência e Taxa de variação da frequência em relação à potência ativa (df/dP): o fator de potência é afetado pelas potências ativas e reativas do gerador. Considerando ambos os índices, [21] aponta que não há um fator tecnicamente convincente de que esses índices exibirão diferenças significativas no seu comportamento antes e após o ilhamento. Sozinhos, tais índices não resultarão em uma técnica melhor para a detecção de ilhamento.

De um modo geral, as propostas de técnicas passivas convencionais que podem ser aplicadas para geradores síncronos e geradores equipados com inversores foram apresentadas. As propostas convencionais levam em consideração parâmetros como a magnitude, frequência e fase da forma de onda da tensão nos terminais do gerador distribuído. Contudo, mesmo se usados com técnicas complementares há situações em que os parâmetros variam pouco, ou lentamente, quando os desbalanços de potência ativa e/ou reativa são pequenos. A condição de pequenos desbalanços dificulta a detecção do ilhamento. Embora não mostrem melhora significativa de desempenho, pois as implicações acabam sendo as mesmas das técnicas baseadas em frequência e tensão, os parâmetros derivados da potência foram apresentados. Isso mostra que indicativos de novos parâmetros precisam ser mais bem investigados, ou correlacionados para melhorar as técnicas passivas de detecção de ilhamento.

\section{Técnicas ativas}

Técnicas ativas inserem perturbações no sistema elétrico com o intuito de mudar algum parâmetro quando ocorrer o ilhamento. A detecção do ilhamento é efetuada com base nas medidas extraídas do ponto de conexão do GD. Tais métodos são dependentes da tecnologia de geração envolvida. No caso de geradores síncronos, as opções que utilizam essa técnica são limitadas, visto que as tensões envolvidas são altas e o controle desses geradores 
não é uma tarefa fácil. Conforme [21] alguns dos métodos que podem ser empregados em geradores síncronos são:

- Medidas de impedância: esse esquema consiste em monitorar a impedância vista pelos terminais do GD. Infelizmente não é uma tarefa fácil determina-la, pois é necessário inserir perturbações, geralmente correntes inter-harmônicas de baixa frequência. A vantagem desse método é que os desbalanços de potência não interferem no desempenho da técnica. Porém, quando há mais de um GD que utiliza a mesma técnica, interferências devido às perturbações inseridas podem afetar as medidas de impedância, diminuindo a eficiência da técnica.

- Métodos da variação da tensão terminal do GD: esse esquema consiste em medir variações no fluxo de potência reativa enquanto a tensão terminal do GD é alterada. Quando o sistema está conectado à rede, a variação de potência reativa é pequena, enquanto que se o sistema estiver ilhado, a variação do fluxo de potência reativa será uma medida que caracteriza o ilhamento.

$\mathrm{Na}$ referência [22] são apresentadas duas técnicas ativas para geradores síncronos distribuídos. Estas técnicas foram intituladas:

- sistema anti-ilhamento de potência ativa;

- sistema anti-ilhamento de potência reativa.

Ambas as técnicas de [22] utilizam o conceito realimentação positiva (positive feedback) ou amortecimento negativo. Isto é, um sinal de amortecimento negativo é introduzido na malha de controle de tensão e/ou frequência, provocando instabilidades na frequência e/ou na tensão nodal quando o gerador distribuído estiver ilhado. O sistema anti-ilhamento de potência ativa monitora as variações de frequência do sistema elétrico e altera a referência de potência ativa do gerador síncrono. O sistema anti-ilhamento de potência reativa monitora as variações de tensão do sistema e modifica as referências de potência reativa do regulador da máquina. Nas conclusões de [22] destaca-se que o desempenho do sistema anti-ilhamento de potência reativa é superior ao do sistema anti-ilhamento de potência ativa quando existe elevada penetração de motores de indução no 
sistema ilhado. Considerando o tempo requerido para detectar o ilhamento em $2 \mathrm{~s}$, ambas as técnicas são eficientes para detectar o ilhamento. Contudo, ao considerar o tempo requerido em $1 \mathrm{~s}$, não foram apresentados ganhos significativos em relação aos métodos passivos tradicionais. Além disto, não foi posto em análise o efeito na estabilidade do sistema quando vários geradores distribuídos equipados com as mesmas técnicas propostas neste artigo são instalados em um mesmo sistema de distribuição.

No caso dos geradores conectados com inversores os métodos ativos utilizam a capacidade do inversor em ajustar a corrente de saída, tensão, ou frequência para perturbar o sistema elétrico e então monitorar sua resposta, indicando que a rede de distribuição, com tensão e frequência estáveis, e baixa impedância foi desconectada [21]. A quantidade de métodos convencionais ativos que são usuais em aplicações que envolvem tecnologias de geração conectadas via inversores de frequência é grande. Em uma revisão sobre essas técnicas [30] cita as mais tradicionais, são elas: Slip Mode Frequency Drift (SMS); Active Frequency Drift (AFD); Sandia Frequency Shift (SFS); Sandia Voltage Shift (SVS); Automatic Phase-Shift (APS); Reative Power Variation (RPV).

Em uma revisão bibliográfica sobre as técnicas de detecção de ilhamento a referência [18] aponta algumas das vantagens e desvantagens das técnicas ativas em comparação com as passivas. A principal vantagem apresentada é a independência dos desbalanços de potência ativa e reativa do sistema ilhado, complementando as técnicas passivas. Embora sejam atrativas sob esse aspecto, algumas implicações também são apontadas: desempenho prejudicado por interferência de GD na rede utilizando a mesma técnica; se utilizados filtros ativos para inserir a perturbação acarretará em altos custos para implantação da técnica; e a lenta operação, pois são técnicas que podem apresentar tempos de detecção superiores a $1 \mathrm{~s}$.

\section{Técnicas híbridas}

Técnicas híbridas, assim como as técnicas ativas, inserem perturbações controladas no SEP. Porém, o que diferencia essa técnica das passivas e ativas é que as perturbações somente são inseridas quando o parâmetro monitorado é caracterizado como suspeita de ilhamento. Trata-se então de uma metodologia que combina ambas as técnicas ativas e passivas [17], [20]. 
A referência [17] discorre sobre duas técnicas híbridas que podem ser empregadas para detecção do ilhamento. São elas:

- Realimentação positiva (RP) e desequilíbrio de tensão (VU): a técnica RP e VU sugere monitorar a tensão nas três fases para determinar o VU. Se ultrapassado o valor ajustado como limiar de VU, então o ajuste de frequência do GD será alterado pela realimentação positiva. Caso o ilhamento ocorra, a frequência do sistema irá variar com a perturbação inserida.

- Tensão e deslocamento adaptativo de potência reativa ou Adaptive Reactive Power Shift (ARPS): a técnica ARPS sugere monitorar a variação da tensão nos terminais do GD, calculando em seguida sua respectiva covariância. Se ultrapassado o valor ajustado como limiar de covariância, então será inserida uma perturbação na corrente de eixo direto. Caso o ilhamento ocorra, a ação de DFA é acelerada, levando a rápidos deslocamentos de frequência.

O grande destaque das técnicas híbridas, embora contenham tempos de detecção prolongados, é ter a introdução de perturbações somente quando há suspeita do ilhamento, o que não acontece nas técnicas ativas. Como resultado, é possível obter zonas de não detecção menores que as técnicas passivas convencionais, com menores riscos para o sistema elétrico, pelo motivo de adicionar limiares de decisão para inserir perturbações.

\subsection{Técnicas passivas inteligentes}

Com base na revisão das técnicas tradicionais para detecção de ilhamento de GD, principalmente o caso dos geradores síncronos, a detecção de ilhamento é um desafio que ainda não foi completamente resolvido utilizando técnicas locais. Implicações como as zonas de não detecção, tempos de detecção longos, falsa operação, e necessidade de inserir perturbações controladas, são efeitos intrínsecos de cada técnica em específico e das relações do GD, inclusive do modo de controle, com o sistema elétrico. Por esses motivos, sobretudo a necessidade de buscar alternativas mais viáveis economicamente do que as técnicas remotas abriu-se o espaço para que os engenheiros busquem novas técnicas locais que possam de fato identificar o ilhamento de GDs. Algoritmos sofisticados foram propostos nos últimos anos buscando respostas em uma série de parâmetros adicionais, obtidos por processamento dos 
sinais de tensão e corrente nos terminais do GD, para caracterizar o ilhamento como técnica passiva.

A expectativa atual é que a correlação entre os parâmetros que já são utilizados em técnicas locais concatenados a novos parâmetros (não convencionais) deem indicativos mais precisos para identificar o ilhamento em tempo hábil. No entanto, para buscar o conhecimento nos parâmetros locais, que ao longo dos anos têm mostrado relações naturalmente complexas, é necessário recorrer a técnicas que consigam extrair padrões que um banco de informações contendo uma série de simulações pode apresentar. Para tal abordagem é necessário utilizar algoritmos inteligentes, entre eles destacam-se:

- Técnicas de mineração de dados;

- Redes Neurais Artificiais (RNA);

- Lógica fuzzy;

Conforme proposto em [31] uma das primeiras tentativas do uso de técnicas de mineração de dados no problema da detecção do ilhamento de GD foi o de extrair ajustes ótimos para as funções de proteção anti-ilhamento. Na construção do banco de dados são realizadas simulações considerando o desligamento de disjuntores que podem resultar na formação do sistema ilhado; a abertura de qualquer disjuntor entre o SEP e o GD; e a perda de conexão no PAC entre GD e SEP. A técnica de mineração de dados utilizada consiste em construir uma árvore de decisão que utiliza um vetor de quatro parâmetros, sendo eles: V; f; $\mathrm{df} / \mathrm{dt}$; dP/dt. O grande destaque da técnica utilizada é que o algoritmo de mineração de dados pode auxiliar nos ajustes de parâmetros dos relés convencionais.

Com o passar do tempo, as técnicas que utilizam mineração de dados passam a considerar mais parâmetros nos seus algoritmos, inclusive alguns não convencionais nas tradicionais técnicas passivas, tais como a potências ativa e reativa; $d P / d t$ e $d Q / d t$; fator de potência e taxa de variação do fator de potência; e $d f / d P$. A referência [32] demonstra como relés inteligentes, empregando análises multivariáveis e técnicas de mineração de dados, podem ser utilizados na proteção anti-ilhamento de geradores síncronos distribuídos na presença de religadores de alta velocidade. A técnica proposta monitora 11 parâmetros correlacionando-os através da técnica de mineração de dados árvore de decisão ou Decision Tree (DT) descrita em [33]. Foi encontrado nessa metodologia, que o relé inteligente é capaz de enviar sinais de abertura compatíveis com as técnicas convencionais, ou seja, 
obedecendo aos tempos de religamento automático de alta velocidade de uma área do sistema elétrico. Os índices de confiabilidade e segurança foram superiores aos dispositivos de proteção passivos convencionais (relés de frequência, $d f / d t$ e tensão). Os tempos de detecção também são comparáveis aos métodos passivos convencionais e menores em situações específicas.

Posteriormente, sendo um dos artigos mais relevantes que utilizam mineração de dados para detectar o ilhamento atualmente, os autores em [34] anunciam uma nova metodologia e comparam diferentes técnicas de mineração de dados com as técnicas passivas empregadas pelos relés de proteção anti-ilhamento. Utilizando a transformada discreta de Fourier (TDF), derivam-se 23 parâmetros, contemplando também as tensões e correntes de sequência positiva e negativa. Após aquisição dos parâmetros, a árvore de decisão é treinada para construir um modelo de mineração de dados capaz de identificar situações de ilhamento, não-ilhamento e distúrbios que estão próximos de serem caracterizados como ilhamento. Em uma discussão adicional, o autor destaca que os parâmetros: taxa de variação da tensão de sequência negativa $\left(\mathrm{dV}_{\mathrm{NEG}} / \mathrm{dt}\right)$; taxa de variação da tensão em relação a potência reativa (dV/dQ); desvio de fase ( $\Delta \mathrm{Phi})$; taxa de variação da distorção harmônica total de corrente $\left(\mathrm{dC}_{\mathrm{THD}} / \mathrm{dt}\right)$ são os que consideravelmente mais impactam nos limiares para construir a árvore de decisão. Além da grande quantidade de parâmetros, três diferentes técnicas de mineração de dados foram comparadas. Entre elas estão:

- Árvore de decisão ou Decision Tree (DT): A técnica DT é eficiente, supervisionada, e pode ser utilizada para resolver problemas de classificação de grandes dimensões. Cada nó interno da árvore é testado no preditor, enquanto cada ramo representa o resultado de um teste. O nó terminal da DT representa a respectiva classificação [33]. Mesma técnica utilizada em [32];

- Floresta aleatória ou Random Forest (RF): a técnica RF é uma combinação de três preditores, cada qual, construindo sua árvore de decisão em específico. Cada árvore depende dos valores de um vetor aleatório amostrado independentemente e com mesma distribuição de probabilidade para todas as árvores. Após um grande número de árvores serem gerados elege-se a classe mais popular para a respectiva entrada [35].

- Máquinas de vetores suporte ou Support Vector Machine (SVM): o SVM é uma técnica de aprendizado computacional baseada na teoria de aprendizado estatístico para resolver problemas de classificação, regressão ou estimação. As 
entradas são mapeadas em um espaço hiperdimensional de produtos escalares, conhecido como espaço espectral. Neste espaço o hiperplano ótimo é determinado para maximizar a capacidade de generalização do classificador. No geral, tem a habilidade de aprender em bancos de dados pequenos, sendo menos susceptíveis a problemas de memorização excessiva ou overfitting e mínimos locais como é o caso das RNAs [34], [36].

Como as três técnicas de mineração de dados apresentaram índices próximos a $100 \%$ de confiabilidade, segurança e precisão, o autor destaca a técnica DT por ser transparente e ser mais fácil sua implementação em processador digital de sinais ou Digital Signal Processor (DSP) e em arranjo de portas programável em campo ou Field Programmable Gate Array (FPGA). Quanto ao tempo de detecção de ilhamento, as técnicas se mostraram rápidas, com tempos de detecção menores que 1 ou $\frac{1}{2}$ ciclo.

Considerando os métodos que utilizam RNA para detectar o ilhamento, uma primeira estratégia pode ser conforme a apresentada em [37]. Os autores programam uma rede perceptron de multicamadas (PMC), capaz de detectar o ilhamento, utilizando apenas a forma de onda da tensão nos terminais do GD, sem nenhum pré-processamento adicional. Diferentes redes são comparadas, envolvendo a alteração do número de amostras por ciclo. Tempos de detecção inferiores a $1 s$ foram obtidos para arquiteturas com 64 e 128 entradas, acarretando em elevada carga computacional. Um dos parâmetros interessantes que o autor considerou, foi que o ilhamento é caracterizado quando a RNA é sensibilizada por 6 ciclos não consecutivos dentro de uma janela de 12 ciclos.

Além dos sinais puros, ou seja, sem pré-processamento, os exemplos que utilizam RNAs podem utilizar técnicas sofisticadas de processamento digital de sinais. Isso é feito para obter melhor desempenho das RNAs, que poderão apresentar arquiteturas simplificadas, geralmente com menor número de entradas, de neurônios e de camadas escondidas. Os autores em [38] sugerem monitorar as correntes trifásicas nos terminais do GD, combinando-as de modo que um único sinal represente todo o sistema. Esse sinal é pré-processado pela transformada discreta de wavelet (TDW), cuja função é extrair o vetor de parâmetros de entrada para rede neural. Apesar de ter sido aplicada em um parque eólico composto por três geradores de indução, o autor utiliza um artifício interessante de seleção dos coeficientes, que reduz o erro quadrático médio do conjunto de teste da RNA da ordem de $1 \times 10^{-2}$ para $1 \times 10^{-26}$. A estratégia utilizada foi reduzir os parâmetros do vetor de entrada, 
selecionando os coeficientes que mais se correlacionam com o ilhamento. Para isso, foi calculada a correlação de cada elemento no vetor de parâmetros com a saída desejada.

Um último exemplo de estratégia utilizando RNAs é a proposta de [39]. O autor ressalta que é uma técnica específica para geradores síncronos que utilizam o controlador automático de carga-frequência ou Automatic Load-Frequency Controller (ALFC). Nesse método é utilizado o sinal de entrada do controlador ALFC como parâmetro de entrada para redes auto-organizáveis de Kohonen ou Self Organizing Maps (SOM). Esses parâmetros de entrada, combinados com a rede neural SOM, são capazes de classificar e apresentaram bom desempenho. Os resultados de validação da rede mostraram sua capacidade de distinguir ilhamentos de não-ilhamentos com tempos de detecção a partir de $200 \mathrm{~ms}$.

Um algoritmo bastante sofisticado e que utiliza a inferência fuzzy é apresentado em [40]. O autor apresenta um método de detecção de ilhamento com base nos sinais trifásicos das tensões e correntes, incluindo os respectivos componentes de sequência negativa no ponto de conexão do GD. Sob esses sinais é aplicada a transformada intitulada Frequency Filtering S-Transform (FFST). A técnica FFST é uma modificação da transformada-S, com melhor desempenho computacional, cuja função é a de extrair e representar o contorno tempofrequência. A partir da transformada FFST são extraídos parâmetros que são utilizados em uma abordagem de mineração de dados. Com base no conhecimento extraído da árvore de decisão da mineração de dados, quando utilizados na técnica de inferência fuzzy, é possível aprimorar a confiabilidade da identificação do ilhamento. Trata-se de uma técnica que apresenta respostas rápidas, menores que um ciclo, com precisão computacional superior ao das técnicas convencionais até mesmo para distúrbios como faltas e chaveamento de banco de capacitores.

Para identificar o ilhamento utilizando técnicas de mineração de dados é importante recorrer a parâmetros que possam ser úteis para caracteriza-lo. Nesse sentido, construiu-se a Tabela 2.1. Os parâmetros da Tabela 2.1 são os mesmos utilizados nas técnicas de mineração de dados apresentadas na referência [34]. No entanto, foram reorganizados da seguinte forma: parâmetros convencionais; parâmetros não convencionais; aplicações associadas; e observações referentes às limitações que cada parâmetro individualmente possa apresentar e referências de metodologias associadas às aplicações dos parâmetros. 
Tabela 2.1 - Quadro de parâmetros encontrados nas técnicas de detecção de ilhamento

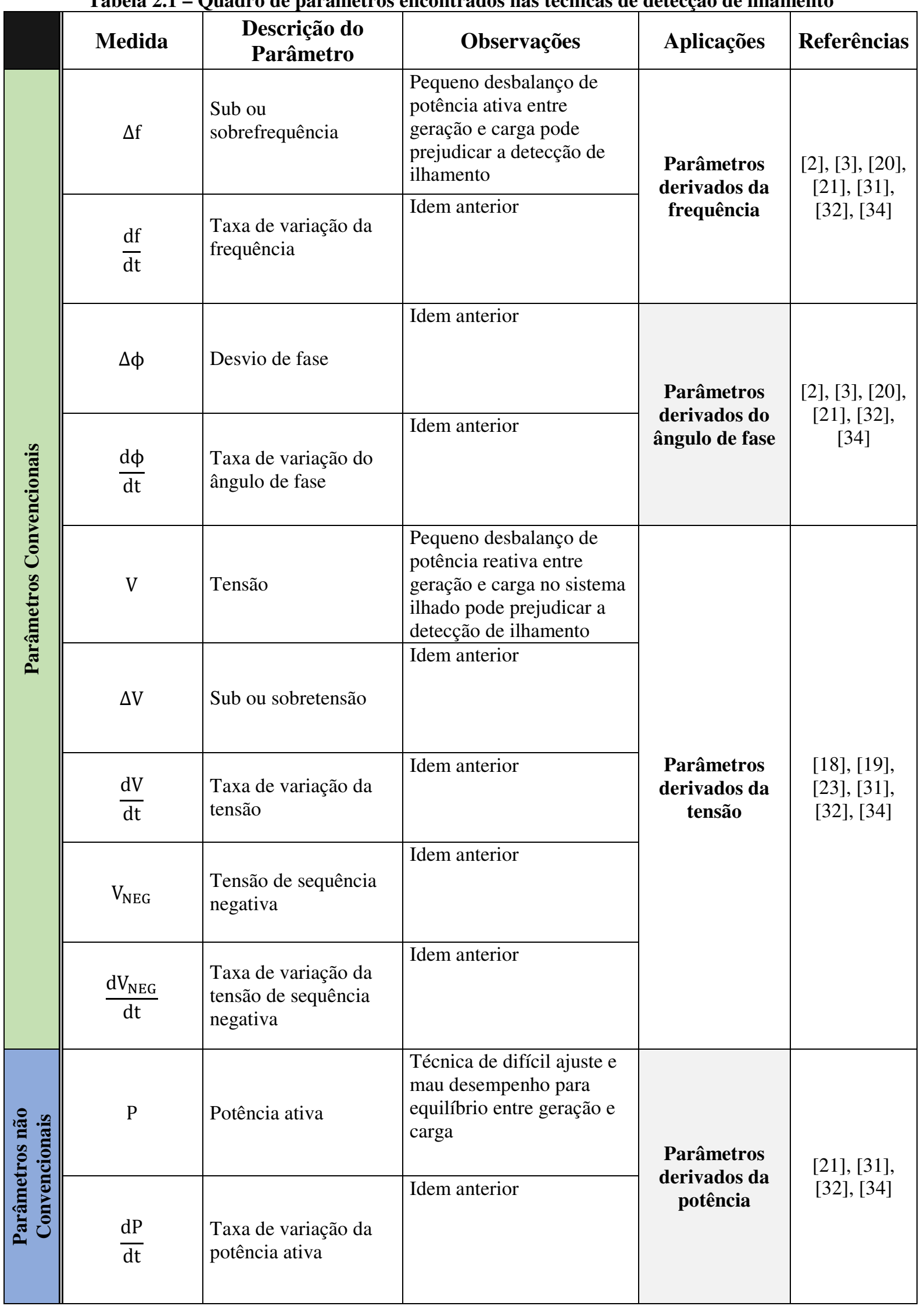




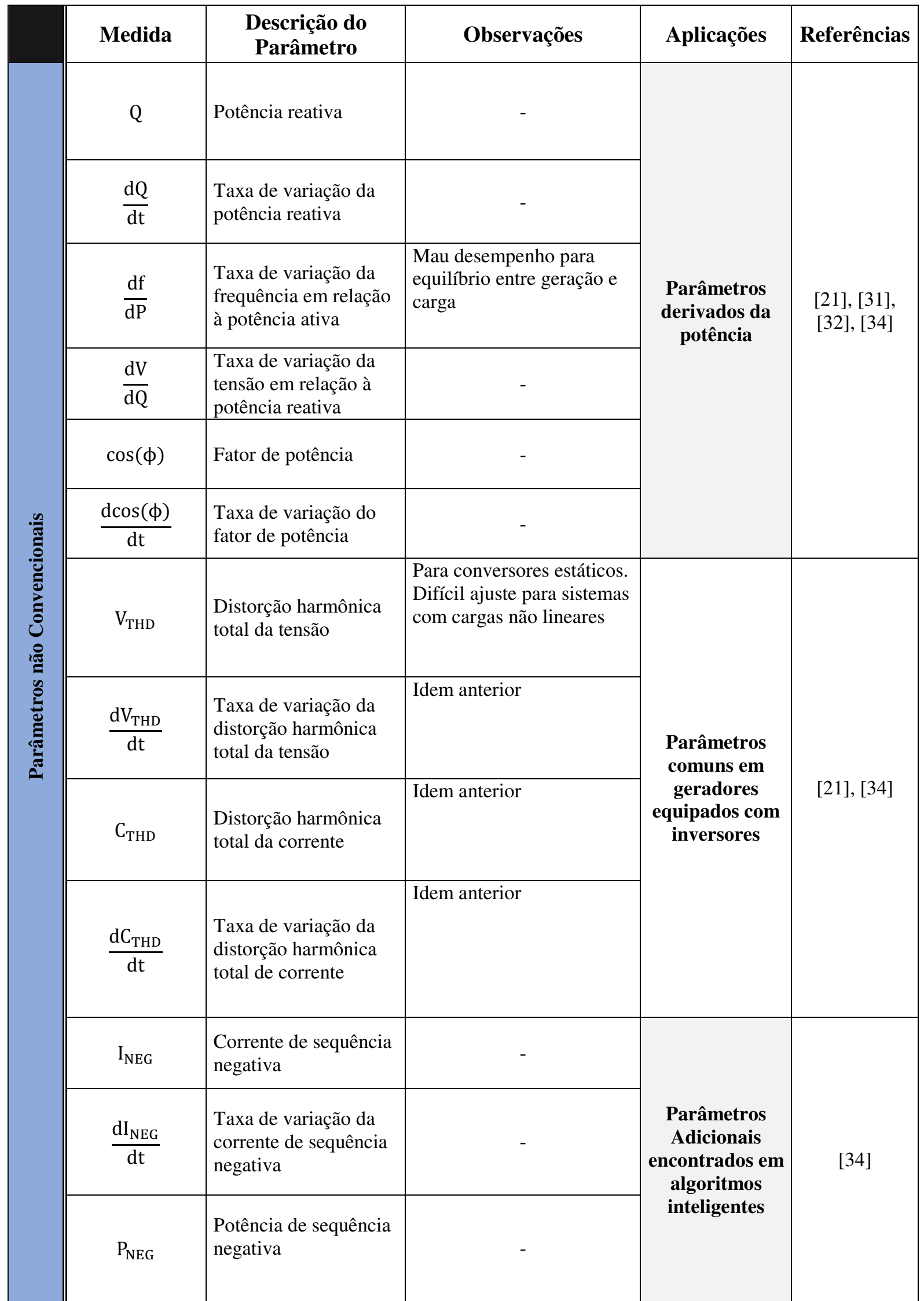




\begin{tabular}{|c|c|c|c|c|c|}
\hline & Medida & $\begin{array}{l}\text { Descrição do } \\
\text { Parâmetro }\end{array}$ & Observações & Aplicações & Referências \\
\hline 悉 & $\frac{\mathrm{dP}_{\mathrm{NEG}}}{\mathrm{dt}}$ & $\begin{array}{l}\text { Taxa de variação da } \\
\text { potência de sequência } \\
\text { negativa }\end{array}$ & - & \multirow{3}{*}{$\begin{array}{c}\text { Parâmetros } \\
\text { Adicionais } \\
\text { encontrados em } \\
\text { algoritmos } \\
\text { inteligentes }\end{array}$} & \multirow{3}{*}{ [34] } \\
\hline 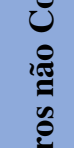 & $U \cos (\phi)$ & $\begin{array}{l}\text { Módulo da tensão de } \\
\text { fase vezes o fator de } \\
\text { potência }\end{array}$ & - & & \\
\hline E & $\frac{\mathrm{dU} \cos (\phi)}{\mathrm{dt}}$ & $\begin{array}{l}\text { Taxa de variação do } \\
\text { módulo da tensão de } \\
\text { fase vezes o fator de } \\
\text { potência }\end{array}$ & - & & \\
\hline
\end{tabular}

\subsection{Discussão adicional}

Técnicas de detecção de ilhamento são apresentadas com diferentes possibilidades práticas dependendo da tecnologia do gerador distribuído. Para ambos os geradores, síncronos ou equipados com inversores, há propostas gerais de técnicas de detecção passivas e ativas, no entanto, há preferências. Em especial o caso dos geradores síncronos, que devido a sua grande potência são os mais capazes de sustentar uma ilha. As preferências para geradores síncronos são por técnicas passivas, pois, há limitações para controlá-los para detecção de ilhamento. No caso dos geradores equipados com inversores há mais possibilidades de escolha de técnicas ativas se comparadas com os geradores síncronos. Como os inversores são uma interface dos geradores com a rede elétrica, a escolha de sua topologia e estrutura de controle pode influenciar diretamente no tipo de técnica de detecção associado.

As técnicas tradicionais (passivas, ativas e remotas) para a detecção do ilhamento de geradores distribuídos possuem algumas destas limitações que foram apresentadas no decorrer deste CAPITULO 2. Atualmente, as pesquisas encaminham-se para investigações baseadas nas técnicas de mineração de dados, RNAs e lógica fuzzy. As primeiras investigações das técnicas de detecção de ilhamento são as técnicas locais, pois, são mais viáveis economicamente e possibilitam utilizar os relés disponíveis comercialmente. Entretanto, há singularidades nas quais as grandezas tradicionais (frequência, fase e tensão) podem variar pouco e/ou lentamente de modo que é difícil, mesmo utilizando técnicas ativas, caracterizar o ilhamento em até $2 s$ conforme a recomendação do IEEE 1547 [15]. O caso do ilhamento não ser detectado acarretaria em uma série de riscos apontados no início do CAPÍTULO 2. 
A alternativa de engenharia seria recorrer a técnicas remotas, o que permite com alguma facilidade, ter acesso ao estado de disjuntores de porções do sistema. Porém, devido ao custo necessário para implantação de tais sistemas, poderia desestimular o desejo dos investidores em instalar geradores distribuídos e mesmo que os sistemas remotos fossem implantados, não eliminaria a necessidade de técnicas locais devidamente ajustadas, pois, é possível que o próprio enlace de comunicação falhe, o que criaria desligamentos desnecessários. Se a rede de comunicação falhar, outro problema relevante é a possibilidade da proteção não atuar caso haja o ilhamento.

Por esses motivos, os pesquisadores, voltam a estudar a detecção do ilhamento de geradores síncronos distribuídos inspirando-se nas técnicas locais, porém agora mais sofisticadas. Parâmetros tradicionais e novos são extraídos e aplicados em técnicas inteligentes (mineração de dados, RNAs e fuzzy), cada qual contendo estratégias de solução ou aplicações de processamento digital de sinais que as tornam originais.

A intenção desse CAPÍtUlo 2 de revisão é ir um passo além da apresentação das consequências da não detecção e das técnicas mais tradicionais de proteção de ilhamento. A verdadeira proposta é a de reflexão com base nas diferentes estratégias utilizadas pelos autores, incluindo os parâmetros antigos e novos, para que ao utilizar quaisquer que sejam as técnicas inteligentes, sejam selecionados criteriosamente parâmetros plausíveis para converter as pesquisas em métodos práticos e servir de base de informação para propor soluções de mineração de dados. É realmente esperado buscar correlacionar parâmetros, diferente da proteção tradicional que estabelece limiares vistos apenas para uma variável com ou sem alguma restrição. A ideia de correlacionar parâmetros por técnicas de mineração de dados pode dar indicativos mais seguros para detecção de ilhamento e com o benefício adicional de reduzir as zonas de não detecção. 


\section{CAṔ́tulo 3}

\section{A Técnica de Mineração de Dados DAMICORE}

Conforme [25] a técnica de mineração de dados Data Mining of Code Repositories (DAMICORE) é uma combinação de algoritmos que busca encontrar relações fortes entre dados, realizando o processo de mineração de dados em arquivos organizados e armazenados em um único diretório (pasta). Esses dados podem ser de qualquer tipo (imagens, textos, matrizes), pois o critério utilizado pelo DAMICORE para checar similaridades entre arquivos é baseado na compressão de amostras. Ao final de sua execução, é construída uma árvore filogenética que representa graficamente a relação entre os dados e a partir dessa árvore são detectados os grupos em que os dados se mostram similares. Os algoritmos utilizados pelo DAMICORE são executados na seguinte sequência:

1. Normalized compression distance (NCD): a NCD é uma métrica utilizada para checar similaridades entre arquivos. Computando essa métrica para todas as combinações do conjunto de arquivos, a matriz de distâncias será obtida. Essa matriz contém as distâncias, tomadas em pares, do conjunto de arquivos fornecidos como entrada ao DAMICORE. Essa matriz possui dimensões $n \times n$, em que: $n$ é o número de arquivos. Além disso, a matriz de distâncias é simétrica, com diagonal principal nula.

2. Neighbor-Joining (NJ): o NJ é uma técnica utilizada para construir árvores filogenéticas. O método utiliza como entrada a matriz de distâncias calculada na etapa 1. Portanto, a árvore filogenética obtida representa a relação entre os dados. 
3. Fast Newman (FN): o FN é uma técnica utilizada para detectar grupos em redes complexas. Nesse sentido, essa técnica utiliza como entrada a matriz de adjacências da árvore filogenética calculada na etapa 2, isto é, uma matriz de zeros e uns que representa todas as conexões entre ramos e nós da árvore. Portanto, o FN identifica no grafo da árvore os grupos similares.

A execução completa das técnicas do DAMICORE é realizada assim como mostra a Figura 3.1. Nesse exemplo, foram fornecidos como entrada ao DAMICORE seis arquivos (dados) para tentar descobrir se há correlações entre eles e se essas correlações apresentam novidades até então desconhecidas sob os dados apresentados. Essa informação pode ser útil para classifica-los. Ao final da execução do DAMICORE, para esse exemplo, foram detectados dois grupos representados pelos clusters 0 e 1 . Portanto, há relações fortes de similaridades entre os arquivos 5; 4 e 3 e os arquivos 1; 6 e 2 caracterizando-os como dois grupos particulares. É conveniente salientar que, obrigatoriamente, para identificar relações entre dados utilizando o DAMICORE, deve-se trabalhar com no mínimo quatro arquivos para que tenha sentido descrever relações de filogenia, ou seja, hereditariedade entre dados.

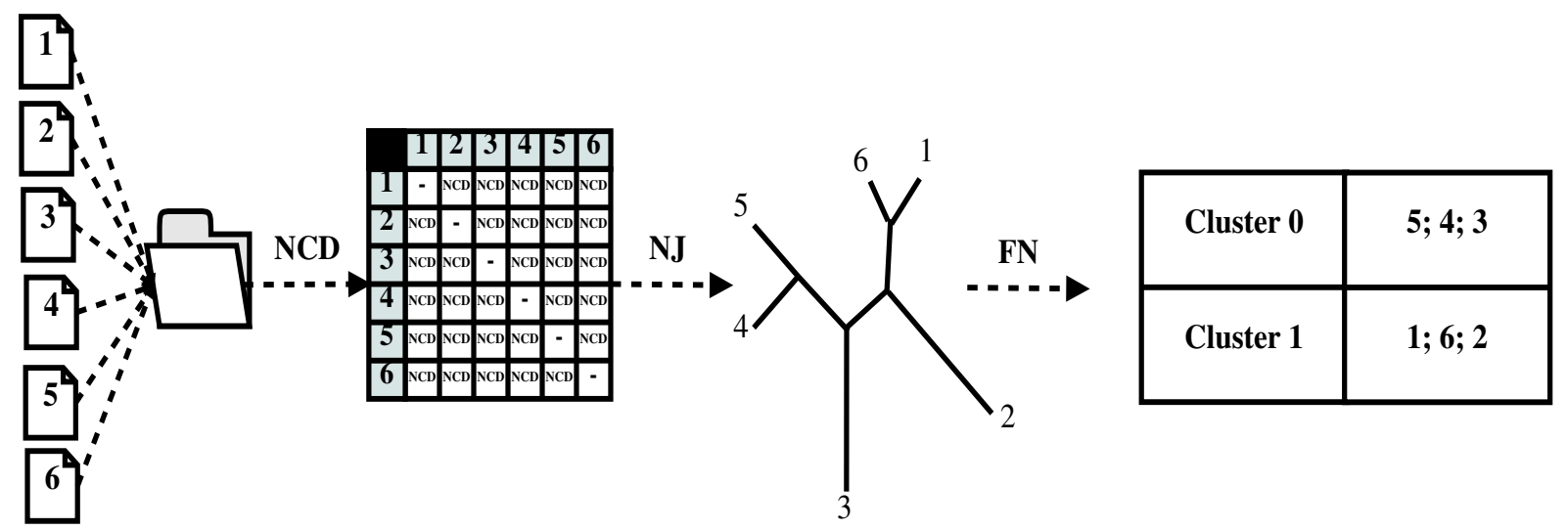

Figura 3.1 - Exemplo de execução do DAMICORE.

Nas próximas seções do CAPÍTULO 3 serão descritos com mais detalhes o princípio de funcionamento de cada uma das técnicas utilizada pelo DAMICORE. Essas técnicas foram programadas em uma versão correspondente para o MATLAB (R2010a), integrando em um único ambiente todos os scripts necessários para o desenvolvimento da proteção anti-ilhamento proposta nessa dissertação. As seções deste CAPÍTULO 3 estão organizadas conforme a própria sequência de execução do DAMICORE. São elas: 
- Métricas de dissimilaridades para matriz de distâncias;

- Técnicas de construção de árvores filogenéticas;

- Técnicas de detecção de comunidades em redes complexas.

\subsection{Métricas de dissimilaridades para matriz de distâncias}

Para computar uma matriz de distância de um conjunto de arquivos é necessário adotar uma métrica de distância. Originalmente, para trabalhar com arquivos de qualquer extensão contidos numa pasta, incluindo textos ou dados numéricos, o DAMICORE utiliza a NCD como métrica de distância para medir a similaridade entre arquivos. Porém, o ilhamento é um problema exclusivamente numérico. Desse modo, foi adicionada ao DAMICORE a opção de substituir a métrica NCD pela distância euclidiana, pois é uma solução mais rápida computacionalmente para esse caso.

\subsubsection{Normalized compression distance}

De acordo com [25], [41] a função do NCD é servir como métrica para buscar similaridades entre dados com base nas técnicas de compressão, ou seja, técnicas cuja função é reduzir a quantidade de bytes de um arquivo de modo que os dados representem a mesma informação, porém com menor redundância. A grande vantagem do cálculo da NCD é a possibilidade de aplicação em qualquer domínio de dado, quer sejam eles música, textos, vetores ou matrizes. De fato, é uma métrica que pode encontrar relações entre dados quando não há o conhecimento dos parâmetros que podem ser utilizados para representar de maneira adequada o cenário a ser caracterizado.

Sejam dois arquivos A e $\mathbf{B}$. Eles terão correlações próximas se $\mathbf{A}$ puder significativamente ser comprimido utilizando a informação contida em $\mathbf{B}$ e vice-versa. A Figura 3.2 mostra um caso em que A e B possuem correlações próximas.

A

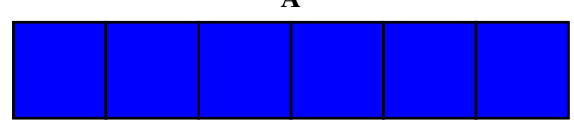

B

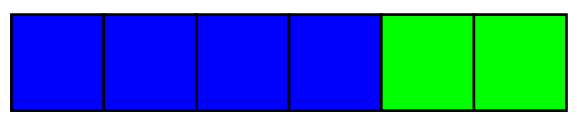

Figura 3.2- exemplo de dois arquivos com forte correlação 
As propriedades de tal compressão são as bases da teoria da complexidade de Kolmogrov. O interesse é descobrir o número mínimo de bits em que uma mensagem ou arquivo em particular possa ser armazenado e efetivamente ser reconstruído em um formato reprodutível. Considerando uma sequência qualquer de bits, a complexidade de Kolmogorov é o tamanho (em bits) do menor programa de computador que imprime a sequência e se interrompe logo em seguida [42].

Embora o cálculo da complexidade de Kolmogorov seja computacionalmente impraticável, felizmente, em [41] foi anunciada uma métrica de compressão próxima da complexidade de Kolmogorov e que pode ser calculada em tempo computacional plausível. Esta métrica é apresentada na equação (3.1).

$$
N C D(x, y)=\frac{C(x y)-\min \{C(x) ; C(y)\}}{\max \{C(x) ; C(y)\}}
$$

em que:

$C(\quad$ ) - É o tamanho do arquivo comprimido;

$x$ - Arquivo $x$;

$y$ - Arquivo $y$;

$x y$ - Concatenação do arquivo x e do arquivo $\mathrm{y}$;

A métrica NCD, portanto, é uma relação de distância normalizada baseada na compressão de amostras. Quanto maior a correlação entre os arquivos, o cálculo do NCD será próximo de zero, ao passo que quanto menor a correlação entre eles, a métrica indica valores próximos a um.

\subsubsection{Distância euclidiana}

De acordo com [43], [44] a distância euclidiana é considerada uma métrica de dissimilaridade que é interpretada como a distância entre dois indivíduos, cujas posições são determinadas em relação às suas coordenadas, definidas com referência a um grupo de eixos cartesianos, os quais possuem ângulos retos. A equação geral que define essa métrica é apresentada na equação (3.2). 


$$
D E_{i j}=\sqrt{\sum_{k=1}^{n}\left(x_{i k}-x_{j k}\right)^{2}}
$$

em que $x_{i k}$ e $x_{j k}$ representam, respectivamente, os indivíduos $i$ e $j$ para $k$-ésima variável.

Ao utilizar a distância euclidiana para identificar similaridades ou dissimilaridades em problemas de multivariáveis é necessário pré-processar os dados com técnicas de normalização, pois a métrica é influenciada pelas escalas do problema. Sendo assim as escalas ficarão harmonizadas. No DAMICORE, a harmonização de escalas foi considerada através da normalização dos dados no início do problema. A expressão geral que descreve essa métrica considerando a normalização é apresentada na equação (3.3).

$$
D E_{i j N o r m}=\sqrt{\sum_{k=1}^{n}\left[w_{k} \cdot\left(x_{i k}-x_{j k}\right)\right]^{2}}
$$

em que $w_{k}$ é um fator de adequação de escalas

Considerando problemas que envolvem dados binários, a distância euclidiana como medida de similaridade também pode ser aplicada. Embora, para esse caso, seja comum o uso da distância euclidiana quadrada, pois essa tem a vantagem da diferença entre indivíduos ser superior ao número de atributos em que eles diferem, com a restrição de que não haja valores faltantes. Outra opção é o uso da distância euclidiana média.

\subsection{Técnicas de construção de árvores filogenéticas}

A matriz de distância obtida a partir do cálculo do NCD pode ser utilizada em metodologias baseadas na filogenética. Para conhecimento adicional, na biologia a filogenética é o campo que busca identificar e compreender as relações evolutivas entre as diferentes formas de vida na Terra. Os primeiros critérios utilizados para reconstrução filogenética foram baseados nas relações de dados morfológicos, ou seja, no estudo da forma dos seres vivos. Contudo, com o acesso recente à estrutura de macromoléculas (DNA, RNA e 
proteínas) é plausível o uso de técnicas estatísticas como fortes aliados na tarefa de encontrar relações de hereditariedade entre espécies [45].

Para descrever essas relações, há uma série de algoritmos com a proposta de construir árvores filogenéticas. Nesse campo de estudo, as técnicas convencionais, que utilizam a matriz de distâncias como entrada, são o Unweighted Pair Grouping Method of Agglomeration (UPGMA) [46] e o Neighbor-Joining (NJ) [47]. Outros métodos que realizam a clusterização hierárquica, assim como o UPGMA e o NJ, são apresentados em [48]. No caso do DAMICORE a técnica utilizada é o NJ de [47], por isso será apresentada em detalhes.

\subsubsection{Neighbor-joining}

Enquadrando-se no princípio da mínima evolução, a técnica NJ de [47] produz ao final de sua execução uma árvore filogenética única. O NJ não necessariamente construirá a árvore filogenética com a mínima evolução global, porém é bastante eficiente computacionalmente e superior em relação a outras técnicas para obter uma topologia de árvore correta. Essa técnica pode ser generalizada para qualquer tipo de problema, pois uma vez que a matriz de distâncias fora estimada, a construção da árvore é feita de modo desacoplado do domínio do problema.

$\mathrm{Na}$ primeira etapa de execução do NJ é considerada uma árvore inicial, de topologia estrela, ou seja, todos os nós folha dessa árvore compartilham um nó interno em comum. A topologia de árvore estrela é apresentada na Figura 3.3. Nesse tipo de topologia, em relação à caracterização de similaridades, não é possível obter conclusões.

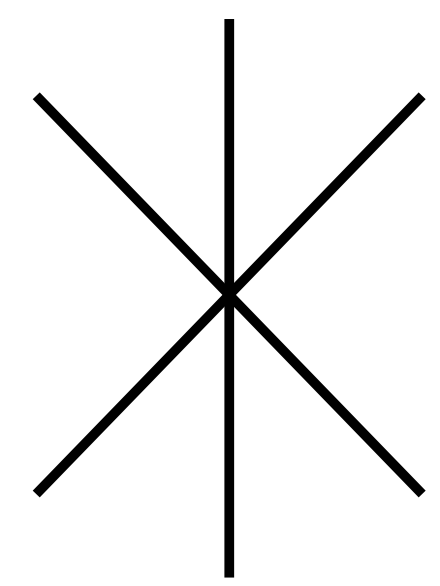

Figura 3.3 - Exemplo de árvore de topologia estrela. 
Durante a execução do NJ, a cada nova iteração, é realizada a junção de dois nós da árvore estrela, substituindo-os por seu respectivo ancestral em comum. Um exemplo da união de dois nós, considerando a árvore estrela inicial, é apresentado na Figura 3.4.
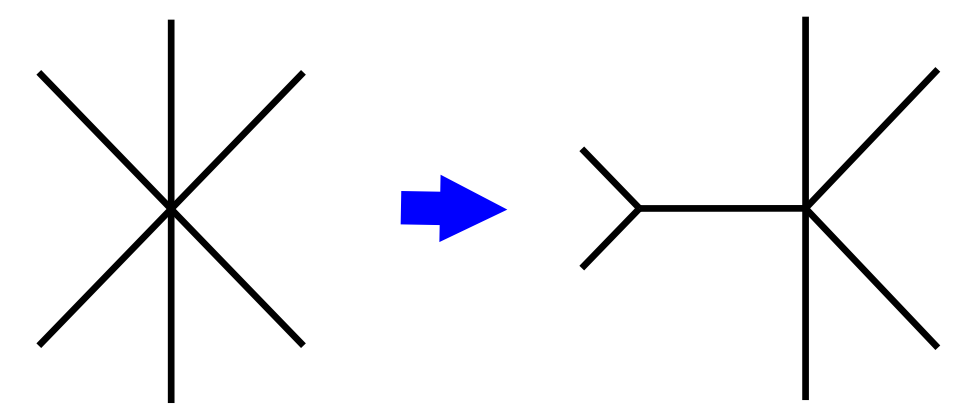

Figura 3.4 - Exemplo da junção entre dois nós de uma árvore com topologia estrela.

Esse processo iterativo de junção de nós ocorre até que a árvore estrela fique com apenas dois nós. Portanto, o número de junções para $n$ amostras será igual à $(n-2)$. Para que esse processo ocorra, três etapas são essenciais. São elas:

1. Determinar dois nós da árvore-estrela atual que sofrerão junção: essa escolha é feita com base na busca da árvore que apresente o valor mínimo para o somatório do comprimento de todos os ramos. Isso é feito escolhendo-se o par que apresentar o valor mínimo da matriz $M$. Essa matriz é baseada na matriz de distâncias $D$ e pode ser calculada conforme a equação (3.4).

$$
M_{i j}=D_{i j}-\frac{R_{i}+R_{j}}{n-2}
$$

em que $i$ e $j$ representa o par de nós da árvore que sofrerá junção e $R_{i}$ a divergência da rede em relação ao nó $i$, definida como o somatório de todas as distâncias referentes à variável i. $R_{j}$ representa a divergência da rede em relação ao nó $j$, definido como o somatório de todas as distâncias referentes à variável $j$. Em termos matemáticos $R_{i}$ e $R_{j}$ é calculada conforme a equação (3.5) e (3.6).

$$
\begin{aligned}
& R_{i}=\sum_{j, i \neq j} D_{i j} \\
& R_{j}=\sum_{i, j \neq i} D_{i j}
\end{aligned}
$$


2. Calcular o comprimento dos ramos do resultante da junção na etapa 1 até o novo nó interno da árvore: isso é feito utilizando as equações (3.7) e (3.8)

$$
\begin{gathered}
S_{i u}=\frac{D_{i j}}{2}+\frac{R_{i}-R_{j}}{2(n-2)} \\
S_{j u}=\frac{D_{i j}}{2}+\frac{R_{j}-R_{i}}{2(n-2)}
\end{gathered}
$$

em que u é o novo nó interno da árvore.

3. Calcular a nova matriz de distâncias após a junção dos nós: isso é feito aplicando a equação (3.9) para todo nó $k \neq i$ e $j$. Após a junção de dois nós, a matriz de distâncias $D^{\prime}$ possuirá dimensões $(n-1) \times(n-1)$, uma vez que o novo nó substitui na matriz $D$ as duas folhas agrupadas.

$$
D_{k u}^{\prime}=\frac{D_{i k}+D_{j k}}{2}-\frac{D_{i j}}{2}
$$

Um exemplo de execução completa do $\mathrm{NJ}$, que considera uma árvore de topologia estrela inicial com 6 folhas é apresentado na Figura 3.5. Esse exemplo mostra como a árvore inicial pode evoluir durante o processo iterativo do NJ. O grande destaque do NJ é que a escolha dos nós da árvore inicial, de topologia estrela, é sempre aquela que leva a nova árvore a ter um valor mínimo no somatório do comprimento de todos os ramos considerando todas as junções possíveis. Por isso, ao término de sua execução, ao ser analisada a árvore final da Figura 3.5, por exemplo, podem ser obtidas informações na árvore filogenética, que devido às relações complexas entre os dados, não eram visualizadas de forma clara anteriormente.
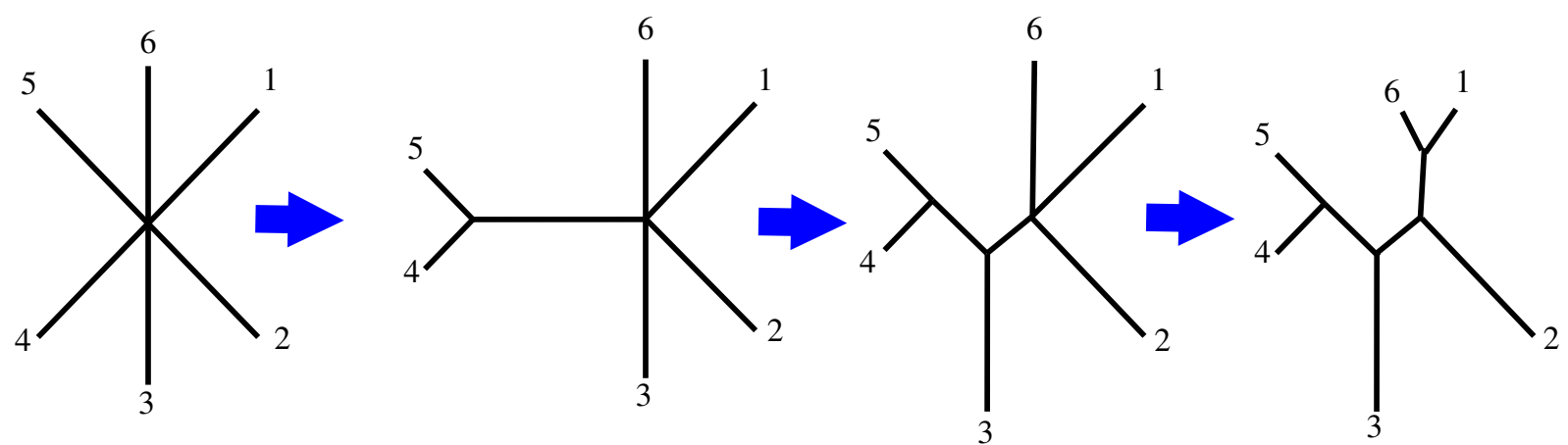

Figura 3.5 - Exemplo de funcionamento do algoritmo NJ.

As correlações obtidas por metodologias envolvendo árvores filogenéticas são sempre marcadas nos nós da árvore, indicando que há um ancestral em comum, e nas distâncias associadas aos ramos da árvore, indicando o quão distante cada individuo está de seu 
ancestral. Essas correlações gráficas indicadas na árvore filogenética serão úteis para avaliar as potencialidades do DAMICORE em caracterizar as situações de ilhamento e não-ilhamento de geradores síncronos distribuídos. Estes resultados serão apresentados no CAPÍTULO 6.

\subsection{Técnicas de deteç̧ão de comunidades em redes complexas}

De acordo com [24], [25] na estrutura da árvore filogenética é necessário verificar se há clados ${ }^{2}$, ou seja, subárvores com alto grau de independência indicando um único ancestral em comum. Desse modo é caracterizado um grupo com característica bastante específica apresentada na estrutura da árvore filogenética. Não somente nas estruturas de árvore filogenética, mas estruturas de rede, no geral, mostram estruturas de comunidades. Os vértices (nós) dessas redes frequentemente podem conglomerar grupos com relações fortes, isto é, grupos que possuem em seu interior alta densidade de arestas e baixa densidade de arestas entre grupos.

Um exemplo de uma possível estrutura de comunidades que pode ser encontrada em uma rede de grafos é apresentado na Figura 3.6. Nesse exemplo é possível identificar três comunidades, aclaradas nas cores azul, amarelo e vermelho, caracterizando grupos específicos dentro da estrutura de rede completa.

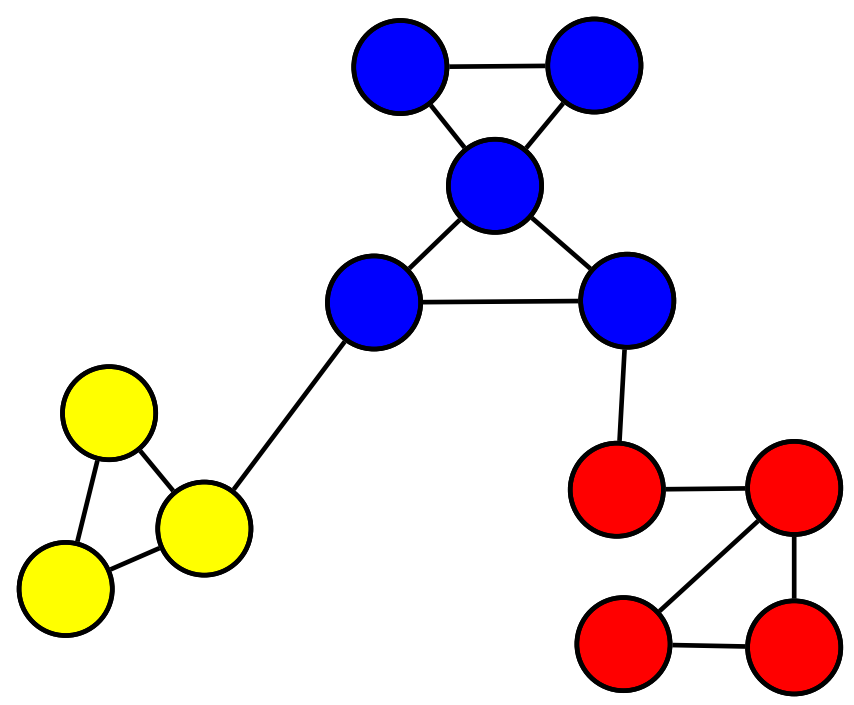

Figura 3.6 - Exemplo de estrutura com três comunidade em uma rede.

${ }^{2}$ A palavra clado, em inglês clade, advém da palavra grega klados que significa ramo. Em biologia, um clado é um grupo de organismos ou espécies originados de um ancestral comum exclusivo. Na representação gráfica da árvore filogenética, clado é um conjunto de ramificações unidas por um único nó em comum [61]. 
No campo de estudo das redes complexas há um grande interesse em descobrir e identificar propriedades em comum em diversos tipos de redes complexas. A própria internet, redes de transporte, redes de e-mail, redes sociais, grafos de chamadas e os sistemas de transmissão e distribuição, são alguns dos exemplos. Todavia, a tarefa de identificar as propriedades em comum de redes grandes e mais complexas não é trivial. Tanto é que os primeiros algoritmos desenvolvidos para identificar grupos em redes de grafos possuíam sua aplicação limitada quanto ao tamanho das redes. Redes pequenas são menos complexas, pois podem ser descritas com matrizes de dimensões menores e isso ajuda na simplificação de métodos computacionais [24], [49], [50].

\subsubsection{Fast algorithm of Newman}

Para resolver às limitações contidas no campo das redes complexas em [49] foi desenvolvido o Fast Newman (FN). Trata-se de um algoritmo rápido para detectar estruturas de comunidade em redes complexas. A técnica FN é baseada em uma métrica de modularidade. Por exemplo, dada uma rede qualquer, o FN transformará alguma subdivisão dos vértices em comunidades, independentemente da rede conter qualquer subdivisão natural. Para testar se a subdivisão em particular é significativa, o método de [49] define uma função de qualidade ou "modularidade" $Q_{m}$ apresentada na equação (3.9).

$$
\begin{gathered}
Q_{m}=\sum_{i}\left(e_{i i}-a_{i}^{2}\right) \\
a_{i}=\sum_{j} e_{i j}
\end{gathered}
$$

Em que:

$e_{i i}$ - metade do número de arestas que conectam as comunidades i e j em relação ao total de arestas da rede;

$e_{i j}$ - número de arestas dentro da comunidade i em relação ao total de arestas;

$a_{i}$ - fração das arestas conectadas a pelo menos um vértice da comunidade $i$;

A referência [50] sintetiza a ideia do algoritmo FN, cuja proposta é maximizar a métrica $Q_{m}$ sobre todas as possíveis divisões da rede em comunidades. Inicialmente é 
considerado que cada vértice (nó) da rede representa uma comunidade. As comunidades são agrupadas em pares considerando todos os pares possíveis, e então é armazenada a estrutura da comunidade, ou seja, do grupo em si, bem como o respectivo valor de $Q_{m}$. Esse procedimento se repete até que o agrupamento que atingir o maior valor de $Q_{m}$ seja preservado. Em termos de um pseudocódigo as etapas são:

Entrada: Grafo (Árvore filogenética nesse caso) com $n$ vértices;

1. Separar os $n$ vértices em $n$ comunidades;

2. Enquanto número de comunidades $>1$ faça:

a. Juntar as comunidades $i$ e $j$ na aglomeração que forneça o menor decréscimo ou o maior acréscimo na métrica $Q_{m}$;

b. Armazenar a divisão resultante e o respectivo $Q_{m}$;

\section{Fim;}

4. Escolher a divisão com a melhor modularidade encontrada

Saída: Estrutura de comunidades (clusters);

No FN apenas as comunidades que possuírem pelo menos uma aresta ligando seus vértices podem ser possivelmente unidas pelo algoritmo. Essa condição limita que um máximo de $p$ pares de comunidades possa ser encontrado, em que $p$ é o número de arestas da rede. De acordo com [49], a variação de $Q_{m}$ ao unir duas comunidades é dada pela equação (3.11).

$$
\Delta Q_{m}=2\left(e_{i j}-a_{i} a_{j}\right)
$$

Em que $\mathrm{e}_{\mathrm{ij}}$ é igual à metade do grau de cada vértice, uma vez que, inicialmente, cada comunidade é formada por apenas um vértice. Após a junção de duas comunidades, os valores de $\mathrm{e}_{\mathrm{ij}}$ precisam ser atualizados.

\subsection{Discussão adicional}

O DAMICORE reúne três técnicas importantes que foram desenvolvidas para aplicações específicas em seus devidos campos da ciência. As técnicas utilizadas resgatam metodologias que têm suas bases na teoria da informação, na reconstrução filogenética, e nas 
técnicas de detecção de comunidades em estruturas de redes complexas. Sozinhas, essas técnicas não foram desenvolvidas especificamente para a mineração de dados. Contudo, ao serem reunidas e executadas sequencialmente, criando o repositório DAMICORE, monta-se um poderoso aliado na tarefa de identificar correlações em dados que são naturalmente complexos. Sobretudo, o DAMICORE é especial por trabalhar com dados, desde que possam ser comprimidos, de qualquer domínio, ou seja, é possível utilizar como entrada desde singelos vetores e matrizes de dados exclusivamente numéricos até textos, músicas, imagens e etc.

Do ponto de vista de análise, a técnica DAMICORE disponibiliza ao usuário a descrição das relações entre dados apresentados sob uma estrutura de árvore filogenética. As subárvores encontradas pela técnica DAMICORE podem ter informações importantes caracterizando semelhança entre grupos de amostras. Das medidas de dissimilaridades como a NCD (útil para qualquer domínio de dado) ou a DE (útil somente quando os dados são exclusivamente numéricos), é construída a árvore filogenética pelo método NJ. Da árvore filogenética identificam-se os grupos pela técnica FN. As análises desses grupos em conjunto com a estrutura da árvore filogenética gerada pelo DAMICORE podem indicar informações que permitam extrair conhecimento dos dados, caracterizando-os como padrões.

De um modo geral, as técnicas utilizadas pelo DAMICORE são indicadas pela literatura como técnicas tradicionais em seus respectivos campos. Todas elas oferecem boas aproximações, são de complexidade reduzida se comparadas a outros métodos e têm a vantagem de serem computadas com boas aproximações se ponderadas ao seu esforço computacional reduzido. 


\section{CAPÍTULO 4}

\section{Modelagem do Sistema Elétrico}

Uma das implicações ao conduzir o uso de técnicas inteligentes nos sistemas elétricos de potência é a carência de dados, particularmente de transitórios eletromagnéticos que precisam ser identificados. No entanto, em sistemas reais são ações impraticáveis e que acarretariam em problemas tanto aos consumidores quanto à concessionária. Para contornar tal implicação, é necessário recorrer aos modelos matemáticos e computacionais do sistema elétrico e seus respectivos elementos em que se deseja aplicar a técnica. Por isso, este CAPÍTUlO 4 apresenta a modelagem e recursos computacionais utilizados para realizar as simulações do sistema elétrico de distribuição, no qual a técnica de detecção de ilhamento dessa dissertação será empregada. O software utilizado, a modelagem necessária e o sistema elétrico são apresentados nas seções:

- O SimPowerSystems: nesta seção será apresentado o software utilizado para realizar a modelagem do sistema elétrico de distribuição. Este software pertence ao ambiente MATLAB/Simulink e é denominado SimPowerSystems. A versão utilizada é a R2010a.

- Modelos dos componentes do sistema elétrico: nesta seção serão apresentados os modelos dos alimentadores; dos transformadores; das cargas elétricas; do gerador síncrono; da turbina e regulador de velocidade; e da excitatriz utilizados para a modelagem do sistema elétrico.

- O sistema elétrico: nesta seção serão apresentadas as informações gerais do sistema elétrico de distribuição utilizado nessa dissertação assim como o correspondente diagrama unifilar. 
Dados adicionais de parametrização dos componentes estão disponíveis no APÊNDICE A.

\subsection{O SimPowerSystems}

O SimPowerSystems [51] é uma ferramenta computacional integrada ao ambiente MATLAB/Simulink que pode ser utilizada para análise de transitórios em sistemas eletromecânicos. Está contido na ferramenta um conjunto de bibliotecas com modelos dinâmicos de diversos componentes de sistemas de potência. O SimPowerSystems é bastante completo por incluir modelos dos elementos RLC concentrados, cargas não lineares, diversos modelos de máquinas e controles associados, modelos de linhas de transmissão, cabos com parâmetros concentrados ( $\pi$-equivalente) e distribuídos (Bergeron), disjuntores, componentes de eletrônica de potência e controles associados entre outros. Os diversos modelos presentes no SimPowerSystems podem ser utilizados em conjunto com modelos existentes no Simulink, bem como modelos desenvolvidos pelo próprio usuário no Simulink, no MATLAB por scripts descritos em (arquivos .m), e, nas linguagens de programação Fortran ou C.

Aliadas com as facilidades descritas da plataforma MATLAB/Simulink, uma importante característica das versões recentes do SimPowerSystems é realizar a simulação de transitórios eletromagnéticos. As variáveis do sistema elétrico podem ser representadas por valores instantâneos, ou em sua forma fasorial. Adicionalmente, há a possibilidade de inicializar parâmetros de máquinas e controles associados com base no cálculo do fluxo de carga calculado. Para realizar as simulações, depois de construído o circuito e parametrizados os blocos de cada um dos componentes inseridos pelo usuário, são realizadas três etapas:

1. power2sys: é uma função que divide os blocos pertencentes ao Simulink dos blocos pertencentes ao SimPowerSystems. Logo em seguida, os parâmetros da rede são obtidos e a topologia é analisada. Os blocos pertencentes ao SimPowerSystems são divididos em blocos lineares e não-lineares e para cada nó elétrico é dado um número automaticamente.

2. Circ2sys: constrói o modelo das variáveis de estado do sistema considerando a parte linear do circuito conforme a equação (4.1). A obtenção dos valores iniciais das variáveis e os cálculos de regime permanente são efetuados nesse 
instante, inclusive os cálculos dos controladores das máquinas elétricas, através de um fluxo de carga.

$$
\begin{aligned}
& \dot{x}=A x+B x \\
& y=C x+D u
\end{aligned}
$$

3. Caso a opção discretizar seja a escolhida, o modelo de variáveis de estado da equação (4.1) é discretizado utilizando o método de Tustin [52]. Na sequência a simulação é iniciada interconectando os modelos lineares e não lineares, sejam eles existentes ou definidos pelo usuário, conforme a Figura 4.1.

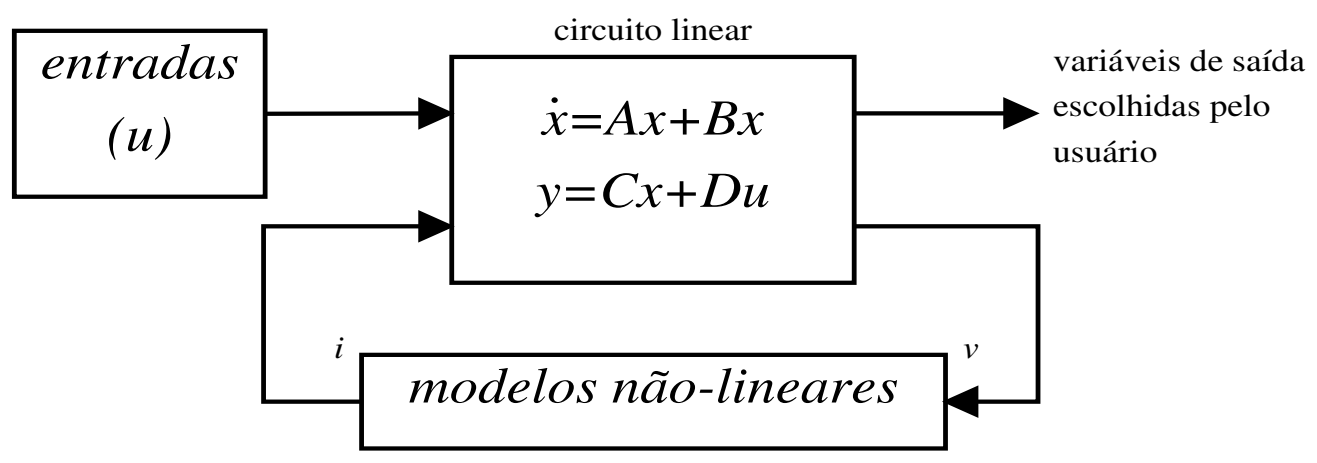

Figura 4.1 - Interconexão dos modelos lineares e não-lineares.

Como pode ser observado na Figura 4.1, componentes não-lineares do circuito são modelados através da relação tensão-corrente $(v \times i)$. Usualmente elementos não-lineares são modelados como fontes de correntes não-lineares conectadas em derivação. As saídas do programa são as variáveis elétricas, mecânicas e de controle escolhidas pelo usuário.

No SimPowerSystems tanto abordagens contínuas quanto discretas podem ser utilizadas na solução das variáveis de estado. As equações diferenciais podem ser solucionadas por um dos diversos métodos a gosto do usuário dos quais empregam passo de integração fixo ou variável. O melhor método de solução (discreto, contínuo ou fasorial), considerando precisão e tempo de processamento, depende das características do circuito e dos fenômenos a serem analisados.

\subsection{Modelos dos componentes do sistema elétrico}

Visando a reprodutibilidade da presente dissertação, é necessário detalhar os modelos computacionais dos componentes do sistema de distribuição em específico assim como os 
controles do gerador síncrono. Nesse sentido, são apresentados nesta seção os modelos dos alimentadores; dos transformadores; das cargas elétricas; do gerador síncrono; da turbina e regulador de velocidade; e da excitatriz.

\subsection{1 $\underline{\text { Alimentadores }}$}

Os alimentadores foram representados por impedâncias RL em série. Como são de distribuição há a possibilidade de considerá-los como linhas curtas. Portanto, o efeito da capacitância em derivação das linhas é desprezível [53].

\subsubsection{Cargas elétricas}

As cargas do sistema são representadas por modelos estáticos dependentes da tensão conforme as equações (4.2). Nesse modelo há a possibilidade de configurar três tipos de carga. São eles o de potência, de corrente, ou, de impedância constante. Para configura-las como um dos modelos citados, basta atribuir aos índices $n_{p}$ e $n_{q}$ das equações (4.2) os valores $0 ; 1$ ou 2 respectivamente.

$$
\begin{aligned}
& P=P_{0}\left(\frac{V}{V_{0}}\right)^{n_{p}} \\
& Q=Q_{0}\left(\frac{V}{V_{0}}\right)^{n_{q}}
\end{aligned}
$$

Em que:

$P$ - A potência ativa consumida pela carga em ( $p . u)$;

$P_{0}$ - A potência ativa nominal da carga em $(p . u)$;

$Q$ - A potência reativa consumida pela carga em $(p . u)$

$Q_{0}$ - A potência reativa nominal da carga em (p.u)

$V$ - A tensão nodal na carga em $(p . u)$

$V_{0}$ - A tensão nominal da carga em $(p . u)$

$n_{p}$ - expoente que indica o comportamento da componente de potência ativa da carga em relação à variação da tensão nodal; 
$n_{q}$ - expoente que indica o comportamento da componente de potência reativa da carga em relação à variação da tensão nodal;

\subsubsection{Transformadores}

Os transformadores trifásicos foram representados pelo modelo $\mathrm{T}$ [51], [54]. O modelo do transformador, disponível na biblioteca do SimPowerSystems, foi simplificado para os estudos aqui descritos. Conforme apresentado na Figura 4.2 as perdas do núcleo são consideradas e os efeitos da saturação do núcleo são desprezados. Nessa figura é representado o circuito equivalente por fase.

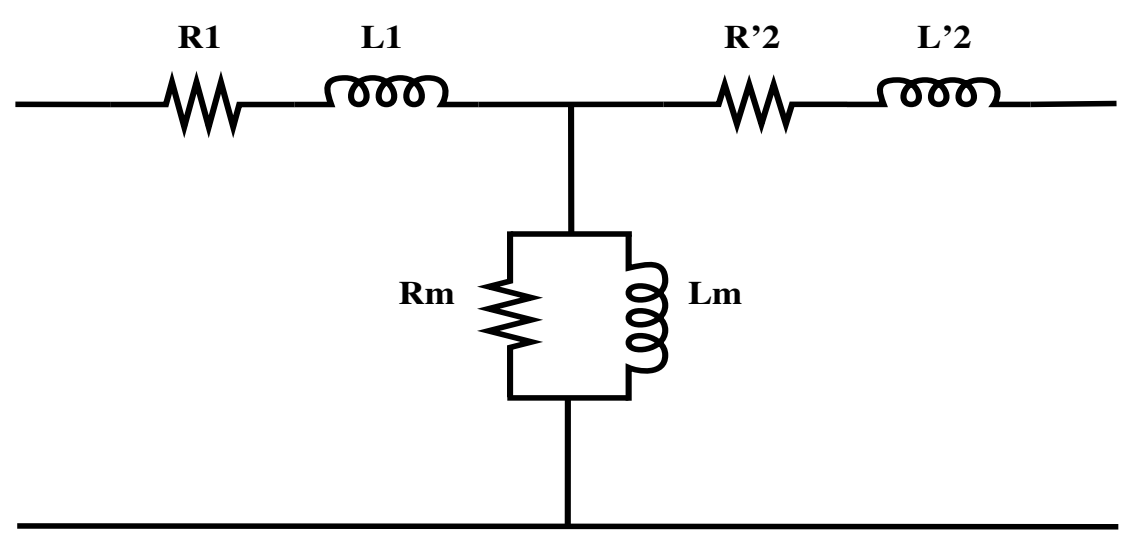

Figura 4.2 - Circuito equivalente do modelo do transformador.

em que:

R1 e L1 - a resistência e indutância do primário;

R'2 e L'2 - a resistência e indutância do secundário vista pelo primário;

$\mathrm{Rm}$ - a resistência de magnetização;

Lm - a indutância de magnetização;

\subsubsection{Gerador síncrono}

No SimPowerSystems a máquina síncrona é representada por um modelo de até oitava ordem. Trata-se de um modelo subtransitório que considera a dinâmica do estator, dos enrolamentos de campo e do amortecimento, sendo válido para ambos os tipos de simulação de transitórios eletromagnéticos, contínuo ou discreto [51], [54]. O gerador síncrono foi considerado equipado com um regulador automático de tensão e uma excitatriz representada 
pelo modelo IEEE DC1A [55]. O controle do gerador é configurado de modo que a tensão terminal ou sua potência reativa permaneçam constantes. Como se trata de um estudo direcionado a geradores distribuídos, não é comum que estes participem da regulação da frequência dos sistemas elétricos de potência, portanto o controle é ajustado para manter a potência ativa constante com fator de potência unitário.

\subsubsection{Turbina e regulador de velocidade}

A máquina primária geradora de potência mecânica e o controlador de velocidade foram modelados através de um sistema de controle de velocidade e uma turbina a vapor de quatro estágios com um eixo de até quatro massas, disponível em [51], [56], [57].

\section{Regulador de velocidade}

O regulador de velocidade da turbina a vapor é um dispositivo que tem a função de controlar a abertura da válvula de vapor com base no desvio de frequência associado à sua entrada. Esse sistema de controle de velocidade é formado por um regulador proporcional, um relé de velocidade e um servomotor conforme apresentado no diagrama da Figura 4.3.

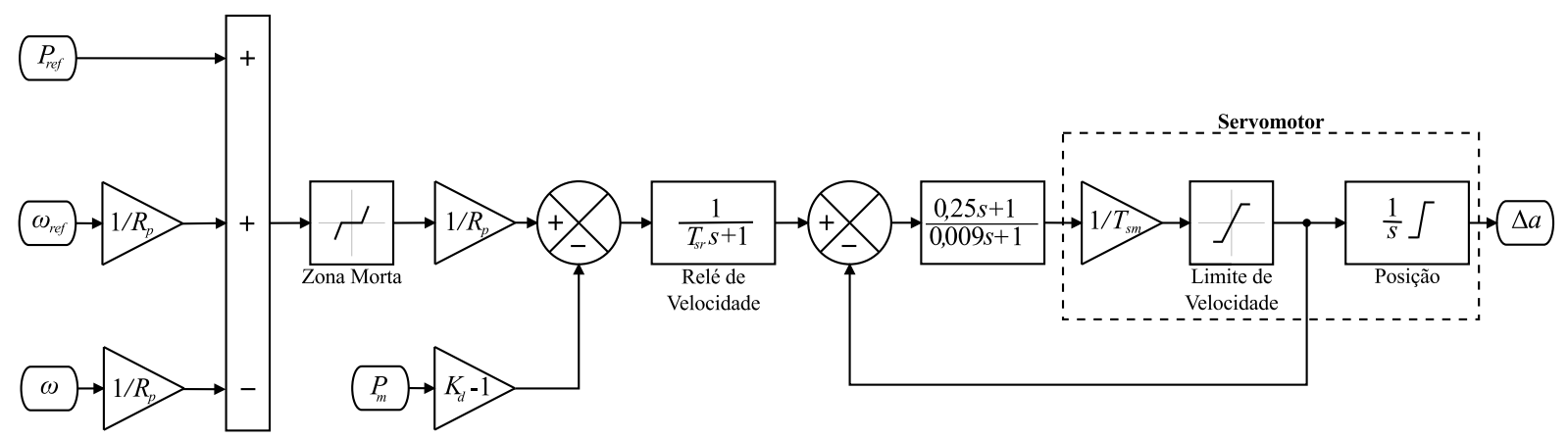

Figura 4.3 - Modelo do Regulador de Velocidade.

Em que:

$P_{\text {ref }}$ - potência elétrica de referência $(p . u)$;

$\omega_{\text {ref }}$ - velocidade de referência $(p . u)$;

$\omega$ - velocidade do gerador;

$R_{p}$ - ganho de estatismo;

$K_{d}$ - ganho do regulador; 
$P_{m}$ - fluxo de potência mecânica da turbina $(p . u)$;

$T_{s r}$ - constante de tempo do relé de velocidade $(s)$;

$\Delta_{a}$ - abertura da válvula $(p . u)$

\section{Turbina}

A turbina a vapor tem quatro estágios individualmente modelados por uma função de transferência de primeira ordem. A primeira fase representa o tanque pulmão, enquanto os três outros estágios representam os reaquecedores. A caldeira não é modelada, portanto considerase que a pressão da caldeira é uma constante ajustada em 1,0 p.u.

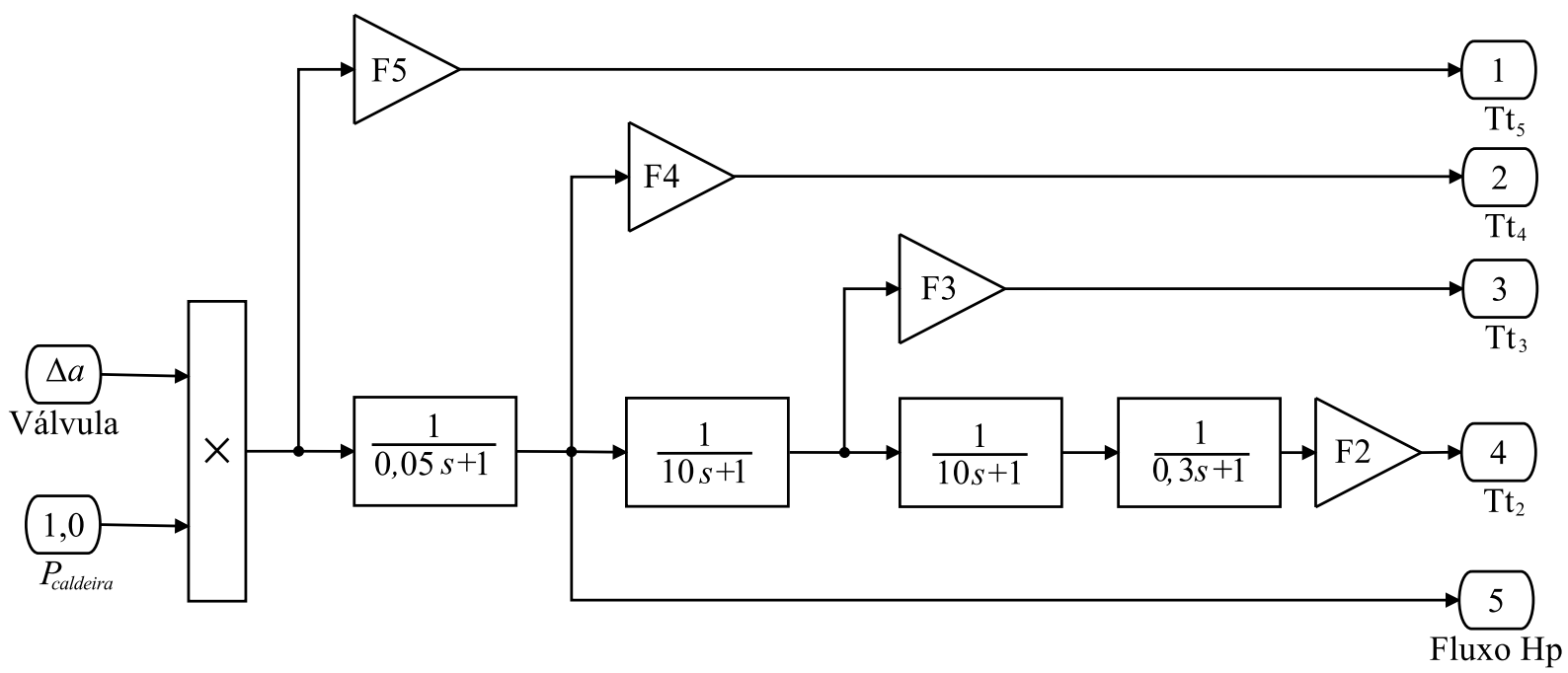

Figura 4.4 - Turbina a vapor com reaquecimento.

Em que:

$P_{\text {caldeira }}$ - potência elétrica de referência $(p . u)$;

$\Delta a$ - abertura da válvula $(p . u)$

F2 à F5 - Frações de torque da turbina;

\subsubsection{Excitatriz e regulador automático de tensão}

O sistema de excitação de geradores síncronos conectados em redes de transmissão é normalmente controlado de forma a manter sua tensão terminal constante. Porém, no caso de geradores síncronos conectados em redes de distribuição, atualmente, não há consenso entre diferentes guias e práticas adotadas por concessionárias distintas sobre qual é a melhor 
filosofia de controle a ser adotada para o sistema de excitação. Há dois modos de controles que podem ser empregados. São eles, o modo de tensão terminal constante ou o modo de fator de potência (potência reativa) constante [1], [3], [58]. De um modo geral, a estrutura de excitação de um gerador síncrono é apresentada na Figura 4.5. Esse sistema emprega transdutores para a medição das correntes e tensões, $\mathrm{TC}^{3}$ e $\mathrm{TP}^{4}$, circuitos de medição e de processamento de sinais, um regulador e uma excitatriz.

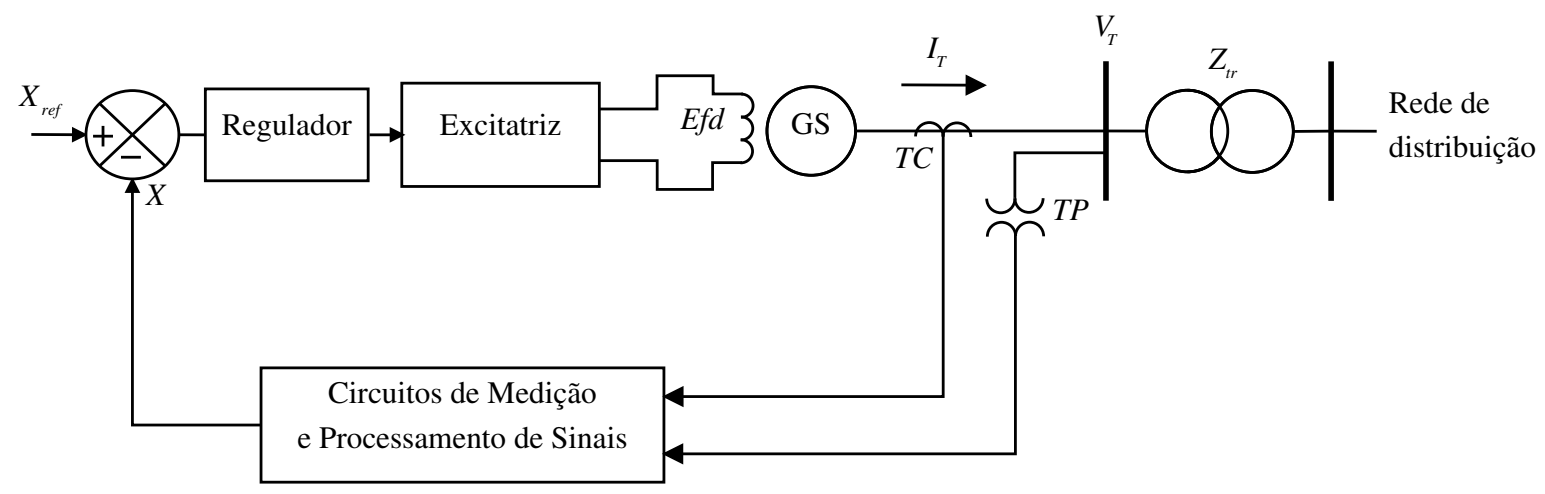

Figura 4.5 - Sistema de controle de excitação de um gerador síncrono.

Como pode ser observado na Figura 4.5, a propagação de um sinal de erro em relação à referência $\left(X_{r e f}\right)$ é enviada ao regulador que ajustará a tensão de campo da excitatriz $\left(E_{f d}\right)$. Normalmente o conjunto regulador/excitatriz é equipado com limitadores de sub/sobre excitação, isto é, são impostos limites para a potência reativa injetada ou consumida pelo gerador síncrono. Esse sistema de excitação pode ser configurado de modo que os sinais de referência (controle) sejam a magnitude da tensão, o fator de potência ou a potência reativa.

O modelo computacional que representa o sistema de excitação é o IEEE tipo DC1A [55]. Esse modelo foi desenvolvido para representar sistemas de excitação baseados em máquinas de corrente contínua. No entanto, devido ao fato de esse modelo ter sido muito empregado em estudos de estabilidade ao longo dos anos, ele é comumente utilizado para representar diferentes tipos de sistemas de excitação quando não há informações detalhadas sobre eles ou se deseja uma modelagem mais simplificada. A Figura 4.6 apresenta o modelo do sistema de excitação.

Em que:

$X$ - sinal de controle (tensão, fator de potência ou potência reativa);

\footnotetext{
${ }^{3} \mathrm{TC}$ - transformador de corrente

${ }^{4} \mathrm{TP}$ - transformador de potencial
} 
$X_{\text {ref }}$ - sinal de referência (tensão, fator de potência ou potência reativa);

$X_{S}$ - sinal do Power System Stabilizer (PSS), se houver;

$T_{B}, T_{C}$ - constantes de tempo do regulador de tensão $(s)$;

$K_{A}$ - ganho do regulador;

$T_{A}$ - constante de tempo principal do regulador $(s)$;

$V_{R \max }, V_{R \max }$ - limites máximo e mínimo da saída do regulador de tensão $(p . u)$;

$K_{F}$ - ganho do circuito de estabilização do sistema de excitação;

$T_{F}$ - constante de tempo do circuito de estabilização do sistema de excitação;

$K_{E}$ - ganho da excitatriz;

$T_{E}$ - constante de tempo da excitatriz $(s)$;

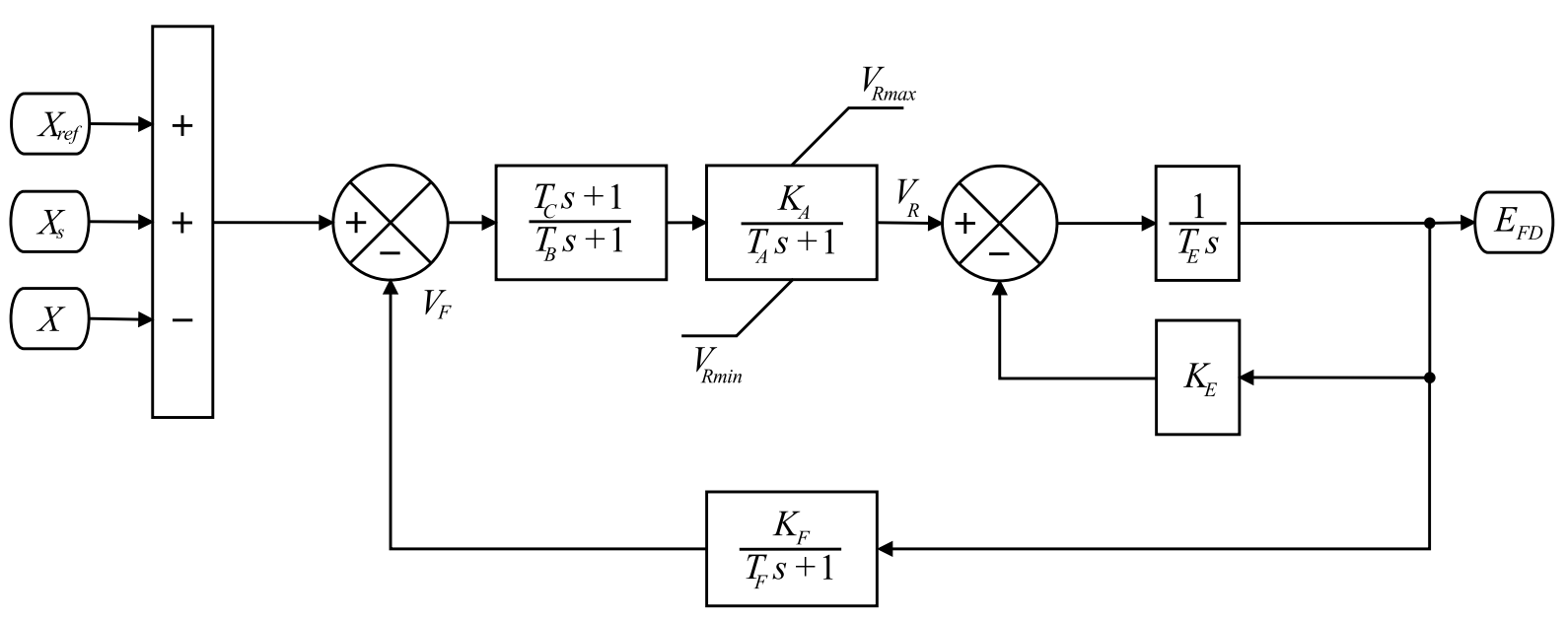

Figura 4.6 - Diagrama simplificado do sistema de excitação IEEE tipo DC1A.

\section{Regulador de tensão}

Quando o sinal de referência do sistema de excitação é a tensão, o sinal de controle $X$ é calculado conforme a equação (4.3).

$$
X=\left\|\bar{V}_{T}-j \bar{I}_{T} X_{C}\right\|
$$

Em que:

$\bar{V}_{T}-$ A tensão terminal do gerador em $(p . u)$;

$\bar{I}_{T}-$ A corrente do gerador em $(p . u)$;

$j$ - Operador complexo; 
$X_{C}-$ A reatância de compensação de corrente reativa em $(p . u)$;

Normalmente, um valor positivo de $X_{C}$ é adotado para compartilhar a corrente reativa entre diferentes geradores conectados a uma mesma barra. Isso é conhecido como compensação de corrente reativa ou reactive droop compensation. Outra possibilidade é adotar um valor negativo de $X_{C}$ para controlar a tensão terminal de uma barra remota, normalmente no lado de alta do transformador, isso é conhecido como compensação de queda na linha ou line drop compensation. De modo a manter a generalidade dos estudos, a compensação de corrente reativa foi negligenciada, isto é, $\left(X_{C}=0\right)$. Portanto, a tensão terminal do gerador é diretamente comparada com a tensão de referência. $\mathrm{O}$ uso de tal compensação não deve ser confundido com os reguladores de fator de potência [59].

\section{Regulador de fator de potência ou potência reativa}

Diferente do regulador de tensão, a referência $X$ agora é o fator de potência ou a potência reativa fornecida pelo gerador síncrono. A tensão de campo $\left(E_{f d}\right)$ é ajustada automaticamente para manter o fator de potência ou potência reativa constante. Com frequência esse regulador é utilizado no controle de excitação de grandes motores síncronos. Todavia, para a GD é uma estratégia vista com bons olhos para os produtores independentes, pois evita o pagamento de multas pelo consumo demasiado de potência reativa, ou, pode maximizar a geração de potência ativa, o que leva a gerar maior receita para o dono do gerador distribuído. Por isso, é comum adotar fator de potência unitário.

\subsection{O sistema elétrico}

O diagrama unifilar da Figura 4.7 representa um sistema de subtransmissão, com tensão nominal de $138 \mathrm{kV}$, frequência $60 \mathrm{~Hz}$, nível de curto-circuito de $500 \mathrm{MVA}$, que alimenta um sistema de distribuição com $11,9 \mathrm{kV}$ onde um gerador síncrono distribuído de 12,6 MVA foi instalado na barra B4. Para as linhas de distribuição, considerou-se o modelo RL de impedância série. A impedância das linhas é $(0,1876+\mathrm{j} 0,4034) \Omega / \mathrm{km}$. Adicionalmente, no APÊNDICE A, estão disponíveis os parâmetros dos componentes do sistema. Nesse sistema serão simulados os eventos de ilhamento, chaveamento de carga, faltas 
e regime permanente, necessários para estruturar um banco de dados que pode ser utilizado como entrada em técnicas de mineração de dados.

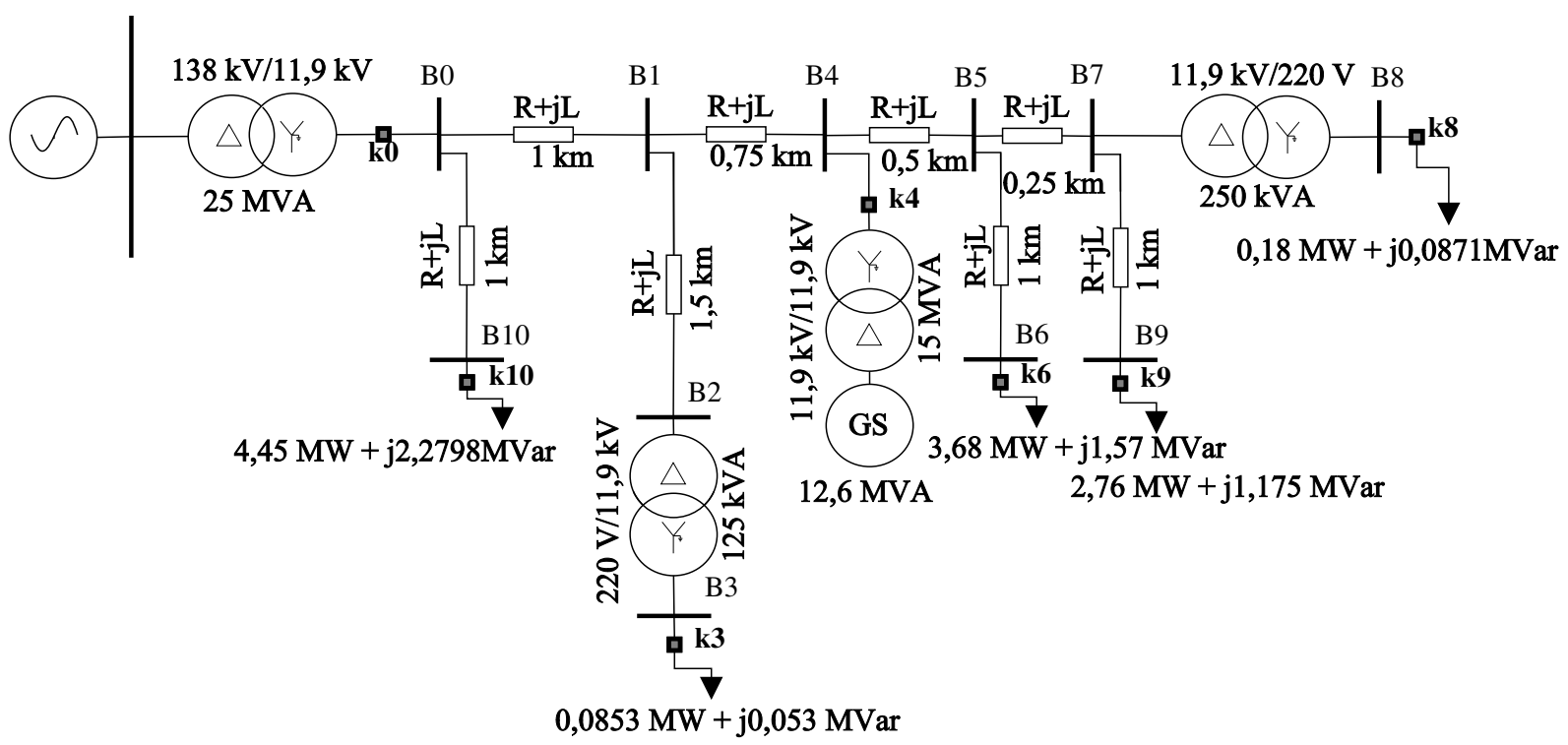

Figura 4.7 - Diagrama unifilar do sistema de distribuição.

\subsection{Discussão adicional}

Um dos importantes passos ao desenhar metodologias de proteção consiste na sua avaliação frente a transitórios eletromagnéticos passíveis de ocorrerem nos sistemas elétricos de potência. Lembrando-se que a metodologia aplicada deverá enxergar e atuar exclusivamente para o fenômeno para o qual foi projetada. O uso de técnicas mais sofisticadas, como é o caso da mineração de dados para a detecção do ilhamento, exige primordialmente que dados representativos estejam disponíveis para caracterizar o evento. Devido a fenômenos transitórios tais como faltas e o ilhamento serem situações de operação impraticáveis, uma vez que há proteções contra tais distúrbios e isso dificulta uma aquisição com dados reais, um banco de dados representativo só poderá ser construído via simulação. Por isso, o CAPítulO 4 buscou descrever em detalhes o funcionamento do SimPowerSystems, dos modelos dos componentes elétricos, do gerador síncrono e controle associado e o sistema elétrico no qual serão aplicadas as simulações de ilhamento e outros distúrbios correlatos. Adicionalmente, espera-se que com uma modelagem condizente, os parâmetros extraídos dos sinais de tensão e corrente nos terminais do GD possam dar indicativos apurados para classificar a ocorrência de ilhamentos. 



\section{CAPítulo 5}

\section{O Esquema de Proteção Anti-Ilhamento}

Neste CAPÍTULO 5 serão apresentados, em detalhes, todos os passos necessários para a formulação do esquema de proteção anti-ilhamento da Figura 5.1, proposto nesta dissertação. Este esquema possui uma etapa de treinamento do método, realizada off-line, em que é aplicada a metodologia de descoberta de novidades em banco de dados, em inglês Knowledge Discovery in Databases (KDD) [26]. Dentro do KDD é utilizada a técnica de mineração de dados do DAMICORE, em que o conhecimento obtido através de análise dos padrões de ilhamento e não ilhamento é armazenado no esquema de decisão função data-mining. A etapa de operação do algoritmo, ou seja, realizada online, pré-processa os sinais de tensão e corrente trifásicos, extraindo desses sinais 10 características. Estas características são acumuladas por uma quantidade de n-ciclos, e somente então, o esquema de decisão função data-mining, carregado com os padrões obtidos por análise offline via DAMICORE e armazenados em memória interna, enviará um sinal de abertura (Trip) no caso de o ilhamento ser detectado pelo esquema de proteção apresentado na Figura 5.1.

De um modo geral, técnicas de mineração de dados são caracterizadas como técnicas cerne do processo KDD. A Figura 5.2 apresenta as etapas do KDD. Observe que neste processo a aplicação da técnica de mineração de dados do DAMICORE é executada após realizar algumas etapas sobre um banco de dados. O esquema de proteção anti-ilhamento entra somente após a fase de interpretação dos padrões, os quais são identificados pelas técnicas de mineração de dados do DAMICORE [26]. 


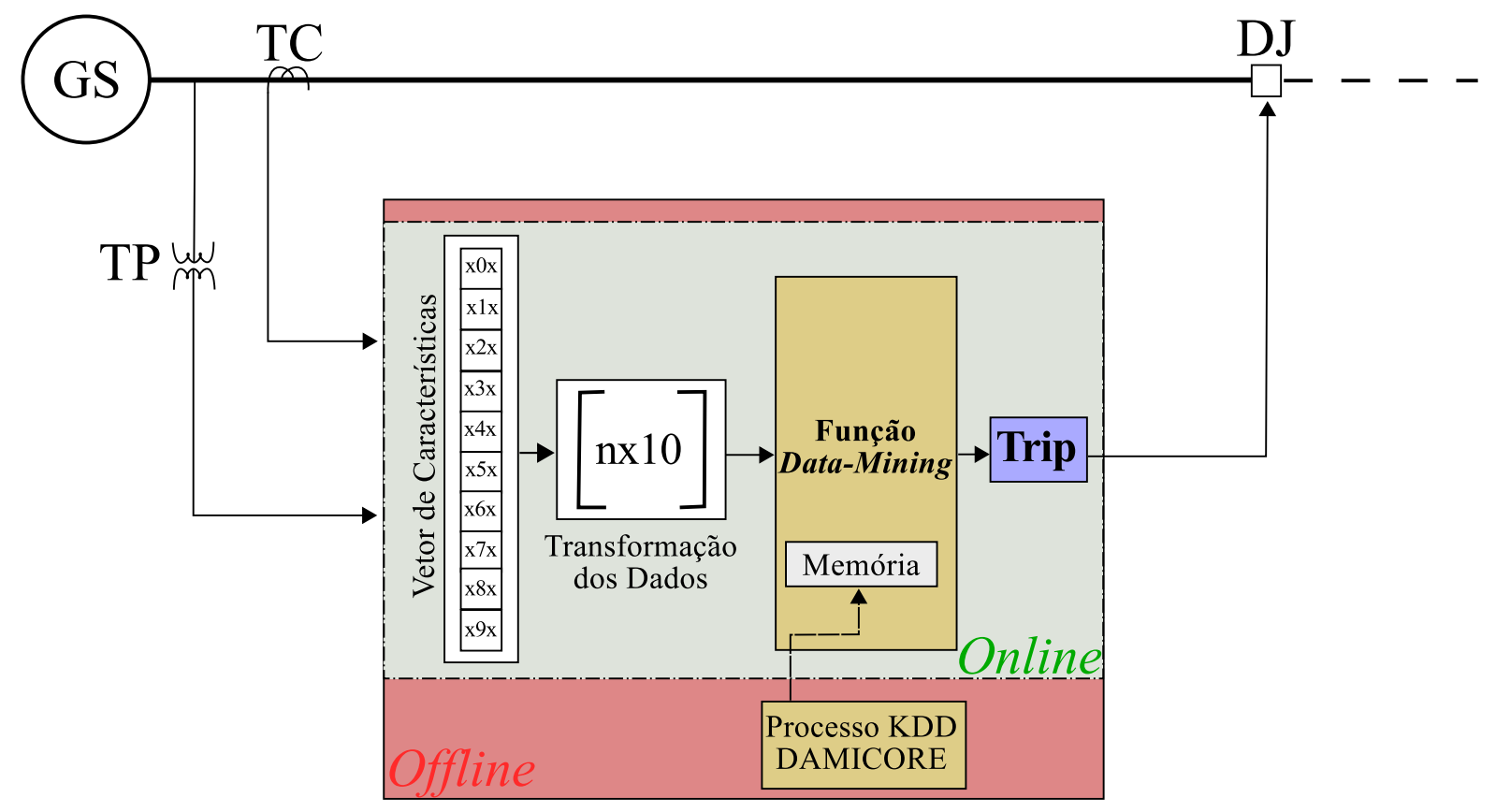

Figura 5.1 - O esquema de proteção anti-ilhamento proposto.

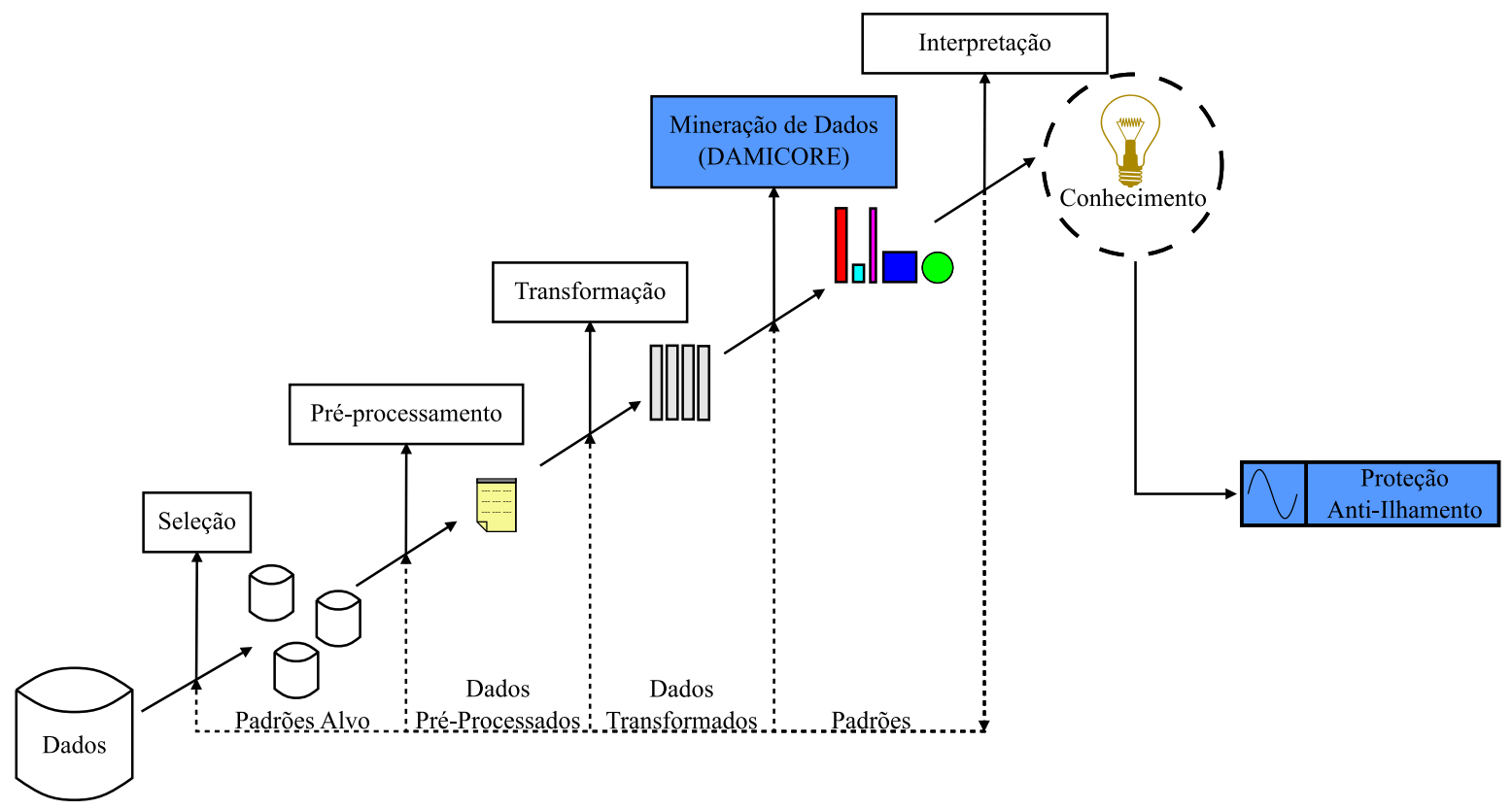

Figura 5.2 - Etapas do processo KDD e o esquema de proteção anti-ilhamento.

De um modo geral, as etapas do KDD são descritas da seguinte forma [26]: 
- Seleção: nesta fase escolhe-se o conjunto de amostras do banco de dados, com todas as variáveis possíveis que farão parte do processo análise de KDD. Esta seleção deve ser feita de modo criterioso, de preferência escolhendo-se amostras que podem apresentar características peculiares. Se essas amostras caracterizarem ou não padrões relevantes, isso será descoberto após a interpretação dos resultados advindos da mineração de dados.

- Pré-processamento: operações básicas sobre as amostras pré-selecionadas são realizadas nesta etapa de modo a garantir o funcionamento adequado da mineração de dados. Neste processo estão inclusos o tratamento de amostras ruidosas; a remoção de redundâncias; o tratamento de dados incompletos; e a eliminação de dados discrepantes ou outliers.

- Transformação: esta é a fase do KDD que antecede a aplicação da técnica de mineração de dados. Nessa fase os dados necessitam ser armazenados e formatados adequadamente de modo que o algoritmo de mineração de dados, no caso o DAMICORE, identifique-os como entradas.

- Mineração de dados (DAMICORE): após os dados serem selecionados, limpos, pré-processados e transformados no formato necessário é aplicada a técnica de mineração de dados do DAMICORE. Os detalhes dessa técnica estão disponíveis no CAPÍTULO 3.

- Interpretação: esta é a fase final do processo de KDD. O conhecimento sobre o conjunto de amostras selecionadas (informação) é obtido através de análise dos resultados da mineração de dados. Esses resultados normalmente são apresentados graficamente e cabe ao usuário identificar o significado dos padrões apresentados. A informação obtida através do KDD pode ser utilizada tanto para a elaboração de relatórios quanto para ser incorporado a outro sistema que fará a tomada automática de decisões baseado no conhecimento obtido via análise dos padrões encontrados na etapa de mineração de dados.

Baseado nos procedimentos do KDD elaborou-se a metodologia de detecção de ilhamento proposta nesta dissertação. Ao final da fase de interpretação dos resultados da mineração de dados do DAMICORE, a informação obtida é utilizada em um novo esquema de proteção anti-ilhamento para geradores síncronos. Portanto, neste CAPítUlo 5 será apresentado o processo de preparação dos dados, que envolve etapas de seleção, 
pré-processamento e transformação advindas do KDD e um novo esquema de proteção via DAMICORE intitulado função data-mining de proteção anti-ilhamento. Nesse sentido, foram organizadas as seções:

- Configuração das simulações;

- Extração das características;

- Função data-mining de proteção anti-ilhamento;

A análise dos resultados da mineração de dados, correspondente à etapa de interpretação do KDD, assim como a análise de desempenho das funções data-mining de proteção anti-ilhamento e o procedimento para ajusta-la estão disponíveis no CAPÍTULO 6.

\subsection{Configuração das simulações}

A configuração das simulações corresponde a duas etapas iniciais advindas do processo KDD (criação do banco de dados e seleção dos dados). Na Tabela 5.1 são apresentados a quantidade e tipo de simulações realizadas durante a aquisição de dados. Para simular os doze casos de ilhamento selecionados, variou-se a potência ativa do gerador e/ou carregamento do sistema. A mesma lógica foi utilizada para gerar diferentes condições de operação para cada um dos eventos simulados. Para cada uma das simulações, os dados de interesse, que servirão para alimentar o DAMICORE, foram selecionados em janelas de dois segundos: um segundo antes de aplicar o distúrbio (condição de regime permanente), e um segundo após o distúrbio. Esse tempo foi escolhido, pois é necessário detectar o ilhamento em tempo menor que o tempo máximo requerido de até $2 s$ [15].

Tabela 5.1 - Configuração das simulações.

\begin{tabular}{|c|c|c|}
\hline Evento & $\begin{array}{c}\text { Número de } \\
\text { Simulações }\end{array}$ & $\begin{array}{c}\text { Período de } \\
\text { Aquisição }\end{array}$ \\
\hline Ilhamento & 12 & $1 \mathrm{~s}$ \\
Abertura de Carga & 6 & $1 \mathrm{~s}$ \\
Fechamento de Carga & 6 & $1 \mathrm{~s}$ \\
Falta Fase-Terra & 15 & $1 \mathrm{~s}$ \\
Total & 39 & - \\
\hline
\end{tabular}




\subsubsection{Obtenção do banco de dados de simulação}

Para simular cada caso no script desenvolvido em MATLAB especifica-se o estado inicial de cada um dos disjuntores do sistema da Figura 4.7. Isso permite configurar diferentes cenários de carga. Em seguida, especifica-se o disjuntor que sofrerá transição de estado (ligado/desligado) durante as simulações e em qual instante de tempo essa transição ocorrerá. Adicionalmente, especifica-se a referência de potência ativa para o gerador distribuído em (p.u), o que corrobora para com a diversificação dos cenários de operação do sistema de distribuição utilizado.

As 39 simulações escolhidas para realizar o processo de mineração de dados através do DAMICORE possuem parametrizações específicas para cada tipo de evento apresentado na Tabela 5.1. Estes eventos foram organizados do seguinte modo:

- Ilhamento: foram especificados 3 referências de potência ativa, sendo 1;0,67 e 0,33 p.u. Cada cenário de geração possui 4 cenários de carga distintos. Esses cenários são apresentados na Tabela 5.2. Todas as simulações de ilhamento são iniciadas com a abertura do disjuntor $\mathrm{k} 0$ no instante $5 \mathrm{~s}$.

Tabela 5.2 - Cenários de Carga para eventos de ilhamento
\begin{tabular}{|c|c|c|c|c|c|}
\hline $\begin{array}{c}\text { Cenários } \\
\text { de Carga }\end{array}$ & \multicolumn{5}{|c|}{ Estado Inicial dos Disjuntores } \\
(k3 & k10 & k6 & k9 & k8) \\
\hline I & 1 & 1 & 1 & 1 & 1 \\
II & 1 & 0 & 0 & 1 & 1 \\
III & 1 & 0 & 1 & 1 & 1 \\
IV & 0 & 1 & 1 & 0 & 0 \\
\hline
\end{tabular}

- Abertura de carga: foram especificados, para todas as 6 simulações, cenário de carga máxima, ou seja, o estado inicial dos disjuntores k4; k3; k10; k6; k9 e k8 é igual a 1. Adotou-se 3 referências de potência ativa, sendo 1; 0,67 e 0,33 p.u. Cada cenário de geração possui 2 casos de abertura de carga. São eles a abertura do disjuntor k10 e a abertura simultânea dos disjuntores k6 e k9. Todas as simulações de abertura de carga são no instante $5 s$.

- Fechamento de Carga: foram especificados, para todas as 6 simulações, que o estado final do sistema é o de carregamento máximo, ou seja, o estado final dos 
disjuntores k4; k3; k10; k6; k9 e k8 é igual a 1. Adotou-se 3 referências de potência ativa, sendo 1; 0,67 e 0,33 p.u. Cada cenário de geração possui 2 casos de fechamento de carga. São eles o fechamento do disjuntor k10 e o fechamento simultâneo dos disjuntores k6 e k9. Todas as simulações de fechamento de carga são iniciadas no instante $5 s$.

- Faltas fase-terra: foram especificados, para todas as 15 simulações, cenário de carga máxima, ou seja, o estado inicial dos disjuntores k4; k3; k10; k6; k9 e k8 é igual a 1. Adotou-se 3 referências de potência ativa, sendo 1; 0,67 e 0,33 p.u. Cada cenário de geração possui 5 casos de faltas fase-terra, com resistência de falta igual à $0,001 \Omega$, aplicadas nas barras B3; B10; B6; B9 e B8. Todas as simulações de faltas fase-terra são iniciadas no instante $5 s$.

\subsection{Extração das características}

Os sinais de tensão e corrente medidos no PAC precisam ser pré-processados de modo a extrair os vetores de características, os quais são organizados em arquivos para que o DAMICORE realize as análises. A Figura 5.3 mostra como os vetores de características são construídos.

As formas de onda da tensão e da corrente são amostradas em períodos de $2,6 \times 10^{-4} s$ ou 64 amostras por ciclo, de modo que os sinais possam ser representados fielmente para a estimação da frequência e dos demais parâmetros. O bloco de detecção por borda de subida/descida de cruzamentos por zero é utilizado para acionar os buffers, possibilitando armazenar um ciclo das formas de onda da tensão e da corrente. Na etapa seguinte são computadas as características da Tabela 5.3.

Isso é feito utilizando as informações disponíveis nos buffers de um ciclo e atualizando essas informações a cada meio ciclo. As 10 características foram selecionadas por serem grandezas representativas para definir uma situação de ilhamento. Para remover respostas ruidosas, foram projetados dois filtros passa-baixas Butterworth: o filtro de entrada é de $2^{\mathrm{a}}$ ordem, com frequência de corte ajustada em $120 \mathrm{~Hz}$, o filtro de saída é de $1^{\mathrm{a}}$ ordem, com frequência de corte ajustada em $10 \mathrm{~Hz}$. 


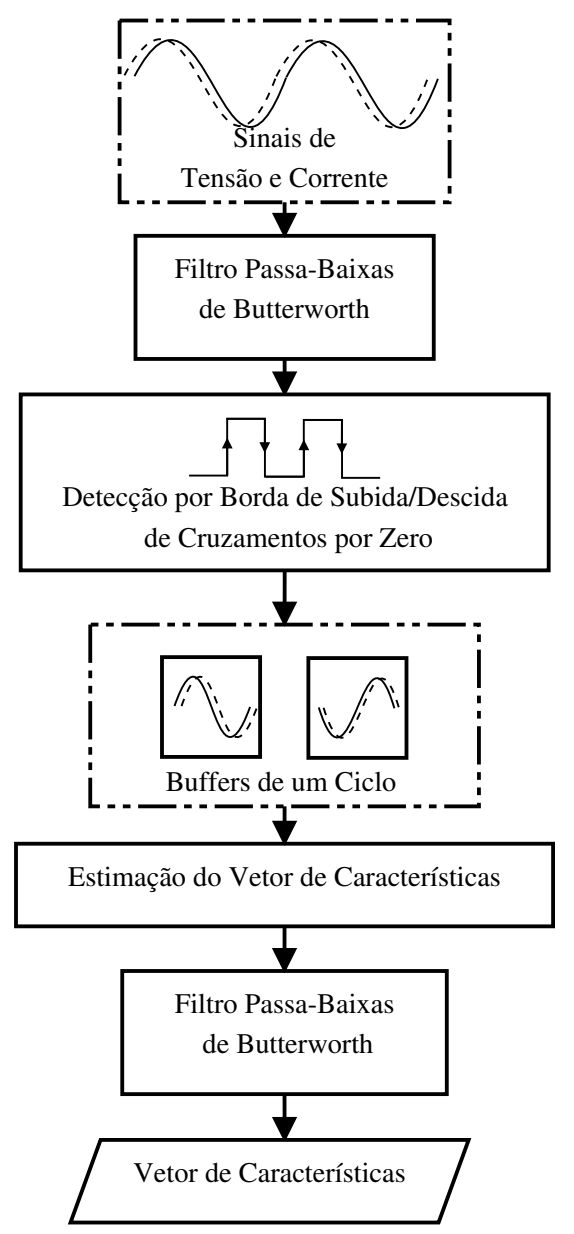

Figura 5.3 - Algoritmo Vetor de Características.

Tabela 5.3 - Saídas geradas pelo algoritmo vetor de características.

\begin{tabular}{|c|c|c|c|}
\hline Saídas & Características & Variável & Unidade \\
\hline $\mathrm{X} 0 \mathrm{x}$ & Frequência & $f$ & $H z$ \\
\hline $\mathrm{X} 1 \mathrm{x}$ & Taxa de variação de X0x & $\frac{d f}{d t}$ & $\frac{H z}{s}$ \\
\hline $\mathrm{X} 2$ & Tensão RMS & $V$ & $p \cdot u$ \\
$\mathrm{X} 3 \mathrm{x}$ & Taxa de variação de X2x & $\frac{d V}{d t}$ & $\frac{p \cdot u}{s}$ \\
\hline $\mathrm{X} 4 \mathrm{x}$ & Potência Ativa & $P$ & $p \cdot u$ \\
$\mathrm{X} 5 \mathrm{x}$ & Potência Reativa & $Q$ & $p \cdot u$ \\
$\mathrm{X} 6 \mathrm{x}$ & Fator de Potência & $F P$ & - \\
$\mathrm{X} 7 \mathrm{x}$ & Taxa de variação de X6x & $\frac{d F P}{d t}$ & $\frac{1}{s}$ \\
\hline $\mathrm{X} 8 \mathrm{x}$ & Salto de Vetor & $\Delta \theta$ & $g r a u$ \\
$\mathrm{X} 9 \mathrm{x}$ & Taxa de variação de X8x & $\frac{d \Delta \theta}{d t}$ & $\frac{1}{S}$ \\
\hline
\end{tabular}




\subsubsection{Transformação dos dados}

Nesta fase os dados necessitam ser armazenados e formatados adequadamente de modo que o algoritmo de mineração de dados, neste caso o DAMICORE, os interprete como entradas. O processo de transformação dos dados, apresentado na Figura 5.4, resume-se em organizar os dados de simulação em arquivos de extensão (.txt). Esses arquivos contêm uma quantidade específica de ciclos dos sinais de tensão e corrente, os quais são representados pelas saídas do algoritmo vetor de características (veja a Tabela 5.3). Cada arquivo de entrada para o DAMICORE contém uma matriz de características de dimensão $n \times 10$, em que $n$ é o número de ciclos e 10 é a quantidade de características referente à Tabela 5.3.

Ao projetar a proteção deve-se adotar uma quantidade $n$ de ciclos para que todos os arquivos armazenados numa pasta (entradas do DAMICORE) contenham dados de matrizes de mesma dimensão. Adicionalmente é necessário normalizar os dados. Isso é feito dividindo-se o valor de módulo máximo, para cada característica em específico, encontrado durante a realização das 39 simulações da Tabela 5.3.

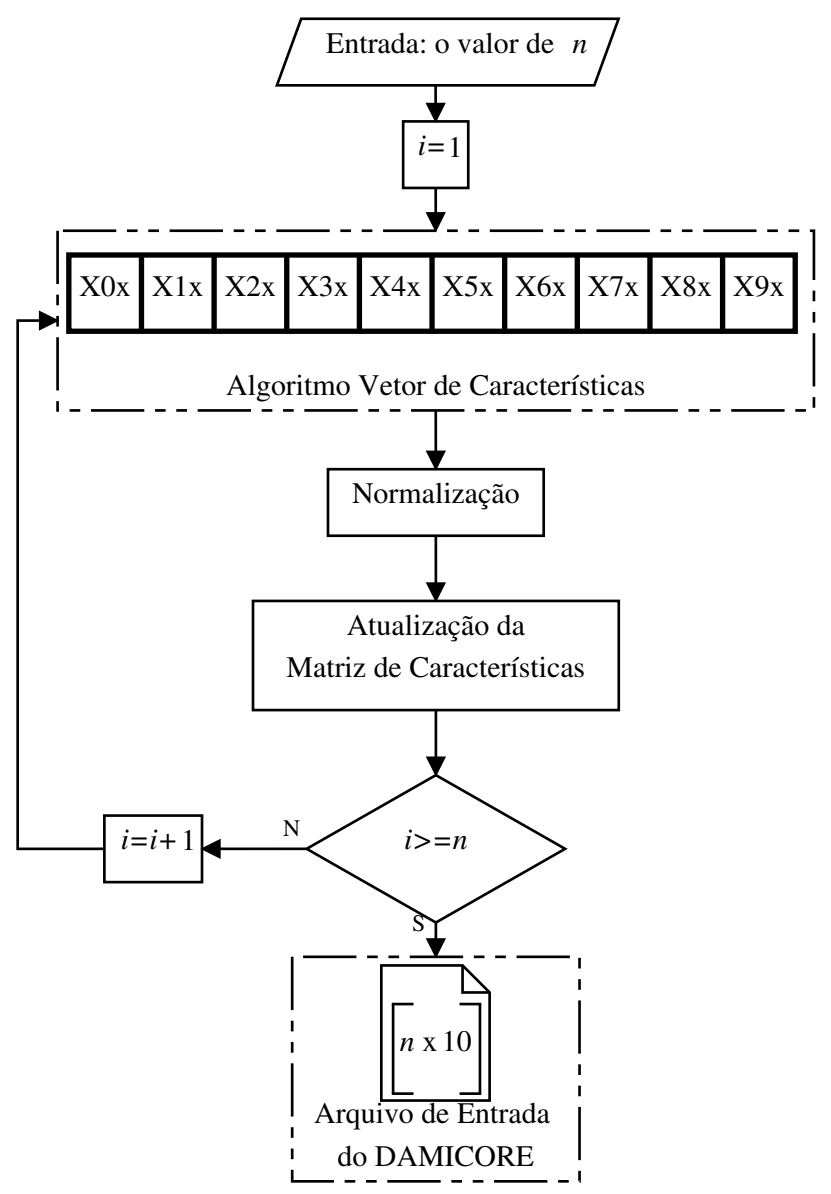

Figura 5.4 - Algoritmo de transformação dos dados. 


\subsection{Função data-mining de proteção anti-ilhamento}

A estrutura lógica de decisão do algoritmo de proteção da Figura 5.5 consiste em realizar a classificação utilizando o valor mínimo da distância euclidiana entre a matriz de características $(n \times 10)$ atual (obtidas constantemente enquanto a função data-mining estiver habilitada) e o banco de dados de matrizes de características $(n \times 10)$ que foram previamente classificadas via DAMICORE. A matriz de características atual pode possuir uma destas três classes:

- Ilhamento (IL);

- Ilhamento Suspeito (ILS);

- Não-ilhamento;

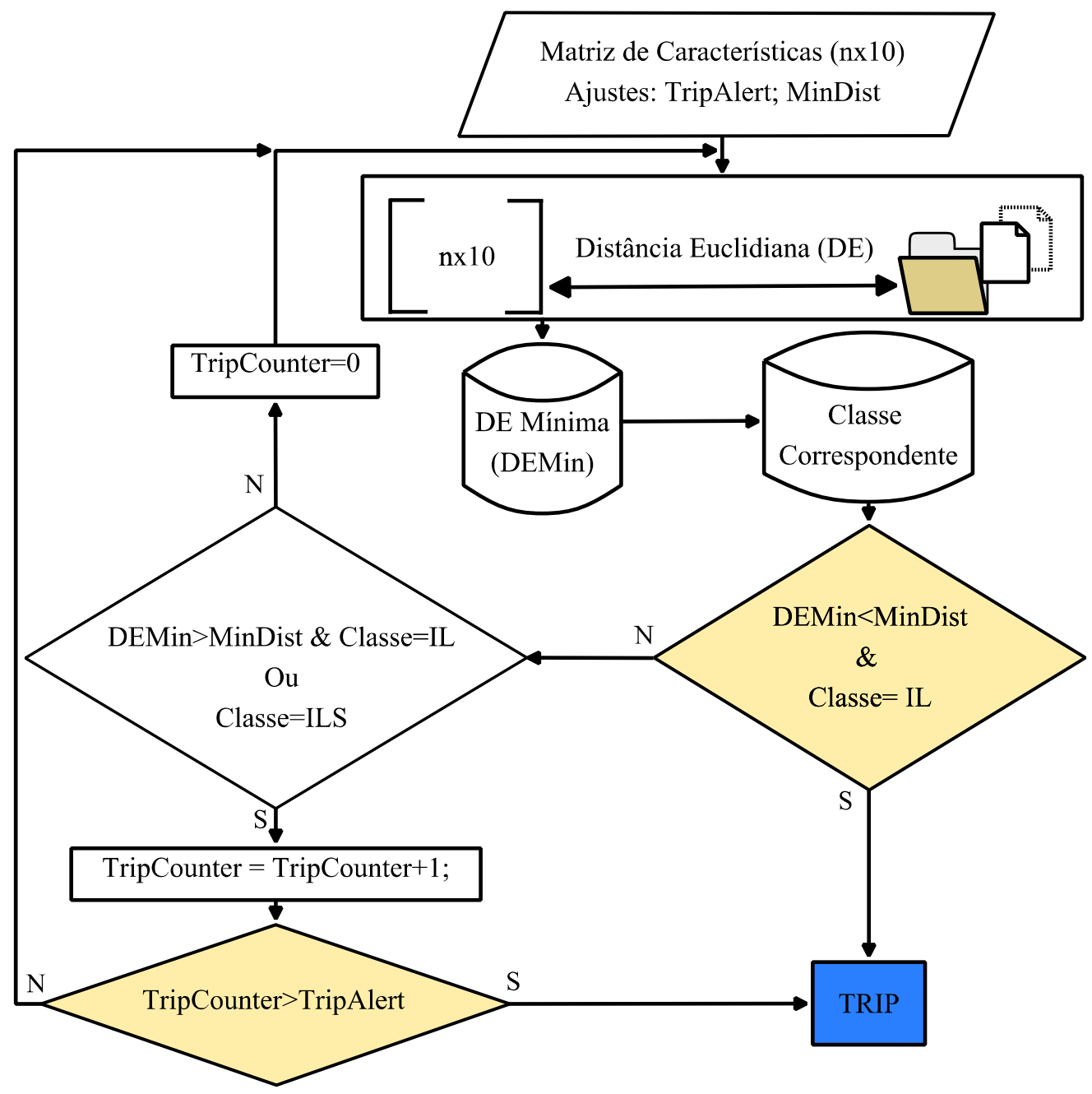

Figura 5.5 - Função data-mining para a proteção anti-ilhamento. 
O algoritmo utiliza dois ajustes para evitar sinais de abertura (trip) indevidos. Esses ajustes são:

- MinDist: é o limiar de distância euclidiana mínima;

- TripAlert: é o valor limite de um contador (TripCounter) de suspeita de ilhamento;

A função de proteção anti-ilhamento da Figura 5.5 pode atuar somente em duas situações. A primeira, se a matriz de características atual pertencer à classe ilhamento e a respectiva distância euclidiana mínima for menor que o limiar (MinDist). A segunda possibilidade é para casos em que o contador de ilhamento suspeito (TripCounter) exceder o limite (TripAlert).

\subsubsection{Procedimento de ajuste da função data-mining}

A aplicação da função data-mining em outros sistemas é dependente de cada caso de estudo. Logo, o processo KDD apresentado ao longo deste CAPÍTULO 5 e a mineração de dados do DAMICORE devem ser replicados considerando características específicas do sistema no qual se deseja instalar o gerador síncrono distribuído.

De um modo geral é necessário selecionar casos que podem ser relevantes de situações de ilhamento e não-ilhamento. Nos casos de não-ilhamento é importante inserir casos nos quais as proteções tradicionais podem se confundir. Logo após deve-se organizar os dados gerados conforme apresentado na seção 5.2 Extração das características. Na sequência devemse apresentar os dados ao DAMICORE e verificar se foram encontrados grupos definidos que caracterizam o ilhamento, diferenciando-o de outros transitórios. Os dados utilizados são armazenados e indexados na função data-mining com sua classe correspondente. Essas classes podem ser: ilhamento, não-ilhamento ou ilhamento suspeito. Somente após o estudo dos padrões da mineração de dados via DAMICORE deve-se proceder com os ajustes minDist e TripAlert da função data-mining.

Para ajustar minDist TripAlert deve-se ensaiar a função data-mining para as mesmas simulações utilizadas pelo DAMICORE e garantir que essa opere corretamente para 100\% dos casos. Os mesmos casos são utilizados, pois é necessário compensar um erro no valor de distância euclidiana mínima que pode ocorrer devido ao deslocamento temporal entre a matriz 
de características $(n \times 10)$ atual e as disponíveis no banco de dados de matrizes de características $(n \times 10)$.

\section{Ajuste minDist}

O ajuste minDist é feito por inspeção do comportamento da distância euclidiana mínima durante o ensaio dos casos utilizados na mineração de dados do DAMICORE. Durante o processo de ajuste de minDist deve-se desligar a função de atuação por TripAlert.

Idealmente o ajuste de minDist deveria ser igual à zero, no entanto isso pode desabilitar a atuação da função data-mining em casos nos quais o sinal atual pertence à classe ilhamento, logo a detecção do ilhamento pode atrasar, pois a matriz de características atual seria classificada pela função data-mining como suspeita de ilhamento. Além disso, o valor de minDist, não deve ser maior que 10, pois isso caracteriza um padrão ainda desconhecido pela função data-mining e pode levar a casos de atuação indevida. Portanto, o melhor ajuste de minDist é o que maximiza os casos em que o ilhamento é detectado e minimiza os casos de atuação indevida. Normalmente, valores na faixa de 1 a 5 podem apresentar esses indicativos.

\section{Ajuste TripAlert}

Após ajustar minDist, deve-se habilitar a função TripAlert para ajusta-la. Esse ajuste possibilita acelerar a detecção do ilhamento, pois considera que casos de ilhamento suspeito podem caracterizar o ilhamento se essa suspeita se manter ao longo do tempo. O ajuste TripAlert é sempre um número inteiro. O procedimento de ajuste é iniciar TripAlert como zero e ensaiar a função data-mining com as mesmas simulações utilizadas pelo DAMICORE. Caso a função data-mining não tenha operado corretamente para $100 \%$ dos casos do ensaio, então o valor de TripAlert deve ser incrementado em 1. Esse procedimento deve ser repetido até que a função data-mining opere corretamente para $100 \%$ dos casos do ensaio com o menor valor de TripAlert.

\subsection{Discussão adicional}

O novo esquema de proteção anti-ilhamento para geradores síncronos distribuídos é resultado de um processo de estudo, advindo do $\mathrm{KDD}$, dos padrões que caracterizam o 
ilhamento. Ao final do processo, a informação obtida via mineração de dados do DAMICORE é utilizada para alimentar o algoritmo de proteção anti-ilhamento, intitulado função data-mining. Para projetar e utilizar o esquema proposto neste CAPÍtUlo 5 é fundamental garantir que a modelagem do sistema elétrico, no qual a técnica de mineração de dados será aplicada, esteja condizente com a representação de seus respectivos transitórios eletromagnéticos, sobretudo o ilhamento.

Observe que o método não utiliza milhares de simulações para extrair padrões de ilhamento e não ilhamento. Isso traria alguns problemas. Dados em excesso podem deixar o método lento e os padrões identificados podem ter pouco significado útil, pois seriam postos em análise ao DAMICORE milhares de casos similares ou até mesmo repetidos. Para contornar essa situação e extrair padrões que podem ser relevantes ao método seguiu-se a etapa de seleção do KDD, apresentando ao DAMICORE apenas 39 casos. Esses casos montam situações específicas de cada um dos fenômenos considerados (falta fase-terra, chaveamento de carga, ilhamento e regime permanente). Além disso, o método considera 10 características dos sinais de tensão e corrente que podem ser encontradas nos esquemas de proteção anti-ilhamento passivos para geradores síncronos. 
CAṔ́tuLo 6

\section{Resultados}

No CAPITUlO 5 foram apresentados todos os procedimentos, sobre os dados advindos de simulações do sistema elétrico desta dissertação, necessários para aplicar a técnica de mineração de dados do DAMICORE e o projeto das funções data-mining de proteção anti-ilhamento. No entanto, antes que o projeto das funções data-mining sejam postos em análise e testes, é necessário interpretar os padrões encontrados via DAMICORE. Isto é, somente após o procedimento do KDD, a informação (conhecimento) é obtida e poderá ser utilizada. Dessa forma, os resultados são postos em análise sob duas perspectivas principais. A primeira é a de verificar as potencialidades de o DAMICORE identificar padrões que caracterizam o ilhamento, diferenciando-o de outros fenômenos (faltas fase-terra, chaveamento de carga e regime permanente), os quais fazem parte do banco de dados de simulações apresentados ao DAMICORE. A segunda é a de testar o esquema de proteção anti-ilhamento proposto (função data-mining) nesta dissertação e comparar seu desempenho com um relé de frequência. Adicionalmente, será colocada sob análise a assinatura da frequência e da tensão para regimes de operação específicos em que o ilhamento pode ocorrer. Nesse sentido, este CAPÍtUlo 6 apresenta a análise dos resultados, os quais estão organizados conforme as seções:

- Análise de padrões do DAMICORE;

- Análise e testes dos esquemas de proteção anti-ilhamento;

- Análise da assinatura de frequência durante eventos de ilhamento. 


\subsection{Análise de padrões do DAMICORE}

O DAMICORE apresenta seus resultados de agrupamento de duas formas. A primeira apresenta a árvore filogenética. Como essa árvore representa a relação entre os dados fornecidos ao DAMICORE, é possível analisa-las por inspeção visual e verificar as relações de similaridades entre esses dados. Caso os dados, sobretudo de ilhamento, sejam similares, é possível verificar que suas correlações caracterizam clados $^{5}$ na árvore, ou seja, agrupamentos em que os dados permanecem unidos por um único ancestral em comum. A segunda forma apresenta um relatório contendo informações dos grupos encontrados na árvore através da técnica FN. Nesse relatório basta analisar se a técnica foi capaz de encontrar grupos específicos que caracterizam o ilhamento. É comum que o FN encontre grupos bastante específicos na árvore, visto que é utilizada uma função de qualidade ou modularidade (veja a seção Fast algorithm of Newman do CAPÍTULO 3) como critério de aprimorar o agrupamento realizado durante o processo iterativo do algoritmo FN. Assim sendo, a informação obtida sob os dados via DAMICORE alimentará um algoritmo de proteção anti-ilhamento intitulado função data-mining. Por esses motivos, os resultados foram organizados conforme as subseções:

- Inspeção visual das árvores filogenéticas;

- Características dos clusters.

\subsubsection{Inspeção visual das árvores filogenéticas}

Os arquivos de entrada são organizados conforme descrito no CAPítulo 5. Para investigar a influência da quantidade de ciclos no desempenho do método, assumiu-se $n$ igual a 5; 10; 15 e 30 ciclos resultando em 4 casos a serem analisados. Portanto, há quatro pastas contendo as mesmas 39 simulações apresentadas na Tabela 5.1. Os arquivos em cada pasta são representados nos nós folha das árvores filogenéticas da Figura 6.1.

\footnotetext{
${ }^{5}$ Relembrando: a palavra clado, em inglês clade, advém da palavra grega klados que significa ramo. Em biologia, um clado é um grupo de organismos ou espécies originados de um ancestral comum exclusivo. Na representação gráfica da árvore filogenética, clado é um conjunto de ramificações unidas por um único nó em comum [61].
} 
Desse modo, em primeira instância é possível avaliar o desempenho do método por inspeção visual. Os nós folha de uma árvore filogenética do DAMICORE representam os dados (arquivos), separados por cores, de acordo com a legenda apresentada na Figura 6.1. Note que as matrizes de parâmetros de dados de regime permanente também foram inseridas nos testes. Os nós internos da árvore, que conectam os nós folha, representam as relações entre os dados. Na Figura 6.1, é possível verificar tendências de clusterização dos casos de ilhamento, isto é, tendências de formar um conjunto de clados de ilhamento, que os separa de outros eventos.

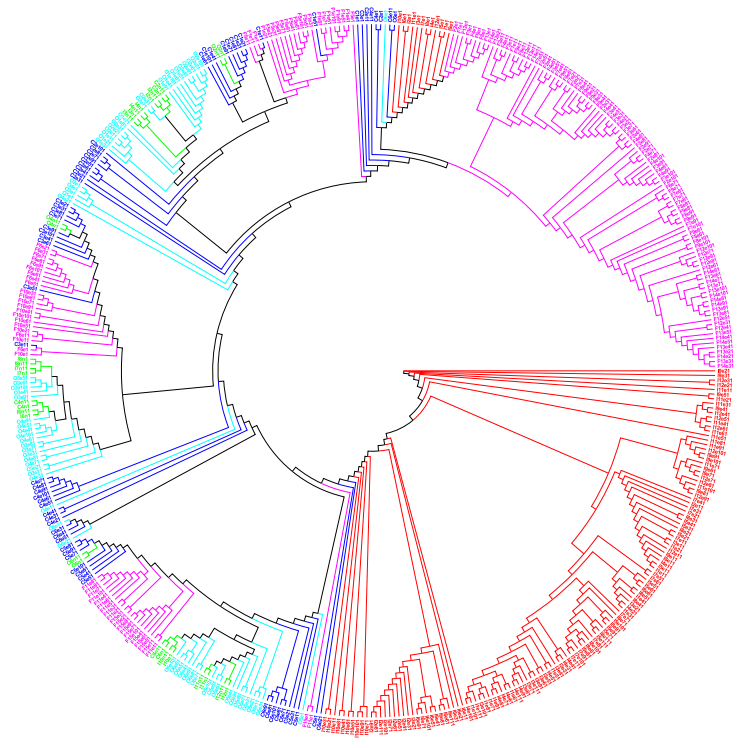

(a) Matriz de características $5 \times 10$.

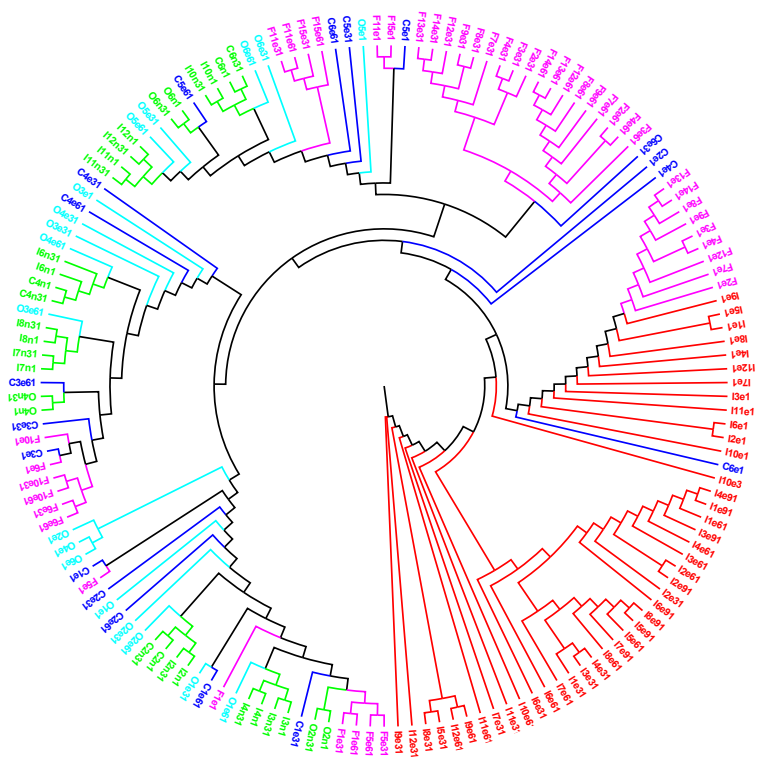

(c) Matriz de características $15 \times 10$.

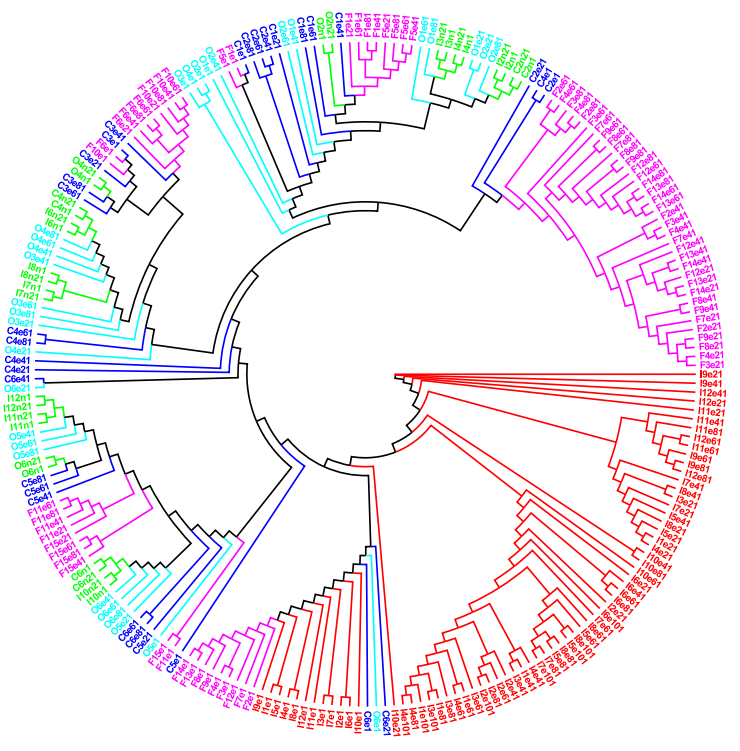

(b) Matriz de características $10 \times 10$.

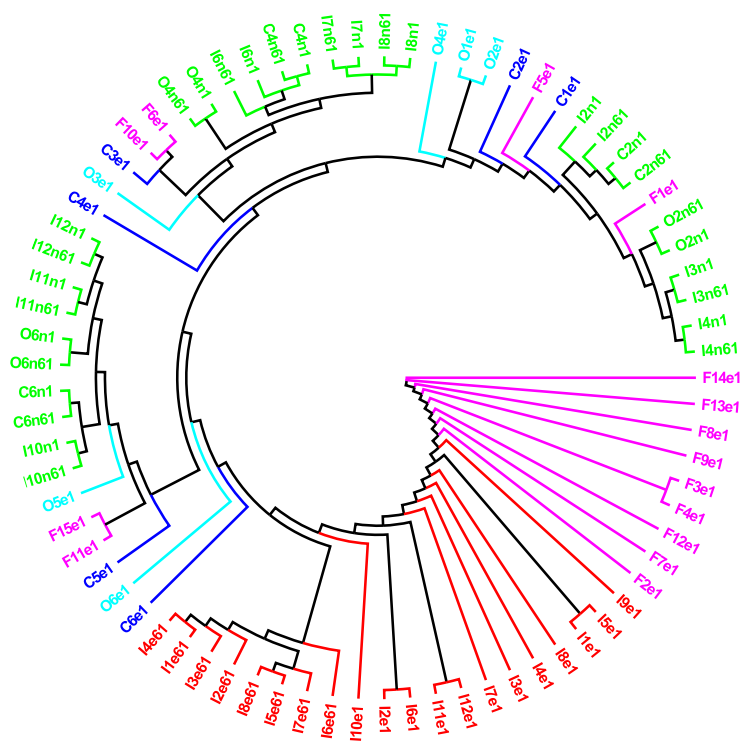

(d) Matriz de características $30 \times 10$.

\begin{tabular}{|lllll}
\hline Ilhamento & Falta & Abertura de Carga & Fechamento de Carga & Regime Permanente \\
\hline
\end{tabular}

Figura 6.1 - Árvores Filogenéticas do DAMICORE. 
$\mathrm{Na}$ árvore (a) da Figura 6.1 há um grande grupo de folhas classificadas como ilhamento, porém há um menor, também classificado como ilhamento, que não se manteve unido ao grande grupo, indicando que o método pode não classificar corretamente todas as situações de ilhamento. Isso ocorre porque a informação pós-distúrbio de um ciclo não é suficiente para caracterizar um evento com confiabilidade, ou seja, o primeiro ciclo de ilhamento pode ser facilmente confundido com um ciclo de chaveamento de carga ou de uma falta fase-terra por exemplo. Contudo, note que com o aumento do número de ciclos (árvore (b) à árvore (d) da Figura 6.1), esse erro tende a ser eliminado.

No tocante das relações entre os dados (ilhamento, chaveamento de carga, faltas fase-terra e regime permanente) considerados observe a árvore (d). Embora a decisão seja lenta, pois na árvore (d) é considerada uma maior quantidade de ciclos, sendo 30 ciclos no total, dentre as árvores da Figura 6.1 é a que melhor representa as relações de similaridades entre eventos. Note que o evento mais similar ao ilhamento é a falta fase-terra. Por outro lado, situações de chaveamento de carga apresentam maior similaridade com casos de regime permanente e casos específicos de faltas fase-terra.

Relembrando o fato que a metodologia foi proposta no sentido de proteger o sistema contra o ilhamento, a escolha do número de ciclos é uma solução de compromisso entre a precisão e velocidade dos métodos. Por esse motivo, o algoritmo de decisão (função data-mining) utiliza como referência os padrões encontrados nas árvores (a) e (b) da Figura 6.1. Isso implica que o atraso mínimo para a decisão será da ordem de $83 \mathrm{~ms}$ ou $166 \mathrm{~ms}$ respectivamente. Caso sejam utilizadas as árvores (c) e (d) o atraso mínimo passa a ser de $250 \mathrm{~ms}$ ou $500 \mathrm{~ms}$ respectivamente.

\subsubsection{Características dos clusters}

Uma segunda perspectiva de análise é obtida ao executar o algoritmo FN que tem a função de encontrar clusters nas árvores filogenéticas da Figura 6.1. Com os resultados obtidos construiu-se a Tabela 6.1.

- O tipo de cluster representa um conjunto de dados que define o cluster;

- O índice de clusters representam nomes de identificação dados pelo DAMICORE para cada cluster encontrado no conjunto de dados apresentado. Esses índices são utilizados para alimentar o esquema de decisão da função data-mining, pois a 
cada novo conjunto de $n$ ciclos dos sinais de tensão e corrente, representados pelo algoritmo vetor de características, será atribuído o seu correspondente índice da Tabela 6.1. Na função data-mining esse processo é feito utilizando o valor mínimo da distância euclidiana entre a matriz de características atual $(n \times 10)$ e o banco de dados de matrizes de características $(n \times 10)$ que foram pré-classificadas via DAMICORE.

Logo, o cluster do tipo 3 contém apenas dados de chaveamento de carga. Para representar o cluster do tipo 3 dois clusters foram encontrados na árvore da Figura 6.1(a) pelo DAMICORE, os quais foram nomeados com índice 25 e 27. Note que os tipos de clusters de 1 a 4 estão relacionados a clusters de eventos exclusivos, ou seja, o cluster do tipo 1 contém apenas dados de ilhamento por exemplo. Por outro lado, os clusters de 5 a 12 representam clusters onde dois ou mais eventos são vistos similares pelo DAMICORE. Além disso, é comum encontrar um conjunto de clusters do mesmo tipo para representar uma classe. Isso acontece porque o FN encontra grupos com alto grau de independência na árvore filogenética.

Na Tabela 6.1, observa-se que para a árvore da Figura 6.1(a), foram encontradas características similares às das análises por inspeção visual das árvores filogenéticas. Um conjunto de clusters que contém exclusivamente dados de ilhamento foi encontrado. Com o aumento do número de ciclos nos casos da Figura 6.1(b) à da Figura 6.1(d), a quantidade de clusters com classes múltiplas diminui. Isso melhora o desempenho do método. No caso da Figura 6.1(d) ocorre uma situação peculiar. Tipos de clusters exclusivos para cada um dos 4 eventos foram encontrados, embora nos outros casos a operação em regime permanente não se separa dos demais eventos. Os estudos dos padrões dos casos da Figura 6.1(a) e da Figura 6.1(b) foram utilizados para projetar as funções data-mining. O cluster do tipo 1 representa a classe ilhamento, os clusters do tipo 5; 6; 10 e 11 representam a classe suspeita de ilhamento e os demais representam a classe não-ilhamento.

Ao sintetizar as informações da Tabela 6.1 é possível quantificar a qualidade das classes obtidas pelo DAMICORE. Neste sentido, a Tabela 6.2 apresenta a quantidade de clusters que contém dados exclusivos de apenas um dos eventos e dos clusters em que dois ou até três eventos foram identificados como similares pelo DAMICORE. Esses dados são apresentados para cada uma das árvores filogenéticas geradas e apresentadas na Figura 6.1 (árvore (a) à árvore (d)). Ao analisar a Tabela 6.2 observa-se que em todas as árvores a maioria dos clusters encontrados são de eventos exclusivos (uma classe) e a minoria são de eventos com 3 classes. A partir da árvore (b) nota-se que a quantidade total de clusters tende a 
diminuir. Isso ocorre por que o número de ciclos armazenados em cada um dos arquivos é maior, fazendo com que a quantidade total de arquivos apresentados ao DAMICORE diminua e consequentemente as árvores geradas possuirão menor número de nós. Geralmente, árvores com menos nós apresentam também menos clusters. Embora o total de clusters diminua proporcionalmente, a quantidade de clusters de três classes reduz, dando lugar a clusters de duas e de uma classe. Portanto, os clusters se tornam cada vez mais específicos à medida que a quantidade de ciclos aumenta.

Tabela 6.1 - Características dos Clusters do DAMICORE.

\begin{tabular}{|c|c|c|c|c|c|}
\hline \multirow[b]{2}{*}{$\begin{array}{l}\text { Tipo de } \\
\text { Cluster }\end{array}$} & \multirow[b]{2}{*}{$\begin{array}{c}\text { Dados nos } \\
\text { Clusters }\end{array}$} & \multicolumn{4}{|c|}{ Índice de Clusters } \\
\hline & & $\begin{array}{c}\text { Árvore } \\
\text { Figura 6.1(a) }\end{array}$ & $\begin{array}{c}\text { Árvore } \\
\text { Figura 6.1(b) }\end{array}$ & $\begin{array}{c}\text { Árvore } \\
\text { Figura 6.1(c) } \\
\end{array}$ & $\begin{array}{c}\text { Árvore } \\
\text { Figura 6.1(d) }\end{array}$ \\
\hline 1 & IL & $\begin{array}{c}3 ; 9 ; 14 ; 15 ; \\
18 ; 20 ; 24 \text { e } 32\end{array}$ & $15 ; 19 ; 20$ e 21 & $5 ; 9 ; 12 ; 14$ e 16 & $12 \mathrm{e} 13$ \\
\hline 2 & $\mathrm{~F}$ & $\begin{array}{c}2 ; 11 ; 16 ; 7 \\
21 \text { e } 22\end{array}$ & $3 ; 4 ; 10$ e 17 & 8 e 17 & 1 \\
\hline 3 & $\mathrm{LS}$ & 25 e 27 & 9 e 18 & - & 7 \\
\hline 4 & $\mathrm{RP}$ & - & - & - & $2 ; 6 ; 10$ e 11 \\
\hline 5 & IL F & 1 & 1 & 1 & 8 \\
\hline 6 & IL LS & 12 & 16 & - & - \\
\hline 7 & F LS & $\begin{array}{l}5 ; 6 ; 23 \\
28 \text { e } 29\end{array}$ & $6 ; 7$ e 14 & 11 e 15 & 5 \\
\hline 8 & RP LS & $\begin{array}{c}4 ; 10 ; 13 \\
30 \text { e } 31\end{array}$ & 12 e 13 & 3 e 13 & - \\
\hline 9 & F RP & - & - & - & 9 \\
\hline 10 & IL F LS & 8 & - & - & - \\
\hline 11 & IL RP LS & - & - & 2 & - \\
\hline 12 & F RP LS & $7 ; 19$ e 26 & $2 ; 5 ; 8$ e 11 & $4 ; 6 ; 7$ e 10 & 3 e 4 \\
\hline Legenda & & II - & $\begin{array}{l}\text { - Falta; LS - } \\
\text { - Regime per }\end{array}$ & $\begin{array}{l}\text { eamento de ca } \\
\text { nte: }\end{array}$ & \\
\hline
\end{tabular}

Tabela 6.2 - Quantidade de clusters por classe.

\begin{tabular}{|c|c|c|c|c|c|}
\hline $\begin{array}{c}\text { Tipo de } \\
\text { Cluster }\end{array}$ & $\mathbf{N}^{\mathbf{o}}$ de Classes & Árvore (a) & Árvore (b) & Árvore (c) & Árvore (d) \\
\hline 1 a 4 & Uma Classe & 16 & 10 & 7 & 8 \\
5 a 9 & Duas Classes & 12 & 7 & 5 & 3 \\
10 a 12 & Três Classes & 4 & 4 & 5 & 2 \\
\hline \multicolumn{2}{|l}{ Total } & $\mathbf{3 2}$ & $\mathbf{2 1}$ & $\mathbf{1 7}$ & $\mathbf{1 3}$ \\
\hline
\end{tabular}

Características similares às das análises das Tabelas 6.1 e 6.2 podem ser observadas ao analisar a quantidade de clusters que contém dados de ilhamento em relação ao total de clusters para cada árvore em específico. A Figura 6.2 mostra que para todas as árvores, a 
maior parte dos clusters que contêm dados envolvendo o ilhamento possui apenas uma classe. $\mathrm{Na}$ árvore (a) apenas 3,13\% dos clusters envolvendo dados de ilhamento são de três classes. $\mathrm{Na}$ árvore (b) clusters de três classes não são encontrados. Isso indica que a confusão para caracterizar o ilhamento será menor. $\mathrm{Na}$ árvore (c), embora haja clusters de três classes, é o caso que caracteriza o ilhamento com a maior quantidade de clusters exclusivos (uma classe) de ilhamento, sendo $29,41 \%$, entre as árvores. Na árvore (d), clusters de três classes se extinguem. Os ganhos de confiabilidade na classificação do ilhamento de (c) para (d) são similares aos casos (a) para (b), no entanto, o caso (d) é o único em que foi possível obter clusters exclusivos para os 4 tipos de eventos.

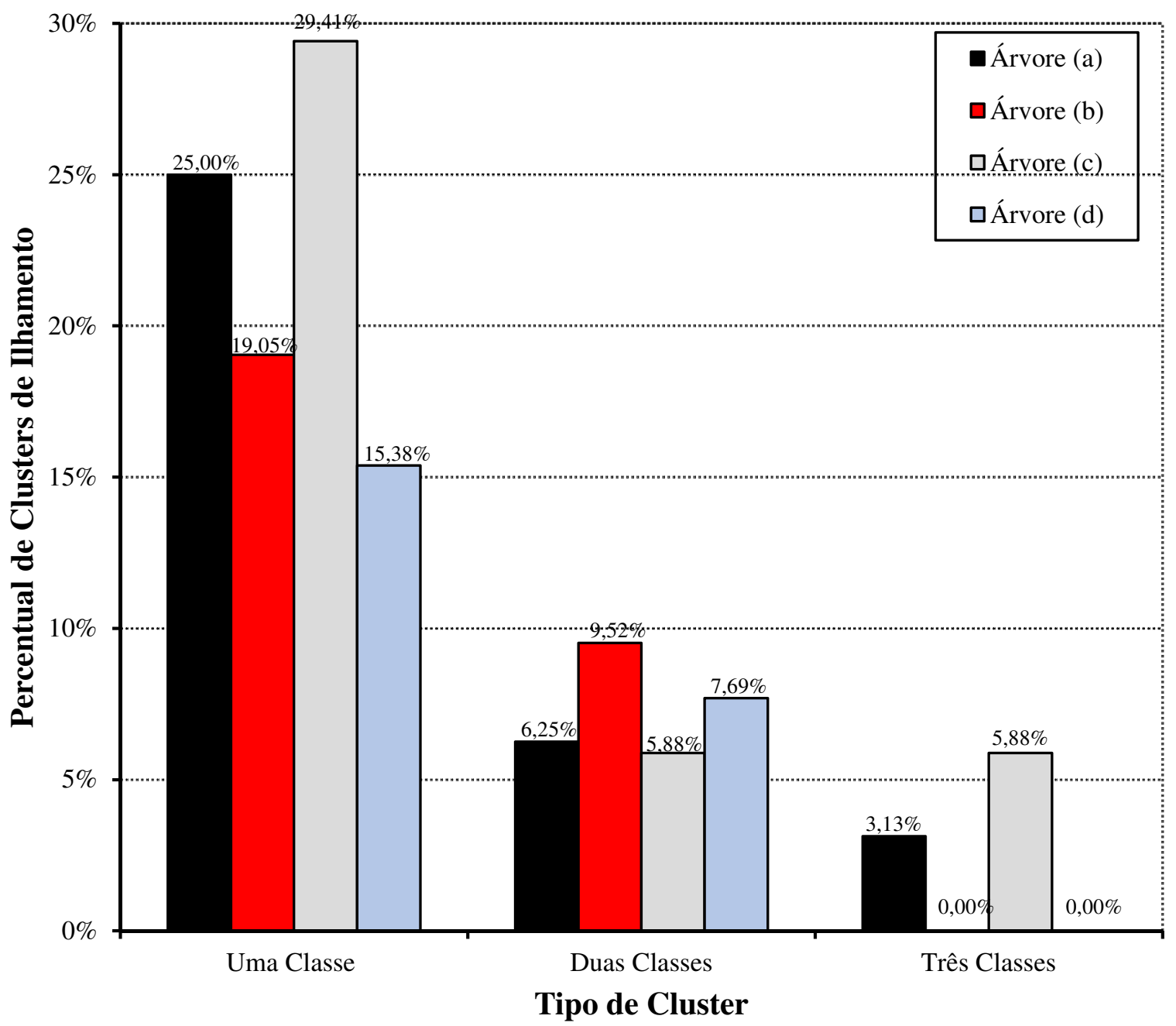

Figura 6.2 - Percentual de clusters de ilhamento em relação ao total de clusters. 


\subsection{Avaliação e testes dos esquemas de proteção anti-ilhamento}

Nesta seção será avaliado o desempenho de três funções de proteção no total. Entre elas estão os relés de frequência 1 e 2, ajustados conforma a Tabela 6.3. O relé de frequência 1 possui dois tipos de parametrizações, sendo uma delas a sub ou sobrefrequência instantânea e uma segunda a sub ou sobrefrequência temporizada. Já o relé de frequência 2 possui somente a parametrização de sub ou sobrefrequência instantânea. Além dos relés de frequência 1 e 2, serão avaliadas as funções data-mining com $n$ igual a 5 e 10 ciclos, ajustadas conforme a Tabela 6.4. Com estes ajustes das proteções serão apresentados dois tipos de testes. Um de desempenho geral e um segundo que verifica a influência do desbalanço de potência ativa na resposta das proteções a centenas de eventos de ilhamento.

Tabela 6.3 - Quadro de ajustes dos relés de frequência.

\begin{tabular}{|c|c|c|c|c|}
\hline Ajustes & $\begin{array}{l}\text { Parâmetro } \\
\text { de Ajuste }\end{array}$ & $\begin{array}{c}\text { Ajuste de } \\
\text { subfrequência }\end{array}$ & $\begin{array}{c}\text { Ajuste de } \\
\text { sobrefrequência }\end{array}$ & Temporização \\
\hline \multirow{2}{*}{$\begin{array}{c}\text { Relé de } \\
\text { frequência } 1\end{array}$} & Instantâneo & $58,5 \mathrm{~Hz}$ & $61,5 \mathrm{~Hz}$ & - \\
\hline & Temporizado & $59,5 \mathrm{~Hz}$ & $60,5 \mathrm{~Hz}$ & $150 \mathrm{~ms}$ \\
\hline $\begin{array}{c}\text { Relé de } \\
\text { frequência } 2\end{array}$ & Instantâneo & $59,5 \mathrm{~Hz}$ & $60,5 \mathrm{~Hz}$ & - \\
\hline \multicolumn{2}{|c|}{ Tensão mínima de operação } & \multicolumn{3}{|c|}{0,5 p.u. } \\
\hline
\end{tabular}

\subsubsection{Ajustes da função data-mining}

Os ajustes de MinDist e TripAlert foram obtidos de maneira empírica, de modo que a proteção opere corretamente sob as 39 simulações da Tabela 5.1.

A classificação precisa do ilhamento é feita quando a matriz de características atual pertence à classe ilhamento e a respectiva distância euclidiana mínima for próxima de zero. Por meio de inspeção do comportamento da distância euclidiana mínima durante as 39 simulações verificou-se que seus valores estavam concentrados em um limiar menor que 3. Esse comportamento manteve-se em ambos os projetos da função data-mining com $n$ igual a 5 e 10 ciclos. Por isso, ajustou-se MinDist igual a 3. 
O ajuste de TripAlert é feito para garantir que a função data-mining seja rápido para detectar o ilhamento mesmo em situações em que os dados se mostram similares a distúrbios de não ilhamento. Caso a suspeita de ilhamento seja mantida por certo tempo, a decisão de abertura deve ser tomada. Como a quantidade $n$ de ciclos utilizada em cada projeto da função data-mining é diferente, então se adota um valor de TripAlert específico para cada um dos projetos. Adotou-se valor de TripAlert igual a 3 para a função data-mining com $n$ igual a 5 ciclos e TripAlert igual a 2 para a função data-mining com $n$ igual a 10 ciclos. Como há uma certeza maior de o ilhamento ser detectado quando se utiliza a função data-mining com $n$ igual a 10 ciclos, a rotina tripAlert se faz menos necessária e por isso adotou-se o valor de tripAlert igual a 2 nesse caso.

Tabela 6.4 - Quadro de ajustes das funções data-mining.

\begin{tabular}{|c|c|c|}
\hline Parâmetro de Ajuste & $\begin{array}{c}\text { Função data-mining } \\
(\mathbf{5} \times \mathbf{1 0})(\mathbf{a})\end{array}$ & $\begin{array}{c}\text { Função data-mining } \\
(\mathbf{1 0} \times \mathbf{1 0})(\mathbf{b})\end{array}$ \\
\hline $\begin{array}{c}\text { Distância euclidiana mínima } \\
(\text { MinDist })\end{array}$ & 3 & 3 \\
$\begin{array}{c}\text { Contador de ilhamento suspeito } \\
\text { (tripAlert })\end{array}$ & 3 & 2 \\
\hline
\end{tabular}

\subsubsection{Teste de desempenho geral}

Antes de iniciar a descrição das simulações do teste de desempenho geral das proteções anti-ilhamento desta dissertação, deixa-se claro que os casos aqui utilizados nestes testes são diferentes dos 39 casos da Tabela 5.1. Portanto, os casos destes testes de desempenho geral não foram utilizados no processo de mineração de dados para descobrir padrões de ilhamento, suspeita de ilhamento e não ilhamento com o DAMICORE e nem no projeto das funções data-mining.

Os testes de desempenho geral dos algoritmos de proteção anti-ilhamento foram configurados para medir-se o tempo de detecção (em $m s$ ) referente a 180 casos. Estes casos correspondem a 60 casos de ilhamento, 60 casos de chaveamento de carga e 60 casos de faltas fase-terra. De um modo geral, cada conjunto de 60 casos foi organizado do seguinte modo: 
- 15 simulações para cada uma das referências de potência ativa do gerador síncrono. Estas referências de potência ativa foram ajustadas em 0,05;0,27;0,40 e 0,94 p.u.

- 5 simulações para cada instante de ocorrência dos eventos. Estes instantes foram ajustados em 4,85; 7,24 e 8,09 $s$ de simulações de $12 s$ de duração. Essas simulações constituem o grupo de 15 simulações para cada uma das referências de potência ativa do gerador síncrono.

Além dessas características gerais, os eventos ilhamento, chaveamento de carga e faltas fase-terra foram configurados de modo específico:

- Ilhamento: além das configurações gerais, foram especificados 5 cenários de carregamento conforme a Tabela 6.5 .

Tabela 6.5 - Cenários de carga para eventos de ilhamento e chaveamento de carga

\begin{tabular}{|c|c|c|c|c|c|}
\hline $\begin{array}{c}\text { Cenários } \\
\text { de Carga }\end{array}$ & \multicolumn{5}{|c|}{ Estado Inicial dos Disjuntores } \\
$\mathbf{( k 3}$ & $\mathbf{k 1 0}$ & $\mathbf{k 6}$ & \multicolumn{1}{|c|}{$\mathbf{k 9}$} & $\mathbf{k 8})$ \\
\hline I & 1 & 1 & 1 & 1 & 1 \\
II & 1 & 0 & 0 & 1 & 1 \\
III & 1 & 0 & 1 & 1 & 1 \\
IV & 0 & 1 & 1 & 0 & 0 \\
V & 1 & 1 & 1 & 0 & 1 \\
\hline
\end{tabular}

- Chaveamento de carga: foram especificados os mesmos 5 cenários de carregamento da Tabela 6.5. Além disso, considerou-se 15 situações específicas de abertura e fechamento de carga, que são configuradas especificando-se os disjuntores do sistema da Figura 4.7 que sofrerão transição de estado (aberto ou fechado e vice-versa). Essas configurações são apresentadas na Tabela 6.6.

- Faltas fase-terra: foram especificados 5 casos de faltas fase-terra, com resistência de falta igual à $0,001 \Omega$ nas barras B3; B10; B6; B9 e B8. O cenário de carga não foi alterado para as simulações de falta. Todos os casos foram simulados com cenário de carga máxima, ou seja, os estados dos disjuntores k3; k10; k6; k9 e k8 são iguais a 1. 
Tabela 6.6 - Configuração dos casos de chaveamento de carga

\begin{tabular}{|c|c|c|c|}
\hline Simulação & $\begin{array}{c}\text { Abertura/Fechamento } \\
\text { dos disjuntores }\end{array}$ & Disjuntores & $\begin{array}{c}\text { Cenário de } \\
\text { Carga }\end{array}$ \\
\hline 1 & Abertura & $\mathrm{k} 6 \mathrm{e} \mathrm{k} 9$ & $\mathrm{I}$ \\
3 & Abertura & $\mathrm{k} 3$ & $\mathrm{II}$ \\
4 & Abertura & $\mathrm{k} 3$ & $\mathrm{III}$ \\
5 & Fechamento & $\mathrm{k} 6 \mathrm{e} \mathrm{k} 9$ & $\mathrm{IV}$ \\
6 & Fechamento & $\mathrm{k} 9$ & $\mathrm{~V}$ \\
7 & Abertura & $\mathrm{k} 10$ & $\mathrm{I}$ \\
8 & Fechamento & $\mathrm{k} 10$ & $\mathrm{II}$ \\
9 & Fechamento & $\mathrm{k} 10$ & $\mathrm{III}$ \\
10 & Abertura & $\mathrm{k} 10$ & $\mathrm{IV}$ \\
11 & Abertura & $\mathrm{k} 10$ & $\mathrm{~V}$ \\
12 & Abertura & $\mathrm{k} 10$ & $\mathrm{I}$ \\
13 & Fechamento & $\mathrm{k} 6$ & $\mathrm{II}$ \\
14 & Fechamento & $\mathrm{k} 6$ & $\mathrm{III}$ \\
15 & Fechamento & $\mathrm{k} 6$ & $\mathrm{~V}$ \\
\hline
\end{tabular}

Na Figura 6.3 estão representados apenas os casos de ilhamento. A princípio houve a detecção do ilhamento em todos os casos e para todas as funções de proteção. No caso das funções data-mining, os tempos de detecção apresentaram tendências de comportamento constantes se comparados com o relé de frequência. Isso pode ser confirmado da seguinte forma. Observe na Figura 6.3 que os tempos de detecção do ilhamento para as funções data-mining (5 e 10 ciclos) estão mais próximos em relação ao seu respectivo tempo de detecção médio, apresentado na Tabela 6.7, ao passo em que, o mesmo não ocorre para o relé de frequência 1 e o relé de frequência 2. As respostas dos relés de frequência são sensibilizadas com o desbalanço de potência ativa. Por isso, existem cenários em que o tempo de detecção de ilhamento é menor que as funções data-mining. Note que, mesmo com um ajuste mais sensível, como é o caso do relé de frequência 2, há casos em que o tempo de detecção é maior que $600 \mathrm{~ms}$. 


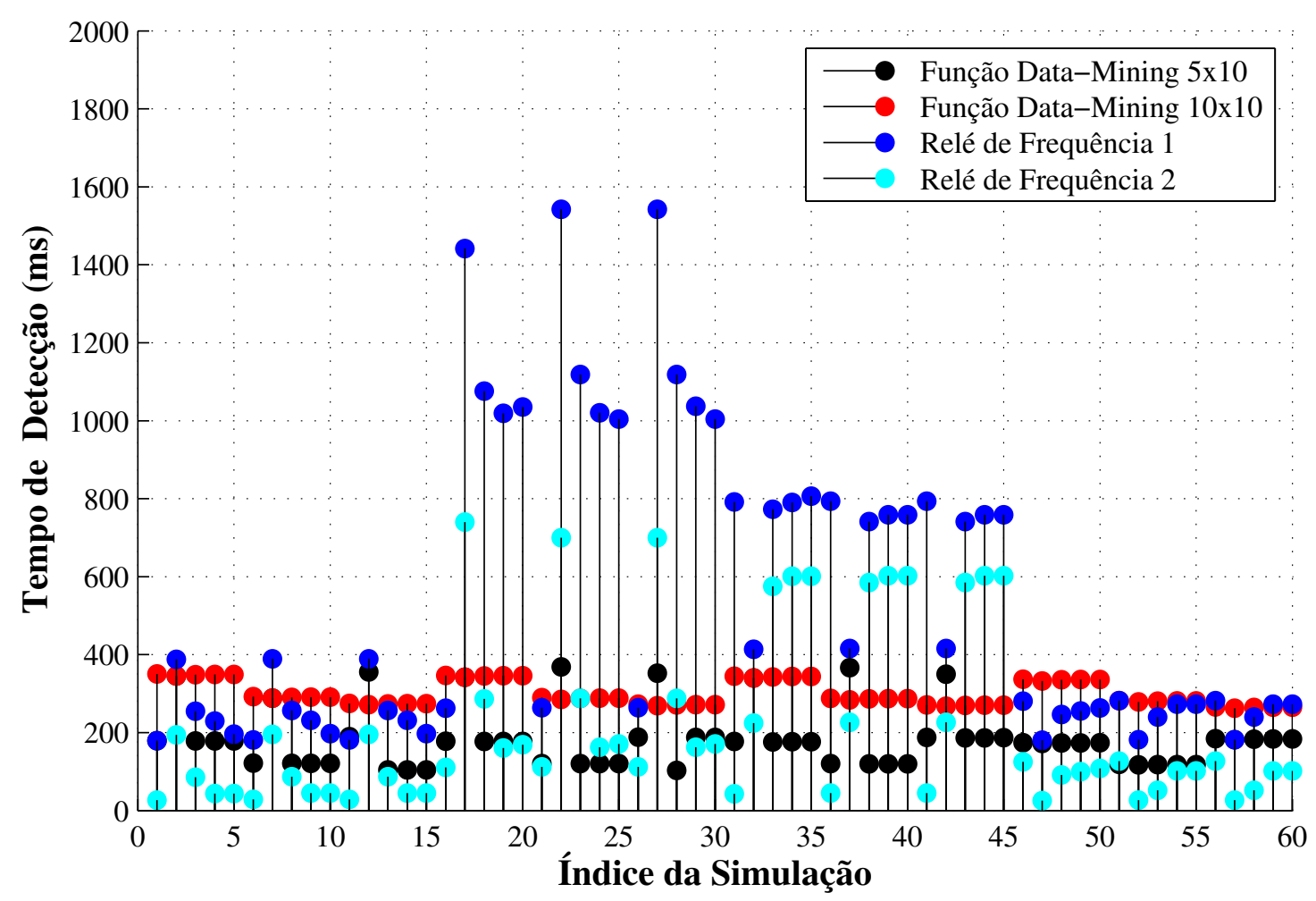

Figura 6.3 - Teste de desempenho geral dos algoritmos de proteção anti-ilhamento.

Tabela 6.7 - Tempo de detecção médio dos algoritmos de proteção anti-ilhamento

\begin{tabular}{|c|c|}
\hline $\begin{array}{c}\text { Esquema de proteção } \\
\text { anti-ilhamento }\end{array}$ & $\begin{array}{c}\text { Tempo de detecção } \\
\text { médio (ms) }\end{array}$ \\
\hline Função data-mining 5x10 & 183 \\
\hline Função data-mining 10x10 & 299,8 \\
\hline Relé de frequência 1 & 545,8 \\
\hline Relé de frequência 2 & 216,1 \\
\hline
\end{tabular}

De um modo geral, a função data-mining com $n$ igual a 5 ciclos apresenta tempos de detecção menores que o de 10 ciclos devido à própria característica de utilizar menos ciclos para a tomada de decisão. No entanto, o uso da rotina contador de ilhamento suspeito se faz mais necessária para a função data-mining de $n=5$ ciclos, visto que a qualidade da classificação obtida pelo DAMICORE é menor. 3\% dos grupos de ilhamento para a função data-mining de $n=5$ ciclos possuem 3 classes, enquanto que para a função data-mining de $n=10$ ciclos não existem grupos de ilhamento com três classes distintas. Por isso, em alguns casos o tempo de detecção é maior que a função data-mining de $n=10$ ciclos. Em ambas as funções data-mining os tempos de detecção não ultrapassam a marca de $500 \mathrm{~ms}$. 
O relé de frequência 2 é o mais rápido para detectar o ilhamento, embora essa resposta seja sensibilizada com o desbalanço de potência ativa. Isso implica em casos nos quais essa proteção pode apresentar respostas lentas para detectar o ilhamento, ultrapassando $600 \mathrm{~ms}$. Além disso, como consequência de ajustes mais sensíveis do relé de frequência 2 em relação ao relé de frequência 1, verificou-se casos de atuação indevida para o relé de frequência 2 durante os 180 testes de desempenho geral.

Para avaliar o desempenho das proteções anti-ilhamento frente aos casos propostos no teste de desempenho geral definiu-se três índices. Estes índices, confiabilidade, segurança e precisão são apresentados na referência [32] e podem ser calculados conforme as equações $6.1 ; 6.2$ e 6.3 .

$$
\begin{gathered}
\text { Confiabilidade }=\frac{\mathrm{ID}}{\mathrm{I}} \times 100 \\
\text { Segurança }=\frac{\mathrm{NID}}{\mathrm{NI}} \times 100 \\
\text { Precisão }=\frac{\mathrm{ID}+\mathrm{NID}}{\mathrm{T}} \times 100
\end{gathered}
$$

\footnotetext{
Em que:

ID $-\mathrm{n}^{\mathrm{o}}$ de casos de ilhamento detectados;

$\mathrm{I}-\mathrm{n}^{\mathrm{o}}$ de casos de ilhamento;

NID $-\mathrm{n}^{\mathrm{o}}$ de casos de não-ilhamento detectados;

$\mathrm{NI}-\mathrm{n}^{\mathrm{o}}$ de casos de não-ilhamento;

$\mathrm{T}-\mathrm{n}^{\circ}$ total de casos.
}

Na Tabela 6.8 são apresentados os resultados dos índices confiabilidade; segurança e precisão para o relé de frequência 2 frente às simulações apresentadas no teste de desempenho geral. Para as demais funções de proteção anti-ilhamento, como não houve casos de atuação indevida, os resultados dos índices propostos em [32] é de 100\%.

Tabela 6.8 - Desempenho geral do relé de frequência 2

\begin{tabular}{|c|c|}
\hline Índice & Resultado \\
\hline Confiabilidade & $100 \%$ \\
Segurança & $83,33 \%$ \\
Precisão & $88,89 \%$ \\
\hline
\end{tabular}


Os casos de atuação indevida do relé de frequência 2 ocorreram em casos específicos das simulações de faltas fase-terra. A Tabela 6.9 apresenta quais foram essas situações.

Tabela 6.9 - Casos de atuação indevida do relé de frequência 2

\begin{tabular}{|c|c|c|}
\hline $\begin{array}{c}\text { Casos de } \\
\text { Atuação Indevida }\end{array}$ & $\begin{array}{c}\text { Referência de Potência } \\
\text { Ativa do GS }(\boldsymbol{p} . \boldsymbol{u})\end{array}$ & $\begin{array}{c}\text { Localização } \\
\text { da Falta }\end{array}$ \\
\hline 1 & 0,05 & Carga k10 \\
2 & 0,4 & Cargas k10; k6 e k9 \\
3 & 0,94 & Cargas k10; k6 e k9 \\
\hline
\end{tabular}

\subsubsection{Teste de variação do desbalanço de potência ativa}

Os testes de variação do desbalanço de potência ativa são feitos do seguinte modo. Primeiramente fixa-se um dos cenários de carga da Tabela 6.10 (observe que o carregamento é configurado de acordo com o estado dos disjuntores do sistema elétrico da Figura 4.7). Na sequência deve-se ajustar a referência de controle de potência ativa do gerador distribuído e considerar fator de potência unitário. Portanto, varia-se a referência de potência ativa do gerador de 1 a 0,1 p.u (na base de 12,6 MVA) e mantem-se a referência de potência reativa igual a 0 , montando 451 situações de ilhamento para cada um dos cenários de carga. Para todas as simulações realizadas durante este teste, o ilhamento ocorre ao desligar o disjuntor $\mathrm{k} 0$ no instante $5 s$ de simulações com duração de $10 s$ cada. Desse modo, os testes mostram o tempo de detecção (em $m s$ ) dos esquemas de proteção anti-ilhamento (função data-mining e relé de frequência) em função do desbalanço de potência ativa entre carga e geração. Da Figura 6.4 à Figura 6.6 são apresentados os resultados destes testes.

Tabela 6.10 - Cenários de carga para testes dos esquemas de proteção anti-ilhamento.

\begin{tabular}{|c|c|c|c|c|c|c|c|}
\hline $\begin{array}{c}\text { Cenário de } \\
\text { Carga }\end{array}$ & \multicolumn{6}{|c|}{ Estado dos Disjuntores } & \multicolumn{3}{|c|}{ Carregamento } \\
k310 & \multicolumn{1}{|c|}{ k6 } & k9 & $\mathbf{k} 8$ & P (MW) & Q (Mvar) \\
\hline I & 1 & 1 & 1 & 1 & 1 & 11,16 & 5,16 \\
II & 0 & 0 & 1 & 1 & 1 & 6,62 & 2,83 \\
III & 1 & 1 & 0 & 0 & 0 & 4,54 & 2,33 \\
\hline
\end{tabular}

Nos testes apresentados na Figura 6.4 a Figura 6.6 quando o desbalanço de potência ativa $(\Delta \mathrm{P})$ for negativo, existe excesso de $\mathrm{P}$ e quando $\Delta \mathrm{P}$ for positivo, existe déficit de $\mathrm{P}$ antes da ocorrência do ilhamento. Para que fique claro, $\Delta \mathrm{P}$ é dado pela equação 6.4. Além disso, há uma descontinuidade no comportamento do tempo de detecção do ilhamento para o relé de 
frequência 1. Esse comportamento é influenciado pelo cenário de carga (I, II, ou III), pois como as cargas foram modeladas como impedância constante os valores de $\Delta \mathrm{P}$ podem variar dinamicamente em função da tensão e corrente que variam durante a ocorrência do ilhamento. Portanto, considerando que o comportamento $\Delta \mathrm{P}$ é dinâmico, antes da descontinuidade é caracterizado cenário de excesso $\mathrm{P}$ e após a descontinuidade é caracterizado déficit de $\mathrm{P}$ durante o ilhamento.

$$
\Delta \mathrm{P}=P_{\text {consumido }}-P_{\text {gerado }}
$$

\section{Cenário de carga I}

Nos testes para o cenário de carga I (Figura 6.4) nota-se que, em função do desbalanço de potência ativa $(\Delta \mathrm{P})$, ambas as funções data-mining tendem a apresentar tempos de detecção do ilhamento com comportamentos constantes, enquanto que o relé de frequência tem sua resposta influenciada diretamente por esse desbalanço. Neste cenário de carga I, o ilhamento é detectado pela função data-mining de 10 ciclos dentro da faixa de 300 a $600 \mathrm{~ms}$, enquanto que a função data-mining de 5 ciclos detecta o ilhamento dentro da faixa de 100 a $200 \mathrm{~ms}$. Já o tempo de detecção do relé de frequência pode ultrapassar $800 \mathrm{~ms}$. No entanto, observe que quando o desbalanço de potência ativa situa-se entre -1 a $1 \mathrm{MW}$ ou de $7 \mathrm{MW}$ em diante o relé de frequência é mais rápido se comparado com a função data-mining de 10 ciclos.

\section{Cenário de carga II}

Nos testes para o cenário de carga II (Figura 6.5), em termos de comportamento, as proteções respondem de modo similar ao dos testes do cenário de carga I. No entanto, ambas às funções data-mining (5 e 10 ciclos) apresentaram melhorias no seu desempenho, com respostas mais rápidas ao realizar o mesmo procedimento de variar o $\Delta \mathrm{P}$ através do gerador distribuído. 


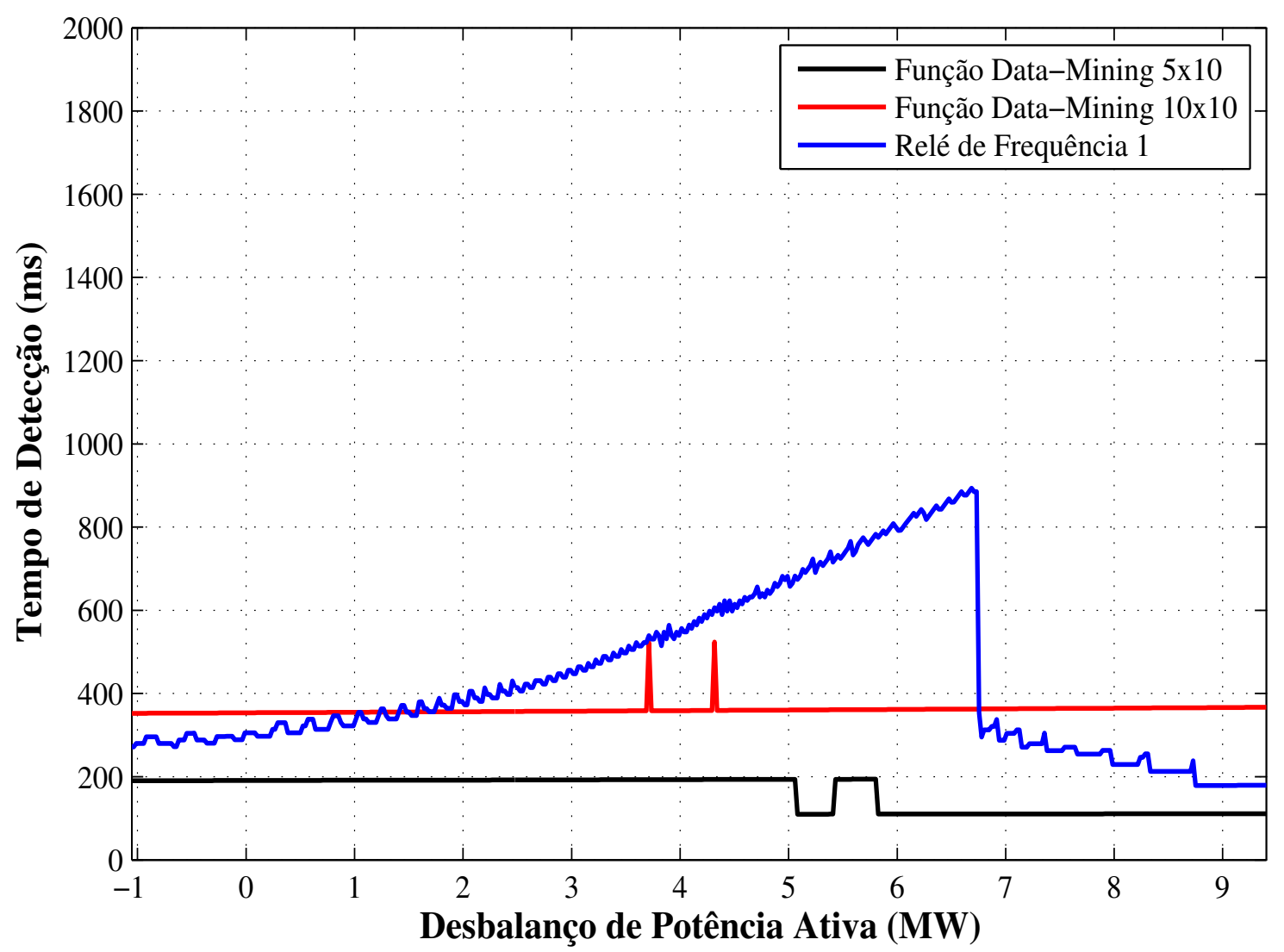

Figura 6.4 - Teste de variação do desbalanço de potência ativa para o cenário de carga I.

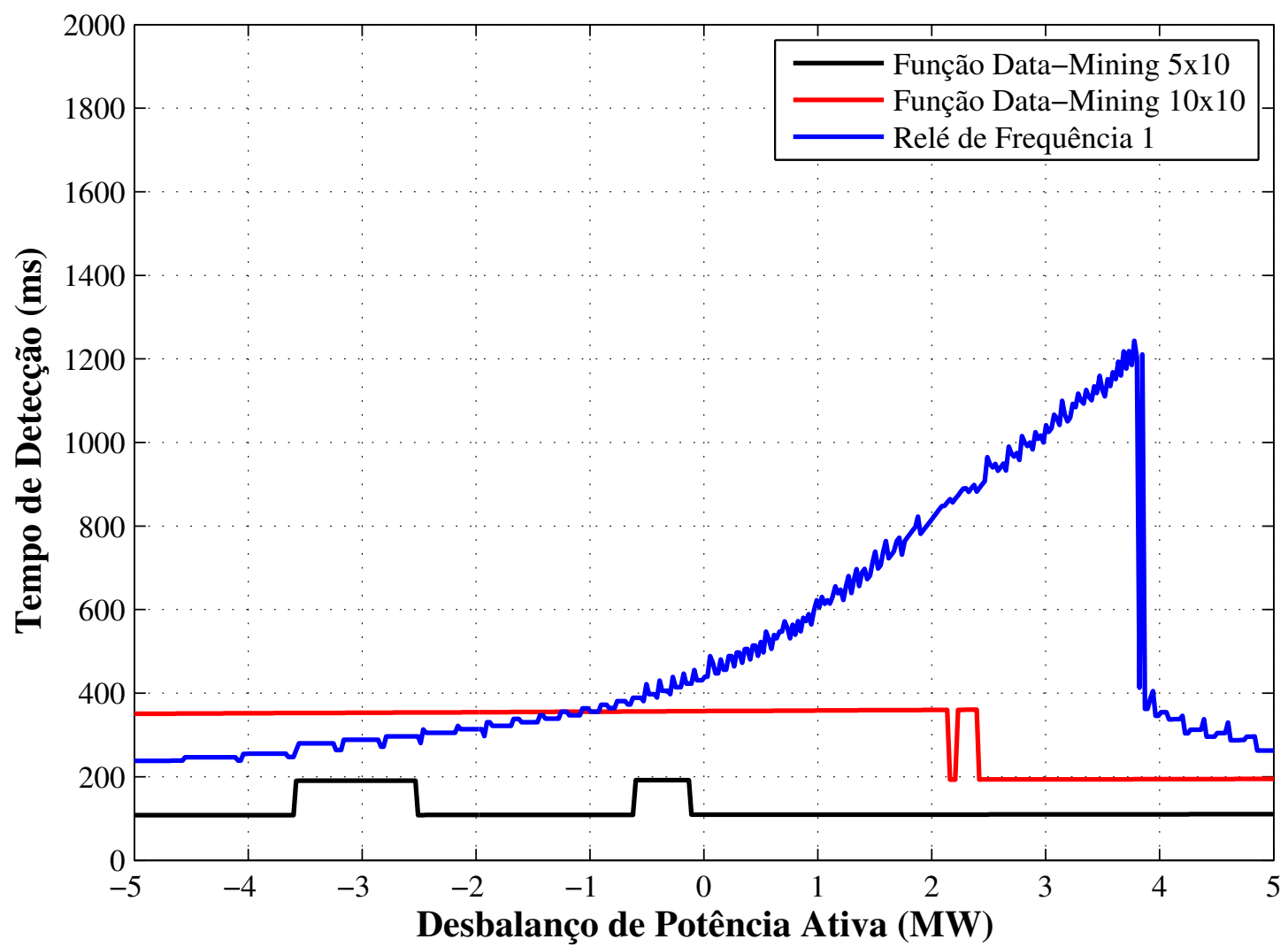

Figura 6.5 - Teste de variação do desbalanço de potência ativa para o cenário de carga II. 
Observe que o tempo de detecção do ilhamento para a função data-mining de 10 ciclos não ultrapassa os $400 \mathrm{~ms}$. Já a função data-mining de 5 ciclos detecta o ilhamento dentro da faixa de 100 a 200 ms. No entanto, nestes testes para o cenário de carga II (Figura 6.5), a maior parte das simulações possui tempos de detecção por volta dos $100 \mathrm{~ms}$, enquanto que, para os testes do cenário de carga I, a maior parte das simulações possui tempos de detecção por volta dos $200 \mathrm{~ms}$. Isso mostra que para este cenário de carregamento II, a rotina de contagem de suspeita de ilhamento (TripCounter) fez-se menos necessária, o que corrobora para com a velocidade das funções data-mining. Por outro lado, não houve melhorias no desempenho do relé de frequência. Observe que o tempo de detecção ultrapassa os $1.200 \mathrm{~ms}$. Isso ocorre porque as cargas do sistema elétrico desta dissertação são do tipo impedância constante e isso influencia na capacidade de detecção do ilhamento de relés baseados em medidas da frequência, pois dinamicamente o $\Delta \mathrm{P}$ pode alterar em função da tensão e corrente durante a operação ilhada, logo em função do cenário de carga e de geração a frequência pode variar mais lentamente, o que dificulta a detecção do ilhamento através do relé de frequência 1.

Note que tanto a potência ativa $(\mathrm{P})$ quanto à potência reativa $(\mathrm{Q})$ do cenário de carga II são menores se comparadas com o cenário de carga I (veja a Tabela 6.10). Como a referência de potência reativa do controle do gerador síncrono foi configurada para manter $\mathrm{Q}=0$, o desbalanço de potência reativa $(\Delta \mathrm{Q})$ para este cenário de carga II também é menor. Portanto, esse novo cenário de carga propicia no plano $(\Delta \mathrm{P} \times \Delta \mathrm{Q})$ situações nas quais a frequência está susceptível a variações mais lentas, o que dificulta a detecção do ilhamento pelo relé de frequência. Embora isso ocorra, note que para $\Delta \mathrm{P}$ entre -5 a $-1 \mathrm{MW}$ o relé de frequência é mais rápida do que a função data-mining de 10 ciclos. Apesar de a função data-mining de 5 ciclos ser a mais rápida, observe que a partir de um $\Delta \mathrm{P}=2 \mathrm{MW}$, ambas as funções data-mining possuem desempenho similares, com tempos de detecção na ordem de 200 ms (função data-mining de 10 ciclos) e 100 ms (função data-mining de 5 ciclos).

\section{Cenário de carga III}

Nos testes para o cenário de carga III (Figura 6.6), entre os três testes, montam casos nos quais é mais difícil detectar o ilhamento a partir de medidas baseadas na frequência fundamental. Há casos nos quais o relé de frequência, ajustado conforme a Tabela 6.3, não detecta o ilhamento dentro dos limites de $2.000 \mathrm{~ms}$. Isso ocorre quando o $\Delta \mathrm{P}$ está entre 
2 a 3 MW. Embora, exclusivamente para este cenário de carga III, em alguns casos, o relé de frequência foi mais rápido do que ambas as funções data-mining. Note que isso acontece quando o $\Delta \mathrm{P}$ está entre -7 a $-3 \mathrm{MW}$.

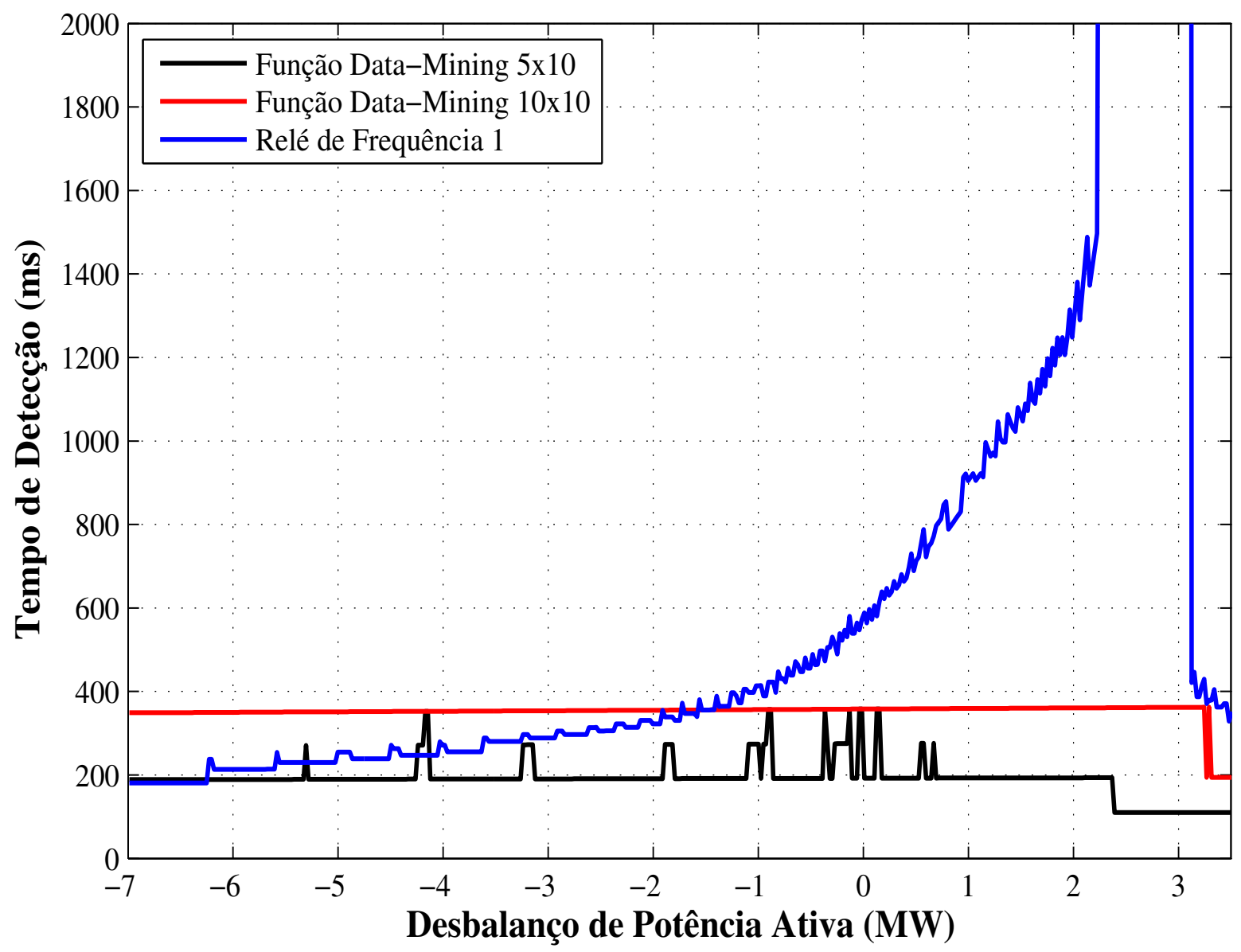

Figura 6.6 - Teste de variação do desbalanço de potência ativa para o cenário de carga III.

Ao comparar somente a função data-mining de 10 ciclos, a faixa de $\Delta \mathrm{P}$ em que se obtém melhor desempenho com o relé de frequência é maior, situando-se entre -7 a -1,5 MW. De um modo geral, o comportamento da função data-mining de 10 ciclos segue a tendência de ser constante quanto ao tempo de detecção do ilhamento. Note que, ao longo do eixo $\Delta \mathrm{P}$, esse tempo de detecção é próximo de $400 \mathrm{~ms}$ e em alguns casos pode chegar a $200 \mathrm{~ms}$. Na função data-mining de 5 ciclos, para a maioria dos casos, o tempo de detecção situa-se entre 100 a $200 \mathrm{~ms}$. No entanto, nota-se que foram encontrados casos específicos nos quais o tempo de detecção pode chegar próximo aos $400 \mathrm{~ms}$.

Isso mostra que o desempenho de ambas as funções data-mining podem se igualar, uma vez que elas consideram uma rotina de confirmação de ilhamento suspeito. Essa rotina evita que as proteções atuem para eventos nos quais não foram projetadas, corroborando para 
com a segurança do método empregado nesta dissertação. Porém, dependendo do $\Delta \mathrm{P}$ na ilha, é possível alcançar respostas mais rápidas com o relé de frequência, enquanto que as funções data-mining auxiliam nas situações em que a detecção através do relé de frequência é mais penosa. Portanto ambas as funções, data-mining com $n=5$ ciclos e relé de frequência 1 podem ser utilizadas de forma redundante para obter melhor desempenho para a proteção contra ilhamento.

\subsection{Análise da frequência e tensão durante o ilhamento}

Nesta seção serão apresentadas as análises do comportamento da frequência e da tensão durante casos específicos de ilhamento. Os casos escolhidos estão apresentados na Tabela 6.11. Observe que foram selecionadas 4 simulações correspondentes aos testes das proteções anti-ilhamento para o cenário de carga II (veja a Tabela 6.10 e a Figura 6.5). Nessas simulações, o ilhamento foi configurado para acontecer em $t=5 \mathrm{~s}$. Observe que as simulações podem pertencer a Região 1 ou a Região 2 na curva de desbalanço de potência ativa, isto é, o $\Delta \mathrm{P}$ correspondente situa-se antes do tempo máximo de detecção do relé de frequência (Região 1) ou após o tempo máximo de detecção do relé de frequência (Região 2). Adicionalmente, para os mesmos casos da Tabela 6.11, é apresentada a resposta do relé de frequência, possibilitando verificar qual dos ajustes desencadeou o processo de detecção do ilhamento.

Tabela 6.11 - Configuração dos testes de análise da frequência e tensão durante ilhamento.

\begin{tabular}{|c|c|c|c|}
\hline Simulação & $\begin{array}{c}\text { Cenário de } \\
\text { Carga }\end{array}$ & $\begin{array}{c}\text { Desbalanço de } \\
\text { Potência Ativa }(\Delta \mathbf{P})\end{array}$ & $\begin{array}{c}\text { Característica da } \\
\text { curva de desbalanço }\end{array}$ \\
\hline $\mathbf{1}$ & & $0 \mathrm{MW}$ & Região 1 \\
$\mathbf{2}$ & & $1 \mathrm{MW}$ & \\
$\mathbf{3}$ & II & $4 \mathrm{MW}$ & Região 2 \\
\cline { 3 - 4 } & & $5 \mathrm{MW}$ & \\
\hline
\end{tabular}


Na Figura 6.7 são apresentados o comportamento da frequência (Figura 6.7a) e da tensão (Figura 6.7b) referentes à simulação 1. Nesse caso, mediu-se antes da ocorrência do ilhamento, com o sistema operando em regime permanente, um valor de $\Delta \mathrm{P}=0 \mathrm{MW}$. Intuitivamente, a frequência após a ocorrência do ilhamento, para esta simulação 1, não deveria variar, uma vez que o $\Delta \mathrm{P}$ possui acoplamento forte com a frequência do sistema elétrico. Isso não ocorre (veja na Figura 6.7a que a frequência aumenta ao longo do tempo), pois é preciso levar em conta que as cargas são do tipo impedância constante e há déficit de potência reativa $\left(\mathrm{Q}_{\text {gerado }}<\mathrm{Q}_{\text {consumido }}\right)$ no sistema. Estando em déficit, com o gerador no modo de controle PQ e com a referência de controle configurada em $\mathrm{Q}=0 \mathrm{MW}$, logo após o ilhamento, note na Figura $6.7 \mathrm{~b}$ que a tensão tende a diminuir exponencialmente, pois o $\Delta \mathrm{Q}$ está em acoplamento forte com a tensão. Como a taxa de variação da tensão é negativa, a potência ativa das cargas se reduz e o $\Delta \mathrm{P}$ aumenta, levando a taxa de variação da frequência ser positiva.

Somadas estas condições: modelo de carga, característica no plano $(\Delta \mathrm{P} \times \Delta \mathrm{Q})$ e controle do gerador, o desempenho das funções de proteção anti-ilhamento baseadas na frequência podem variar. Ainda neste caso da simulação 1, por consequência da elevação na frequência ao longo do tempo, o ilhamento foi detectado pelo relé de frequência aos $5,441 \mathrm{~s}$ através da função de sobrefrequência (810) temporizada. Note que, com a função de sobrefrequência instantânea, ajustada em $+61,5 \mathrm{~Hz}$, o tempo de detecção do ilhamento seria maior, chegando a 5,766 s. Além disso, a tensão mínima de operação do relé de frequência acontece para $t=5,91 \mathrm{~s}$. Portanto, ambas as funções de sobrefrequência, de fato, poderiam detectar o ilhamento para esse caso, embora a função de sobrefrequência temporizada, ajustada conforme mostra a Figura 6.7 seja mais rápida e pode atuar em um tempo menor que $500 \mathrm{~ms}$. 


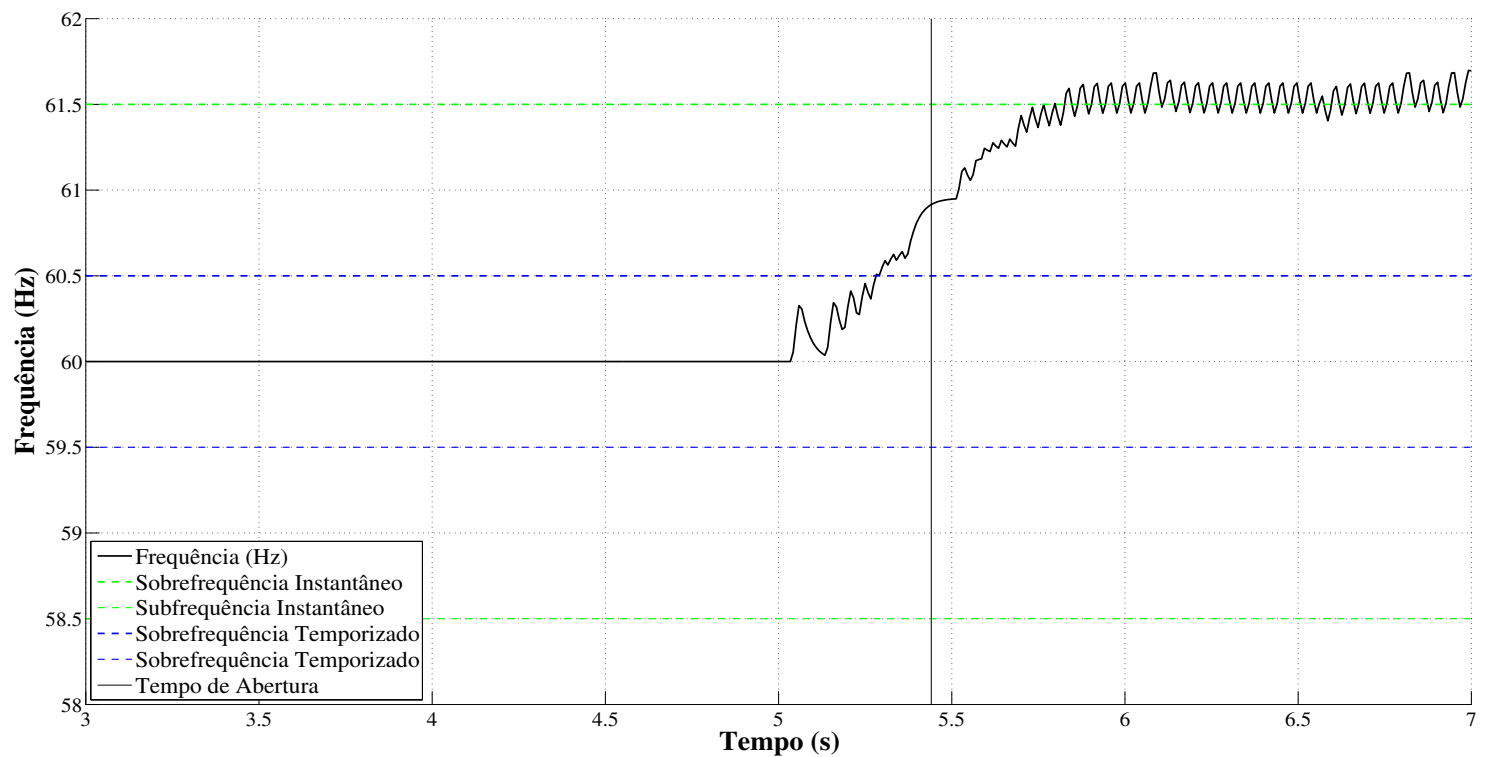

(a) - Frequência

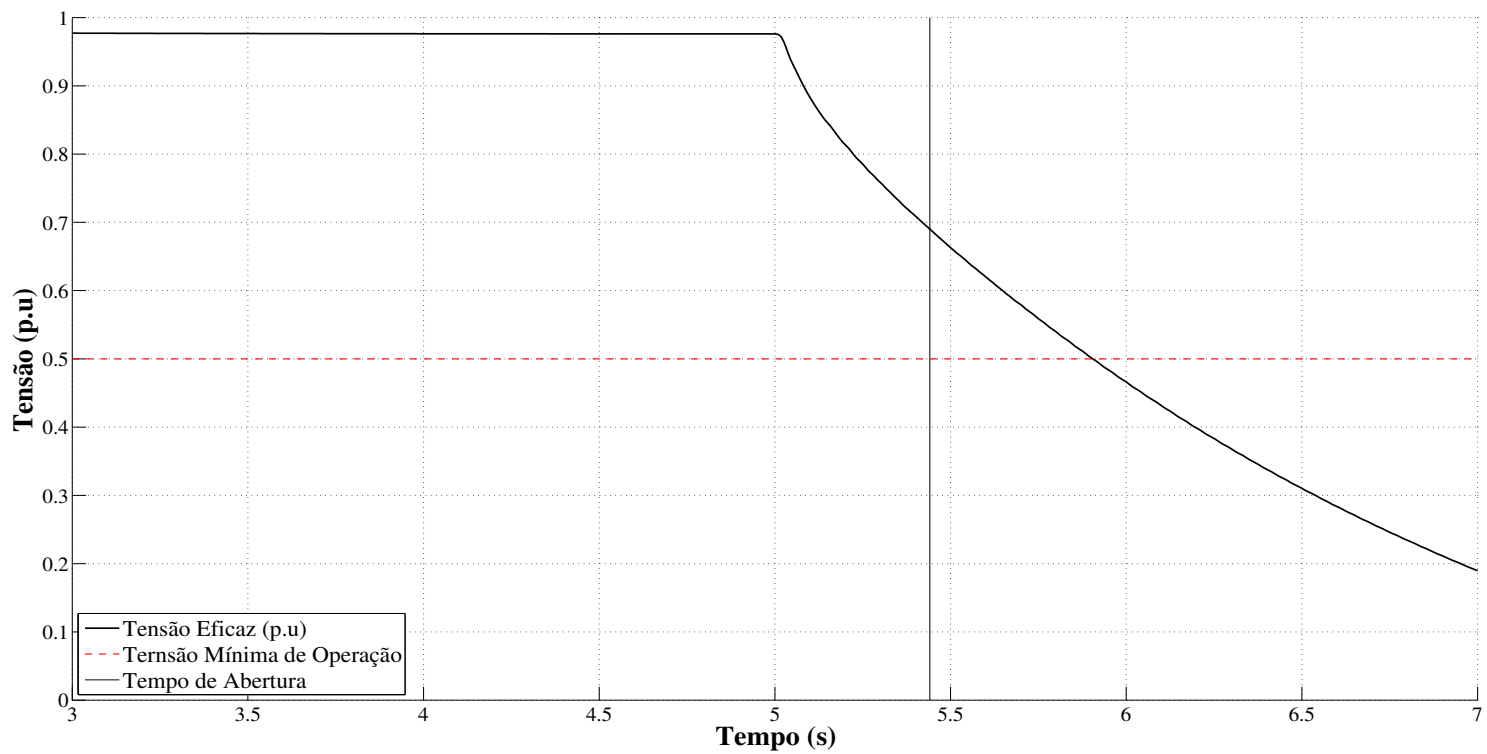

(b) - Tensão

Figura 6.7 - Assinatura da frequência e da tensão durante ilhamento com $\Delta P$ de 0 MW.

Na Figura 6.8 são apresentados o comporamento da frequência (Figura 6.8a) e da tensão (Figura 6.8b) referentes à simulação 2. Antes da ocorrência do ilhamento mediu-se um cenário de déficit de geração, onde $\Delta \mathrm{P}=1 \mathrm{MW}$. Em termos de comportamento, esse caso é bastante similar ao apresentado na Figura 6.7. A frequência em (a) tende a subir, enquanto que a tensão em (b) decai exponencialmente. Esse comportamento se repete ao longo das simulações contidas na Região 1 . No entanto, note que a frequência nesta simulação 2 varia mais lentamente, logo o relé de frequência também levará mais tempo para detectar o ilhamento. Isso se deve a redução de potência ativa (P) fornecida pelo gerador distribuído. Após o ilhamento, a diminuição na tensão reduz o consumo de potência ativa, uma vez que as 
cargas foram modeladas com impedância constante. Como o tempo de detecção tende a aumentar, veja na Figura 6.5 que isso acontece para a faixa $(-5<\Delta \mathrm{P}<4 \mathrm{MW})$, é possível concluir que, dinamicamente, após o ilhamento, o $|\Delta \mathrm{P}|$ tenha atingido valores menores que no caso da Simulação 1. Esse $|\Delta \mathrm{P}|$ menor torna a frequência susceptível a variações lentas. Note que, nesta Simulação 2, a frequência durante o ilhamento não conduz ao acionamento, em momento algum, da função 810 instantânea. Portanto, assim como no caso da simulação 1, o ilhamento é detectado em $t=5,608 \mathrm{~s}$ pela função 810 temporizada. Adicionalmente, não houve problemas quanto à operação do relé de frequência, uma vez o valor de tensão mínima de operação $(0,5$ p.u) ocorre em $t=5,9 \mathrm{~s}$.

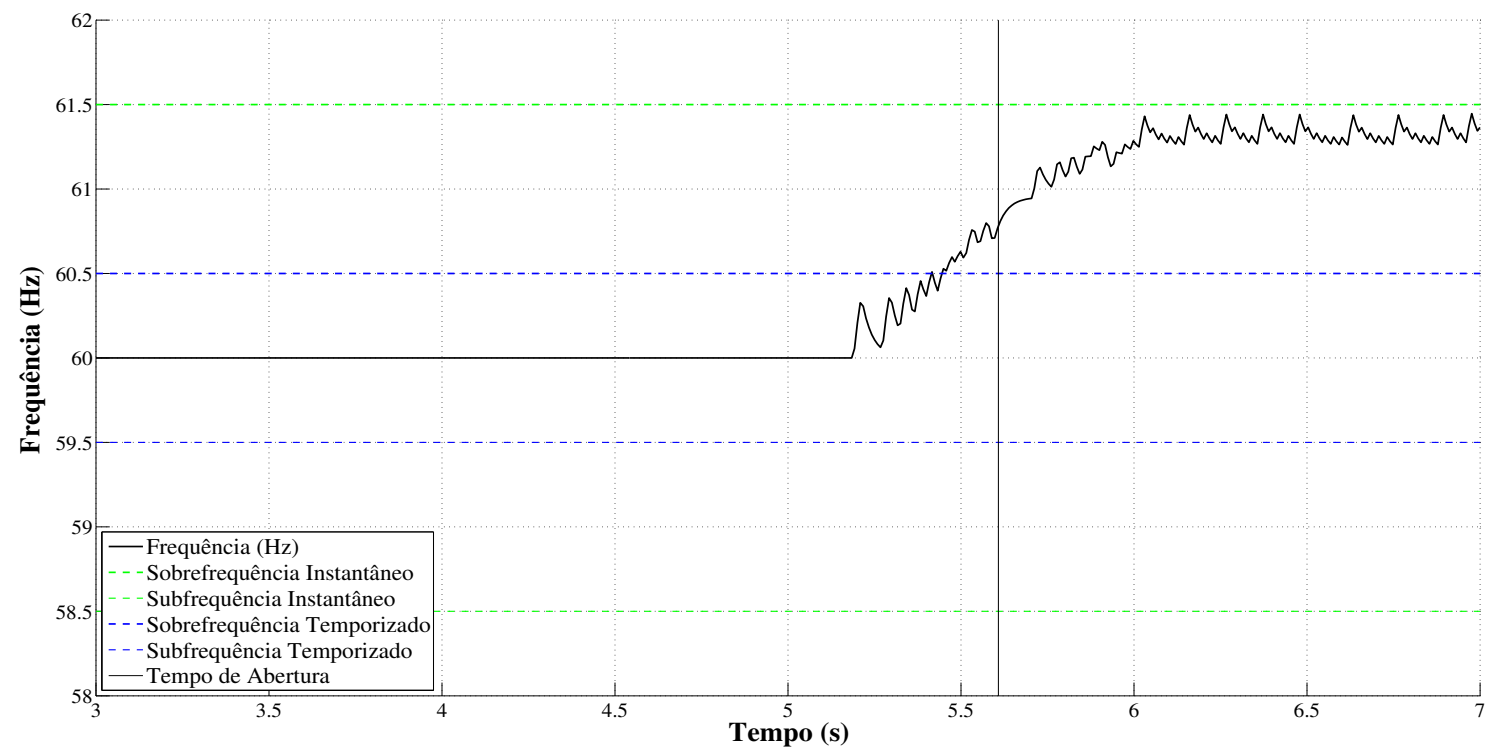

(a) - Frequência

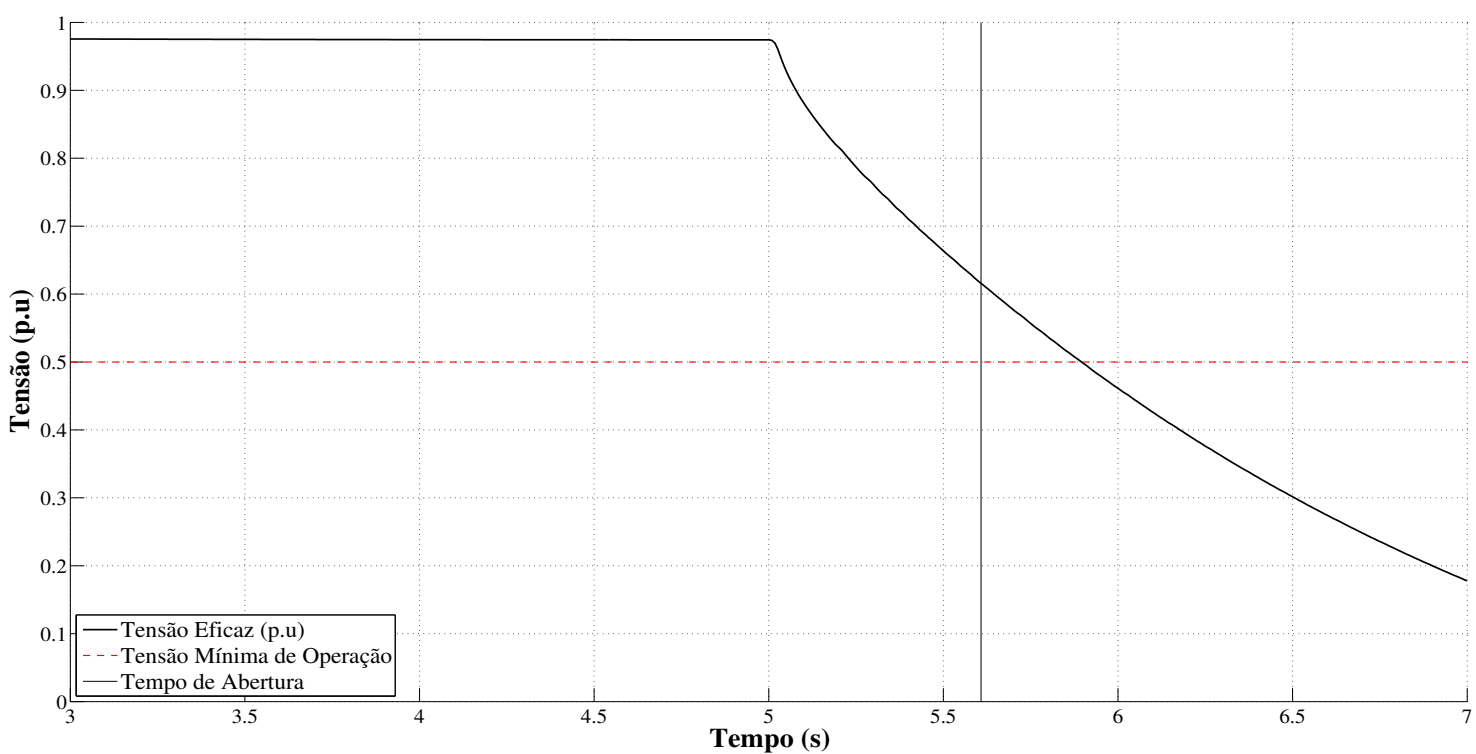

(b) - Tensão

Figura 6.8 - Assinatura da frequência e da tensão durante ilhamento com $\Delta \mathrm{P}$ de $1 \mathrm{MW}$. 
Na Figura 6.9 são apresentados o comportamento da frequência (Figura 6.9a) e da tensão (Figura 6.9b) referentes à simulação 3. Antes da ocorrência do ilhamento mediu-se um cenário de déficit de geração, onde $\Delta \mathrm{P}=4 \mathrm{MW}$. Assim como nas simulações 1 e 2 , a tensão (Figura 6.9b) se comporta como curva de decaimento exponencial. Já a frequência (Figura 6.9a), não obstante das simulações 1 e 2, tende a diminuir instantes após o ilhamento. Essa queda na frequência ocorre porque há déficit de potência ativa $\left(\mathrm{P}_{\text {gerado }}<\mathrm{P}_{\text {consumido }}\right)$. Passados $t=5,3 \mathrm{~s}$, a taxa de variação da frequência passa a ser positiva.

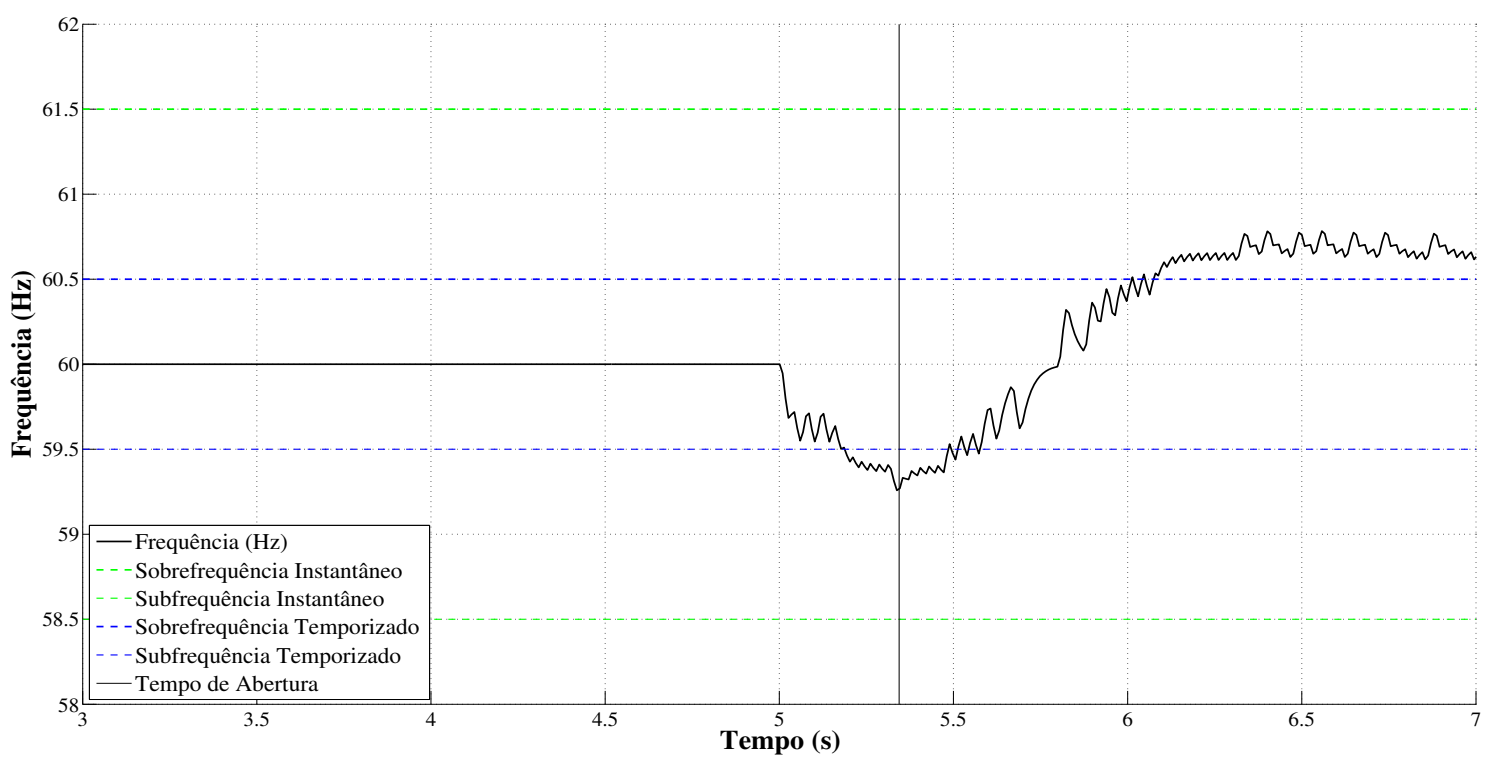

(a) - Frequência

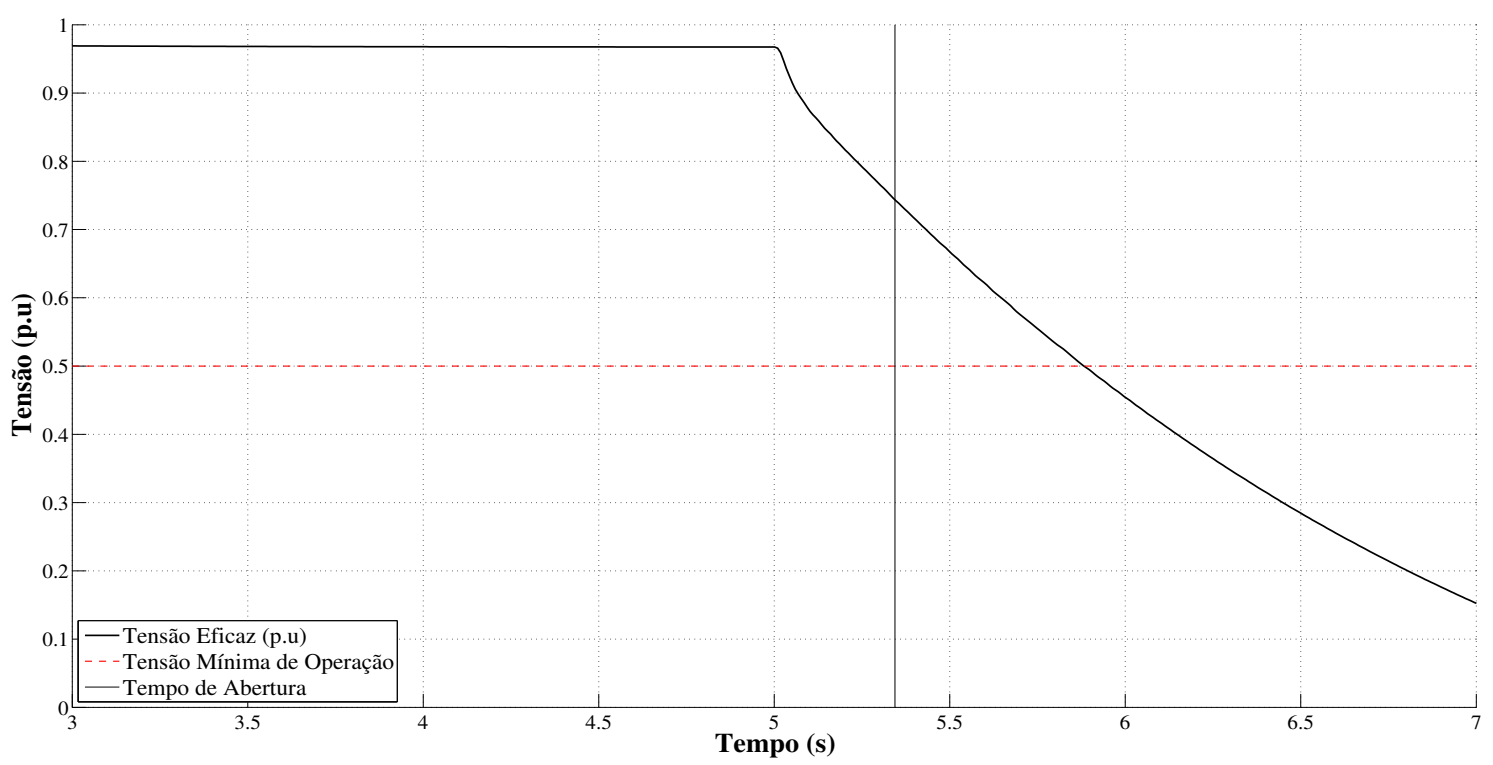

(b) - Tensão

Figura 6.9 - Assinatura da frequência e da tensão durante ilhamento com $\Delta \mathrm{P}$ de $4 \mathrm{MW}$. 
Este comportamento da Figura 6.9 se repete ao longo das simulações contidas na Região 2. Assim como nos casos anteriores, o aumento na frequência se deve às cargas serem do tipo impedância constante e pelo déficit de potência reativa. Assim sendo, a diminuição da tensão, reduz a potência ativa consumida pelas cargas e isso reflete na resposta da frequência do sistema. Caso haja excesso de potência ativa $\left(\mathrm{P}_{\text {gerado }}>\mathrm{P}_{\text {consumido }}\right)$, a resposta natural do sistema é que a frequência aumente. Nesta simulação 3, o ilhamento é detectado em $t=5,371 \mathrm{~s}$ pela função de subfrequência (81U) temporizada. Note que, como a frequência logo assume comportamento ascendente, a função $81 \mathrm{U}$ instantânea não é acionada. Além disso, nesta simulação 3, o ilhamento não poderia ser detectado com a função 810 temporizada ou instantânea, pois no momento em que a frequência ultrapassa o limiar de sobrefrequência temporizada, $t=6 \mathrm{~s}$, a tensão é menor que a restrição de 0,5 p.u.

Na Figura 6.10 é apresentado o comportamento da frequência (Figura 6.10a) e da tensão (Figura 6.10b) referentes à simulação 4. Este caso, assim como o caso da simulação 3, pertencem à Região 2 da curva (tempo de detecção $\times$ desbalanço de potência ativa), portanto o comportamento da tensão e da frequência serão semelhantes para ambas as simulações. No entanto, nesta simulação 4 (Figura 6.10), logo após o ilhamento, a frequência tende a cair mais rapidamente. A potência ativa fornecida pelo gerador distribuído na simulação 4 é menor que na simulação $3, \operatorname{logo} \mathrm{o}|\Delta \mathrm{P}|$ na simulação 4 é maior. Isso pode auxiliar na detecção do ilhamento com as funções $81 \mathrm{U}$ instantânea ou temporizada. Como consequência de uma queda mais brusca, se comparada com a simulação 3, a taxa de variação da frequência (Figura 6.10a) demora mais tempo para se tornar positiva. Isso acontece em $t>5,5 \mathrm{~s}$ e somente em em $t>6 s$ a frequência ultrapassa o ajuste de sobrefrequência temporizada. Como esse tempo é demasiadamente longo a detecção do ilhamento pela função 810 instantânea ou temporizada não ocorre. Nesta simulação 4, o ilhamento foi detectado em $t=5,261 \mathrm{~s}$ pela função $81 \mathrm{U}$ temporizada. 


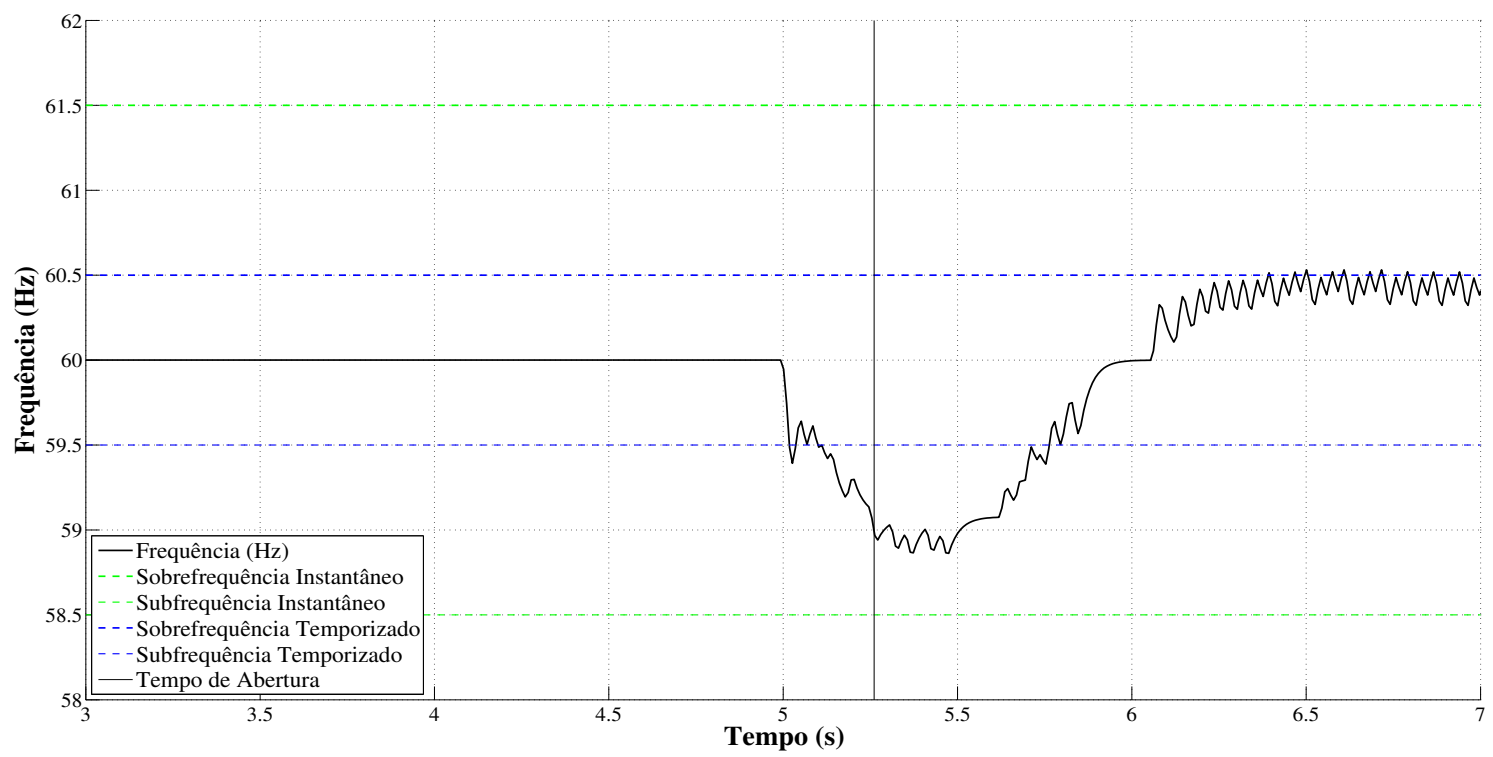

(a) - Frequência

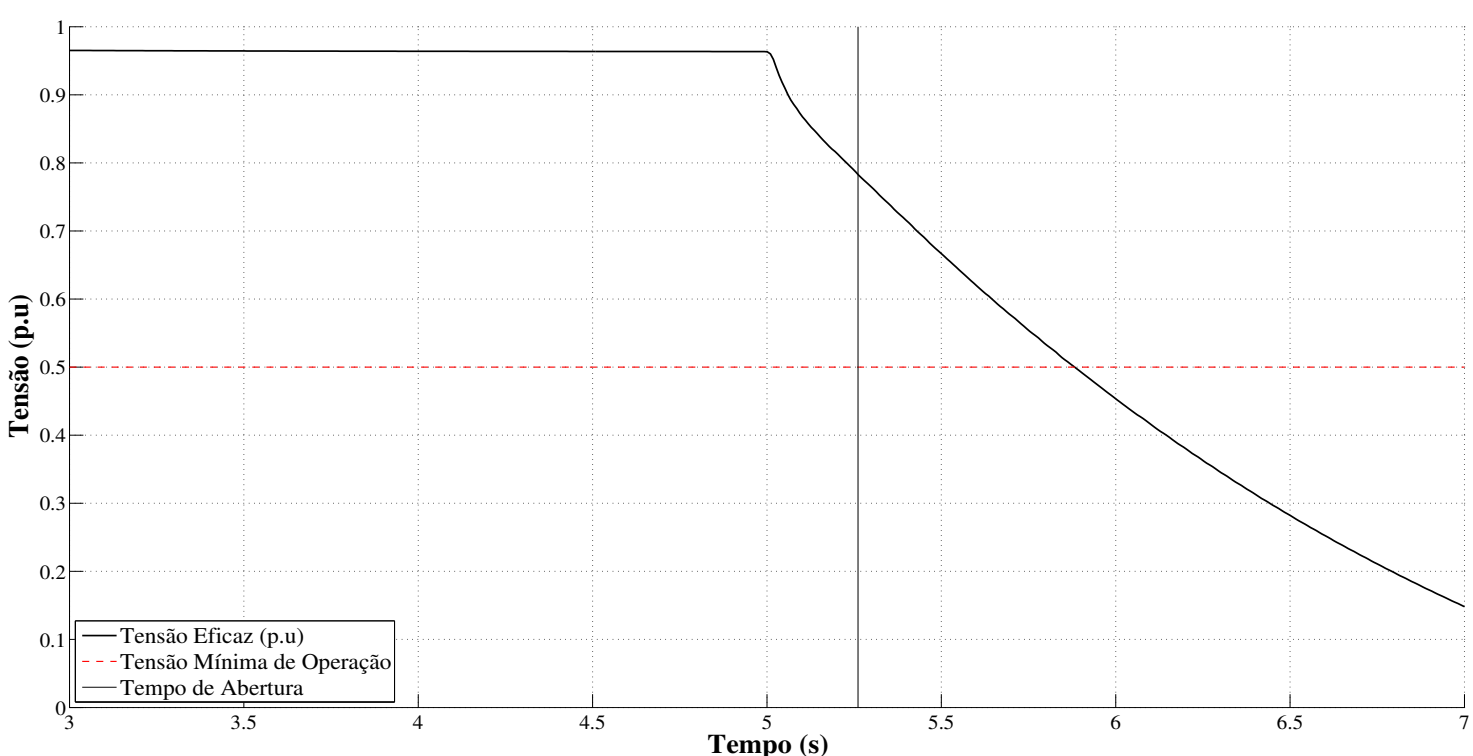

(b) - Tensão

Figura 6.10 - Assinatura da frequência e da tensão durante ilhamento com $\Delta \mathrm{P}$ de 5 MW. 



\section{CAṔ́TULO 7}

\section{Conclusões}

Esta dissertação de mestrado está inserida no contexto de proteção de sistemas elétricos de distribuição com GD. Trata-se de uma nova técnica passiva-inteligente de proteção anti-ilhamento para geradores síncronos distribuídos. O método proposto utiliza a mineração de dados do DAMICORE para formular um novo algoritmo de decisão, intitulado função data-mining, capaz de identificar ilhamentos com medidas locais.

Sobre uma ótica de implementações, algumas contribuições foram alcançadas. Uma delas em especial foi o desenvolvimento de uma versão do DAMICORE para MATLAB. Funcionalidades adicionais foram integradas ao método, tal como o emprego da métrica euclidiana, que pode lidar com problemas exclusivamente numéricos, como é o caso do ilhamento, sendo mais rápida por dispensar o uso de técnicas de compressão para ser calculada, como é o caso da Normalized Compression Distance (NCD), que pode lidar com qualquer domínio de dado. Adicionalmente, a versão em MATLAB do DAMICORE realiza automaticamente a normalização dos dados e remove automaticamente dados em duplicata, o que corrobora para realizar análises mais qualitativas sobre os mesmos. A próxima contribuição é o algoritmo vetor de características. O método pré-processa os sinais de tensão e corrente trifásicas medidas no PAC de modo a extrair 10 características, das quais, podem ser encontradas nos esquemas de proteção anti-ilhamento passivos para geradores síncronos. Essas 10 características são oferecidas simultaneamente como entradas para o DAMICORE realizar as análises e posteriormente são utilizadas para detectar o ilhamento com o algoritmo função data-mining.

A técnica função data-mining pode ser utilizada somente após a fase de interpretação dos padrões, os quais são identificados pelas técnicas de mineração de dados do DAMICORE. 
Trata-se de uma etapa de treinamento do método, em que é necessário descobrir padrões que caracterizam situações de ilhamento, diferenciando-o de distúrbios correlatos como chaveamento de carga ou faltas fase-terra. Neste trabalho foram necessárias apenas 39 simulações para formular essa etapa de treinamento. A função data-mining monta uma estrutura de decisão que utiliza a informação obtida pelo DAMICORE e que considera em seu princípio de funcionamento 3 classes. São elas, o ilhamento, o não-ilhamento e a suspeita de ilhamento. Além disso, o método considera dois ajustes. Trata-se do limiar de distância euclidiana mínima (MinDist) e o limiar (TripAlert) de um contador de suspeita de ilhamento. Ambos os ajustes do método e a formulação adequada da etapa de treinamento, que consiste na execução do processo KDD, auxiliam a proteção anti-ilhamento proposta nesta dissertação a detectar todos os casos corretamente, evitando atuações indevidas.

Das análises feitas com o DAMICORE verificaram-se casos que podem ser semelhantes ao ilhamento e a influência da quantidade de ciclos no desempenho do método. À medida que a quantidade de ciclos aumenta, a qualidade das classes que caracterizam o ilhamento é maior. Isso foi confirmado durante as análises por inspeção visual das árvores filogenéticas e comprovou-se que, árvores que consideram mais ciclos, proporcionalmente possuem maior quantidade de clusters de 1 classe, ao passo que clusters contendo 2 ou 3 classes tendem a aparecer com menor frequência. $O$ método tem certa dificuldade de caracterizar o ilhamento logo nos primeiros ciclos. Alguns casos de chaveamento de carga ou faltas fase-terra são similares ao ilhamento. Essa característica tende a se extinguir com o tempo ou ao considerar mais ciclos na classificação. No entanto, quanto mais ciclos, menos rápida e mais segura será a proteção anti-ilhamento. Portanto, deve haver um balanço entre a velocidade e seletividade do método. Para que a proteção atenda esse balanço, projetou-se as funções data-mining de 5 e 10 ciclos.

A etapa final desta dissertação consistiu na comparação de desempenho das funções data-mining e o relé de frequência. Nesse sentido, realizou-se em primeira instância um teste de desempenho geral, no qual foram considerados 180 casos específicos, com diferentes cenários de carga e geração para os seguintes distúrbios: chaveamento de carga, faltas fase-terra e ilhamentos. Nesses testes, as proteções operam corretamente, detectando os casos de ilhamento e não atuando em distúrbios correlatos. Embora o teste de desempenho geral apresente o tempo de detecção das proteções nos casos de ilhamento, os testes de variação do $\Delta \mathrm{P}$ são mais indicados para avaliar o desempenho das proteções em função dos possíveis cenários do ilhamento. Nesses testes as funções data-mining apresentam tempos de detecção geralmente menores que $500 \mathrm{~ms}$, vencendo em desempenho o relé de frequência para a 
maioria dos casos. No geral, a função data-mining de 5 ciclos é a mais rápida, embora em alguns casos seu desempenho seja igual ao da função data-mining de 10 ciclos. Ao variar a potência ativa do gerador de 1 a 0,1 p.u (na base de 12,6 MVA), montando 451 situações de ilhamento para cada um dos 3 cenários de carga, conclui-se que as funções data-mining são pouco afetadas pelo $\Delta \mathrm{P}$, pois o tempo de detecção tende a ser constante. Além disso, verificou-se que as funções data-mining são confiáveis enquanto as referências de controle do gerador síncrono forem a potência ativa na faixa $0,1<\mathrm{P}<1$ p.u com fator de potência unitário, ou seja, potência reativa $Q=0 p . u$. O desempenho do relé de frequência é mais afetado pelas variações no plano $(\Delta \mathrm{P} \times \Delta \mathrm{Q})$ e pelas cargas do tipo impedância constante. Por esse motivo, principalmente nos casos de grandes desbalanços de potência entre carga e geração, é possível obter melhor desempenho com o relé de frequência.

De um modo geral, a melhor solução para proteger o sistema contra o ilhamento, utilizando os métodos apresentados nesta dissertação é utilizar duas proteções operando com redundância. São elas a função data-mining de 5 ciclos e um relé de frequência ajustado. Uma das vantagens de utilizar ambas as funções é que o ajuste do relé de frequência pode ser feito menos sensível, de modo que esse não atue indevidamente para distúrbios correlatos. Portanto, levando em consideração a rapidez dos métodos, o relé de frequência deve ser configurado de modo a operar nos casos de elevado desbalanço de potência ativa, enquanto que a função data-mining detecta o ilhamento quando o desbalanço de potência ativa for menor.

\subsection{Sugestões para trabalhos futuros}

Os conceitos e implementações abordados nesta dissertação abrem espaço para estudar outros tópicos nessa linha de pesquisa. Entre eles destacam-se:

- O emprego da metodologia de mineração de dados do DAMICORE na detecção de ilhamento em sistemas com multi-geradores distribuídos;

- Desenvolvimento de proteção anti-ilhamento com função de auto-apredizagem online através da mineração de dados do DAMICORE;

- O emprego do DAMICORE na tarefa de selecionar ajustes para funções de proteção anti-ilhamento;

- O emprego do DAMICORE e lógica fuzzy na tarefa de detectar o ilhamento. 
Além das sugestões relacionadas à aplicação do DAMICORE no problema da detecção do ilhamento, algumas melhorias relacionadas à versão do DAMICORE para dados exclusivamente numéricos (distância euclidiana) podem ser realizadas, como seguem:

- O emprego de técnica de eliminação de amostras discrepantes ou outliers por distância de Mahanalobis [60];

- Desenvolvimento de técnicas de redução automática de dados em problemas de mineração de dados online.

\subsection{Publicação resultante do trabalho até o momento}

Até o momento esta dissertação de mestrado resultou na seguinte publicação:

- E. A. P. Gomes, J. C. Melo, D. V. Coury, and A. C. Delbem, "Detecção de ilhamento de geradores síncronos distribuídos por identificação de padrões via técnicas de mineração de dados," in Simpósio Brasileiro de Sistemas de Energia Elétrica, SBSE 2016, 2016. 


\section{REFERÊNCIAS BIBLIOGRÁFICAS}

[1] N. Jenkins, R. Allan, P. Crossley, D. Kirschen, and G. Strbac, Embedded generation. London: Institution of Engineering and Technology, 2000.

[2] N. Jenkins, J. B. Strbac, and G. Ekanayake, Distributed Generation. London: Institution of Engineering and Technology, 2010.

[3] J. C. M. Vieira, "Metodologias para ajuste e avaliação do desempenho de relés de proteção anti-ilhamento de geradores síncronos distribuídos," Tese (Doutorado), Faculdade de Engenharia Elétrica e de Computação, Universidade Estadual de Campinas, 2006.

[4] L. B. dos Reis, Geração de energia elétrica, $2^{\mathrm{a}}$ ed. Barueri: Manole, 2011.

[5] MME, "PROINFA - Programa de Incentivo as Fontes Alternativas de Energia Elétrica," 2004. [Online]. Disponível em: http://www.mme.gov.br/programas/proinfa. [Acesso em: 01-Jan-2014].

[6] ANEEL, "BIG - Banco de Informações de Geração," 2015. [Online]. Disponível em: http://www.aneel.gov.br/. [Acesso em: 29-Set-2016].

[7] ANEEL, "Resolução Normativa n ${ }^{\circ}$ 482, de 17 de abril de 2012." [Online]. Disponível em: http://www.aneel.gov.br/. [Acesso em: 01-Jan-2014].

[8] ANEEL, "ANEEL amplia possibilidades para micro e minigeração distribuída," 2015. [Online]. Disponível em: http://www.aneel.gov.br/. [Acesso em: 26-Jan-2016].

[9] MME, "Brasil lança programa de geração distribuída com destaque para energia solar," 2015. [Online]. Disponível em: http://www.mme.gov.br/. [Acesso em: 25-Jan-2016].

[10] G. S. Cardoso, "Uma visão crítica do cenário da geração distribuída no Brasil," Dissertação (Mestrado), Centro de Engenharia, Modelagem e Ciências Sociais Aplicadas, Programa de Pós-graduação em Energia, Universidade Federal do ABC, Santo André, 2009.

[11] W. Freitas, J. C. M. Vieira Jr., A. M. França, L. C. P. Da Silva, and V. F. Da Costa, "Análise comparativa entre geradores síncronos e geradores de indução com rotor tipo gaiola de esquilo para aplicação em geração distribuída," Sba Control. Automação Soc. Bras. Autom., vol. 16, no. 3, 2005. 
[12] A.-M. Borbely and J. F. Kreider, Distributed generation: the power paradigm for the new millennium. Boca Raton: CRC Press Taylor \& Francis Group, LLC, 2001.

[13] P. Gomes, A. C. B. Martins, C. R. Zani, and S. L. A. Sardinha, "Connection requirements and grid codes for distributed generation," 2009 CIGRE/IEEE PES Jt. Symp. Integr. Wide-Scale Renew. Resour. Into Power Deliv. Syst., 2009.

[14] H. Laaksonen, "Advanced islanding detection functionality for future electricity distribution networks," IEEE Trans. Power Deliv., vol. 28, no. 4, pp. 2056-2064, 2013.

[15] IEEE, "IEEE Application Guide for IEEE Std 1547(TM), IEEE Standard for Interconnecting Distributed Resources with Electric Power Systems," IEEE Std 1547.22008, pp. 1-217, 2009.

[16] J. C. M. Vieira, W. Freitas, W. Xu, and A. Morelato, "An investigation on the nondetection zones of synchronous distributed generation anti-islanding protection," IEEE Trans. Power Deliv., vol. 23, no. 2, pp. 593-600, 2008.

[17] P. Mahat, Z. Chen, and B. Bak-Jensen, "Review of islanding detection methods for distributed generation," in Electric Utility Deregulation and Restructuring and Power Technologies, 2008. DRPT 2008. Third International Conference on, 2008, pp. 27432748.

[18] J. C. M. Vieira, "Detecção de Ilhamento de Geradores Distribuídos: Uma revisão bibliográfica sobre o tema," Rev. Eletrônica Energ., vol. 1, pp. 3-14, 2011.

[19] Jun Yin, Liuchen Chang, and C. Diduch, "Recent developments in islanding detection for distributed power generation," in 2004 Large Engineering Systems Conference on Power Engineering (IEEE Cat. No.04EX819), pp. 124-128.

[20] D. Motter, "Modelagem computacional de funções de proteção baseadas em medidas de frequência para detecção de ilhamento de geração distribuída," Dissertação (Mestrado), Escola e Engenharia de São Carlos, Departamento de Engenharia Elétrica e de Computação, Universidade de São Paulo, 2014.

[21] W. Xu, K. Mauch, and S. Martel, “An Assessment of DG Islanding Detection Methods and Issues for Canada," report \# CETC-Varennes 2004-074 (TR). CANMET Energy Technology Centre - Varennes, Natural Resources Canada, p. 53, 2004.

[22] P. Du, J. K. Nelson, and Z. Ye, "Active anti-islanding schemes for synchronousmachine-based distributed generators," IEE Proc. - Gener. Transm. Distrib., vol. 152, no. 5, p. 597, 2005.

[23] C. J. Mozina, "Interconnection protection of IPP generators at commercial/industrial facilities," IEEE Trans. Ind. Appl., vol. 37, no. 3, pp. 681-688, 2001. 
[24] A. Sanches and A. C. B. Delbem, "Identifying Merge-Beneficial Software Kernels for Hardware Implementation," in 2011 International Conference on Reconfigurable Computing and FPGAs, 2011, pp. 74-79.

[25] B. A. Silva, L. A. Cuminato, A. C. B. Delbem, P. C. Diniz, and V. Bonato, "A technique to guide heterogeneous multi-core processor design along with an heterogeneity-aware scheduling policy," IET Comput. Digit. Techiniques, p. 25, 2014.

[26] U. Fayyad, G. Piatetsky-Shapiro, and P. Smyth, "From data mining to knowledge discovery in databases," AI Mag., vol. 17, no. 3, pp. 37-53, 1996.

[27] S. O. Pitombo, "Proteção adaptativa anti-ilhamento de geradores síncronos distribuídos," Dissertação (Mestrado), Escola de Engenharia de São Carlos, Universiadade de São Paulo, São Carlos, 2010.

[28] Schweitzer Engineering Laboratories, “Tabela ANSI." [Online]. Disponível em: http://www.selinc.com.br/tab_ansi.aspx. [Acesso em: 09-Fev-2016].

[29] W. Freitas, W. Xu, C. M. Affonso, and Z. Huang, "Comparative analysis between ROCOF and vector surge relays for distributed generation applications," IEEE Trans. Power Deliv., vol. 20, no. 2, pp. 1315-1324, 2005.

[30] H. Beltran, F. Gimeno, S. Seguí-chilet, and J. M. Torrelo, "Review of the Islanding Phenomenon Problem for Connection of Renewable Energy Systems," in International Conference on Renewable Energy and Power Quality Journal (ICREPQ'06), 2006.

[31] K. El-Arroudi and G. Joós, "Data mining approach to threshold settings of islanding relays in distributed generation," IEEE Trans. Power Syst., vol. 22, no. 3, pp. 11121119, 2007.

[32] H. G. Far, A. J. Rodolakis, and G. Joos, "Synchronous distributed generation islanding protection using intelligent relays," IEEE Trans. Smart Grid, vol. 3, no. 4, pp. 16951703, 2012.

[33] J. Abonyi and B. Feil, Cluster analysis for data mining and system identification. Springer Science \& Business Media, 2007.

[34] S. R. Samantaray and S. Kar, "Data-mining-based intelligent anti-islanding protection relay for distributed generations," IET Gener. Transm. Distrib., vol. 8, no. 4, pp. 629639, Apr. 2014.

[35] L. Breiman, "Random forests," Mach. Learn., vol. 45, no. 1, pp. 5-32, 2001. 
[36] F. R. Gomez, A. D. Rajapakse, U. D. Annakkage, and I. T. Fernando, "Support vector machine-based algorithm for post-fault transient stability status prediction using synchronized measurements," IEEE Trans. Power Syst., vol. 26, no. 3, pp. 1474-1483, 2011.

[37] V. L. Merlin, R. C. Santos, A. P. G. Pavani, D. Coury, M. Oleskovicz, and J. C. Vieira, "A methodology for training artificial neural networks for islanding detection of distributed generators," in Innovative Smart Grid Technologies Latin America (ISGT LA), 2013 IEEE PES Conference On, 2013, pp. 1-6.

[38] M. S. ElNozahy, E. F. El-Saadany, and M. M. a Salama, “A robust wavelet-ANN based technique for islanding detection," IEEE Power Energy Soc. Gen. Meet., pp. 1-8, 2011.

[39] A. Moeini, A. Darabi, S. M. R. Rafiei, and M. Karimi, "Intelligent islanding detection of a synchronous distributed generation using governor signal clustering," Electr. Power Syst. Res., vol. 81, no. Jun, pp. 608-616, 2011.

[40] P. K. Dash, S. K. Barik, and R. K. Patnaik, "Detection and classification of islanding and nonislanding events in distributed generation based on fuzzy decision tree," $J$. Control. Autom. Electr. Syst., vol. 25, no. 6, pp. 699-719, 2014.

[41] R. Cilibrasi and P. M. B. Vitányi, "Clustering by compression," IEEE Trans. Inf. Theory, vol. 51, no. 4, pp. 1523-1545, 2005.

[42] P. Grunwald and P. Vitanyi, "Shannon Information and Kolmogorov Complexity," arXiv Prepr. cs/0410002, p. 54, Out. 2004.

[43] A. da S. Meyer, "Comparação de Coeficientes de Similaridade Usados em Análises de Agrupamento com Dados de Marcadores Moleculares Dominantes,” Tese (Doutorado), Escola Superior de Agricultura, Universidade de São Paulo, 2002.

[44] B. M. Campos, "Redes Neurais Artificiais e WARD-MLM Aplicados à Análise da Divergência Genética Em Goiaba (Psidium guajava L.)," Dissertação (Mestrado), Centro de Ciências e Tecnologias Agropecuárias, Universidade Estadual do Norte Fluminense Darcy Ribeiro, 2012.

[45] S. Kumar, "A stepwise algorithm for finding minimum evolution trees.," Mol. Biol. Evol., vol. 13, no. 4, pp. 584-593, 1996.

[46] P. H. A. Sneath and R. R. Sokal, Numerical taxonomy. The principles and practice of numerical classification. San Francisco: W. H. Freeman and Company, 1973.

[47] N. Saitou and M. Nei, "The neighbor-joining method: a new method for reconstructing phylogenetic trees.," Mol. Biol. Evol., vol. 4, no. 4, pp. 406-425, 1987. 
[48] W. H. E. Day and H. Edelsbrunner, "Efficient algorithms for agglomerative hierarchical clustering methods," J. Classif., vol. 1, no. 1, pp. 7-24, Dec. 1984.

[49] M. E. J. Newman, "Fast algorithm for detecting community structure in networks," Physics (College. Park. Md)., no. 2, pp. 1-5, 2003.

[50] M. K. Crocomo, "Algoritmo de Otimização Bayesiano com Detecção de Comunidades," Tese (Doutorado), Instituto de Ciências Matemáticas e de Computação, Universidade de São Paulo, 2012.

[51] HYDRO-QUÉBEC; TRANSÉRNERGIE TECHNOLOGIES, "SimPowerSystems for use with Simulink: user's guide version R2010a," 2010. [Online]. Disponível em: http://www.mathworks.com. [Acesso em: 26-Mar-2015].

[52] C.-T. Chen, Linear system theory and design, 3rd ed. New York: Oxford University Press, 1999.

[53] R. D. Fuchs, Transmissão de energia elétrica: linhas aéreas; teoria das linhas em regime permanente, vol. 2. Rio de Janeiro: Livros Técnicos e Científicos, Escola Federal de Engenharia de Itajubá, 1977.

[54] P. Kundur, N. J. Balu, and M. G. Lauby, Power system stability and control, vol. 7. New York: McGraw-hill, 1994.

[55] IEEE, "IEEE Recommended Practice for Excitation System Models for Power System Stability Studies," IEEE Std 421.5-2016 (Revision IEEE Std 421.5-2005), pp. 1-207, 2016.

[56] IEEE, "Dynamic Models for Steam and Hydro Turbines in Power System Studies," IEEE Trans. Power Appar. Syst., vol. PAS-92, pp. 1904-1915, 1973.

[57] IEEE, "Second Benchmark Model for Computer Simulation of Subsynchronous Resonance," IEEE Trans. Power Appar. Syst., vol. PAS-104, no. 5, pp. 1057-1066, 1985.

[58] R. L. Lima, "Análise de Requisitos Técnicos para Ilhamento Intencional de Geradores Síncronos Distribuídos," Dissertação (Mestrado), Escola e Engenharia de São Carlos, Universidade de São Paulo, 2013.

[59] J. D. Hurley, L. N. Bize, and C. R. Mummert, "The adverse effects of excitation system VAr and power factor controllers," Energy Conversion, IEEE Trans., vol. 14, no. 4, pp. 1636-1645, 1999.

[60] V. Hodge and J. Austin, "A Survey of Outlier Detection Methodologies," Artif. Intell. Rev., vol. 22, no. 2, pp. 85-126, Out. 2004. 
[61] P. Lemey, M. Salemi, and A.-M. Vandamme, The phylogenetic handbook: a practical approach to phylogenetic analysis and hypothesis testing, 2nd ed. New York: Cambridge University Press, 2009. 


\section{APÊNDICE $\mathbf{A}$}

\section{Dados do Sistema Elétrico}

O APÊNDICE A apresenta os parâmetros utilizados para simular o sistema elétrico dessa dissertação. Os dados estão organizados de acordo com as entradas dos blocos do programa SimPowerSystems. Nas Tabelas A.1 à A.6 estão disponíveis os parâmetros: das cargas; das linhas; transformadores; do gerador síncrono; do regulador de tensão e sistema de excitação; e da turbina a vapor e regulador de velocidade.

Tabela A.1 - Parâmetros das cargas do sistema

\begin{tabular}{|c|c|c|}
\hline Barra & $\mathbf{P}(\boldsymbol{M W})$ & $\mathbf{Q}(\boldsymbol{M V a r})$ \\
\hline B10 & 4,45 & 2,2798 \\
B3 & 0,0853 & 0,053 \\
B6 & 3,68 & 1,57 \\
B9 & 2,76 & 1,175 \\
B8 & 0,18 & 0,0871 \\
\hline
\end{tabular}

Tabela A.2 - Parâmetros das linhas do sistema

\begin{tabular}{|c|c|c|c|c|}
\hline Barra Inicial & Barra Final & Distância $(\boldsymbol{k m})$ & $\mathbf{R}(\boldsymbol{O h m s})$ & $\mathbf{X}_{\mathbf{L}}(\boldsymbol{O h m s})$ \\
\hline B0 & B10 & 1 & 0,1876 & 0,4034 \\
B0 & B1 & 1 & 0,1876 & 0,4034 \\
B1 & B2 & 1,5 & 0,1876 & 0,4034 \\
B1 & B4 & 0,75 & 0,1876 & 0,4034 \\
B4 & B5 & 0,5 & 0,1876 & 0,4034 \\
B5 & B6 & 1 & 0,1876 & 0,4034 \\
B5 & B7 & 0,25 & 0,1876 & 0,4034 \\
B7 & B9 & 1 & 0,1876 & 0,4034 \\
\hline
\end{tabular}


Tabela A.3 - Parâmetros dos transformadores do sistema

\begin{tabular}{|c|c|c|c|c|}
\hline Parâmetro & $\begin{array}{c}\text { TR B0 } \\
138 \mathrm{kV} / 11,9 \mathrm{kV}\end{array}$ & $\begin{array}{c}\text { TR GD } \\
11,9 \mathrm{kV} / 11,9 \mathrm{kV}\end{array}$ & $\begin{array}{c}\text { TR B2 } \\
11,9 \mathrm{kV} / 220 \mathrm{~V} \\
\end{array}$ & $\begin{array}{c}\text { TR B7 } \\
11,9 \text { kV } / 220 \mathrm{~V}\end{array}$ \\
\hline Potência Nominal & $25 \mathrm{MVA}$ & $15 \mathrm{MVA}$ & $125 \mathrm{kVA}$ & $250 \mathrm{kVA}$ \\
\hline Enrol. Primário & $\Delta$ & Yg & $\Delta$ & $\Delta$ \\
\hline Enrol. Secundário & Yg & $\Delta$ & Yg & Yg \\
\hline Tensão no Primário & $138 \mathrm{kV}$ & $11,9 \mathrm{kV}$ & $11,9 \mathrm{kV}$ & $11,9 \mathrm{kV}$ \\
\hline Tensão no secundário & $11,9 \mathrm{kV}$ & $11,9 \mathrm{kV}$ & $220 \mathrm{~V}$ & $220 \mathrm{~V}$ \\
\hline Resistência (p.u) & 0 & 0 & 0 & 0 \\
\hline Reatância $(p . u)$ & 0,07375 & 0,03 & 0,01625 & 0,01625 \\
\hline
\end{tabular}

Tabela A.4 - Parâmetros do gerador síncrono do sistema

\begin{tabular}{|c|c|}
\hline Parâmetro & Valor \\
\hline Pares de polos & 2 \\
Potência nominal $(M V A)$ & 12 \\
Tensão nominal $(k V)$ & 11,9 \\
Constante de inércia $(s)$ & 2 \\
$X d(p . u)$ & 2,393 \\
$X^{\prime} d(p . u)$ & 0,305 \\
$X^{\prime \prime} d(p . u)$ & 0,216 \\
$X q(p . u)$ & 1,209 \\
$X^{\prime} q(p . u)$ & 0,221 \\
$X^{\prime \prime} q(p . u)$ & 0,05 \\
$T^{\prime} d o(s)$ & 7,19 \\
$T^{\prime \prime} d o(s)$ & 0,052 \\
$T^{\prime} q o(s)$ & - \\
$T^{\prime \prime} q o(s)$ & 0,202 \\
Resistência do estator $(p . u)$ & 0,0039 \\
Reatância de dispersão $(p . u)$ & 0,05 \\
\hline
\end{tabular}

Tabela A.5 - Parâmetros do regulador de tensão e sistema de excitação

\begin{tabular}{|c|c|c|}
\hline Parâmetro & Valor & Unidade \\
\hline $\begin{array}{c}\text { Constante de tempo do filtro } \\
\text { passa-baixas [Tr] }\end{array}$ & 0,005 & $S$ \\
\hline $\begin{array}{c}\text { Ganho do regulador e } \\
\text { constante de tempo }[\mathrm{Ka}, \mathrm{Ta}]\end{array}$ & {$\left[\begin{array}{lll}200 & 0,1\end{array}\right]$} & {$[-s]$} \\
\hline Excitatriz $[\mathrm{Ke}, \mathrm{Te}]$ & {$\left[\begin{array}{ll}1 & 0\end{array}\right]$} & {$[-s]$} \\
\hline Ganho de redução transitória $[\mathrm{Tb}, \mathrm{Tc}]$ & {$\left[\begin{array}{ll}0 & 0\end{array}\right]$} & $S$ \\
\hline $\begin{array}{l}\text { Ganho do filtro de amortecimento e } \\
\text { constante de tempo [Kf, Tf] }\end{array}$ & {$\left[\begin{array}{lll}0,048 & 0,95\end{array}\right]$} & {$[-s]$} \\
\hline $\begin{array}{l}\text { Limiares de saída do regulador e } \\
\text { ganho [Efmin, Efmax, Kp] }\end{array}$ & {$\left[\begin{array}{lll}-6 & 6 & 0\end{array}\right]$} & {$[p . u p . u-]$} \\
\hline $\begin{array}{c}\text { Condição inicial da tensão terminal e } \\
\text { tensão de campo [Vt0, Vf0] }\end{array}$ & {$[12,47164]$} & $p . u$ \\
\hline
\end{tabular}


Tabela A.6 - Parâmetros da turbina a vapor e regulador de velocidade

\begin{tabular}{|c|c|c|}
\hline Parâmetro & Valor & Unidade \\
\hline $\begin{array}{c}\text { Ganho do Regulador, droop } \\
\text { permanente, zona morta } \\
\text { [Kp Rp Dz] }\end{array}$ & {$\left[\begin{array}{lll}1 & 0,05 & 0\end{array}\right]$} & {$\left[\begin{array}{ll}-p . u p . u\end{array}\right]$} \\
$\begin{array}{c}\text { Constantes de tempo do relé } \\
\text { de velocidade e servo-motor } \\
\text { [Tsr, Tsm] }\end{array}$ & {$\left[\begin{array}{lll}0,001 & 0,005\end{array}\right]$} & {$\left[\begin{array}{l}-p . u p . u\end{array}\right]$} \\
$\begin{array}{c}\text { Limites do controle de } \\
\text { abertura }\end{array}$ & {$\left[\begin{array}{llll}-10 & 10 & 0 & 1\end{array}\right]$} & $s$ \\
$\begin{array}{c}\text { vgmin, vgmax, gmin, gmax }] \\
\text { Velocidade nominal }\end{array}$ & 3.600 & $r p m$ \\
$\begin{array}{c}\text { Constantes de tempo } \\
\text { daturbina }\end{array}$ & {$\left[\begin{array}{llll}0 & 0 & 0,3 & 0\end{array}\right]$} & $s$ \\
[T2, T3, T4, T5] & {$\left[\begin{array}{llll}0 & 0 & 1 & 0\end{array}\right]$} & - \\
\hline $\begin{array}{c}\text { Frações do torque da turbina } \\
\text { [F2, F3, F4, F5] }\end{array}$ & \\
\hline
\end{tabular}


